TI 2014-004/VI/DSF70

Tinbergen Institute Discussion Paper
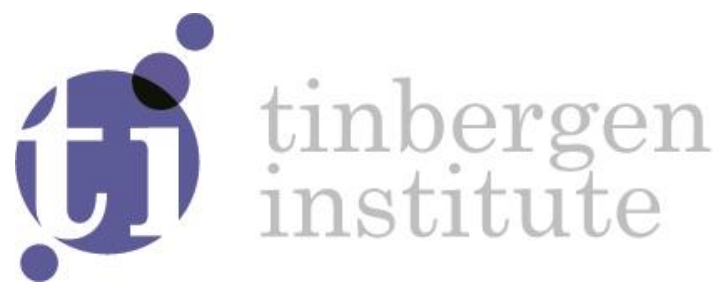

\title{
Financial Fragility and the Fiscal Multiplier
}

\section{Revision: 19-09-2017}

Christiaan van der Kwaak ${ }^{1}$

Sweder van Wijnbergen ${ }^{2}$

${ }^{1}$ Rijksuniversiteit Groningen, The Netherlands

${ }^{2}$ University of Amsterdam; Tinbergen Institute, The Netherlands 
Tinbergen Institute is the graduate school and research institute in economics of Erasmus University Rotterdam, the University of Amsterdam and VU University Amsterdam.

Contact: discussionpapers@tinbergen.nl

More TI discussion papers can be downloaded at http://www.tinbergen.nl

Tinbergen Institute has two locations:

Tinbergen Institute Amsterdam

Gustav Mahlerplein 117

1082 MS Amsterdam

The Netherlands

Tel.: +31(0)205984580

Tinbergen Institute Rotterdam

Burg. Oudlaan 50

3062 PA Rotterdam

The Netherlands

Tel.: +31(0)10408 8900 


\title{
Financial Fragility and the Fiscal Multiplier*
}

\author{
Christiaan van der Kwaak ${ }^{\dagger}$ and Sweder van Wijnbergen ${ }^{\ddagger}$
}

September 19, 2017

\begin{abstract}
We investigate the effectiveness of fiscal stimuli when banks are undercapitalized and have large holdings of government bonds subject to sovereign default risk. Deficit-financed government purchases then crowd out private expenditure and fiscal multipliers can turn negative. Crowding out increases for longer maturity bonds and higher sovereign default risk. We estimate a DSGE model with financial frictions for Spain and find that investment crowding out indeed leads to a negative cumulative fiscal multiplier. When monetary policy is exogenous, like at the ZLB or in a currency union, fiscal stimuli become more effective but multipliers are reduced when banks are undercapitalized.
\end{abstract}

Keywords: 'Financial Intermediation; Macrofinancial Fragility; Fiscal Policy; Sovereign Default Risk'

JEL classification: E44; E62; H30

\footnotetext{
${ }^{*}$ We acknowledge the generous support of the Dutch Organization for Sciences, through the NWO Research Talent Grant No. 406-13-063.

${ }^{\dagger}$ Rijksuniversiteit Groningen, the Netherlands

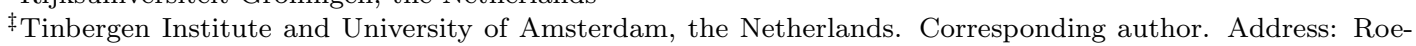
tersstraat 11, 1018 WB, Amsterdam. Email: s.j.g.vanwijnbergen@uva.nl
} 


\section{Introduction}

The debate on the size of the fiscal multiplier has been at the forefront of academic research ever since the financial crisis of 2007-2009 (Christiano et al. 2011; Eggertsson, 2011; Woodford, 2011). In this paper, we focus on the role of undercapitalized commercial banks that have large holdings of domestic government bonds with substantial default risk on their balance sheet. We show that fiscal stimuli become much less effective when they are financed by balancesheet-constrained commercial banks, to such an extent that the direct and even the cumulative multiplier may actually turn negative. We dissect the channels that contribute to the decreased effectiveness, and then ask whether there are ways to mitigate the impact that an undercapitalized commercial banking system has on the effectiveness of fiscal stimuli. Finally, we look at the case where monetary policy is exogenous, to capture the case of a small country belonging to a large monetary union.

The most obvious example of such an environment is Southern-Europe after the outbreak of the European sovereign debt crisis in 2011, as we document in Section 2. The relevance of our results, however, applies much broader: Gennaioli et al. (2014) document that $12.7 \%$ of commercial banks' assets in emerging economies consist of government bonds. Moreover, over the last couple of years, commercial banks and sovereigns in these countries have heavily borrowed in low-interest-rate US dollars. A rise in US rates and an appreciating US dollar is increasing the debt burden in domestic currency terms, and causes an undercapitalized banking system to emerge, precisely the circumstances where our results apply.

We first analyse this queston analytically using a two period general equilibrium model incorporating leverage constrained banks, long term debt and endogenous sovereign default risk (weak sovereigns). To demonstrate the empirical relevance of our results we then construct a DSGE model with financial frictions and estimate the model with the help of Bayesian techniques using Spanish data; Spain clearly fits the earlier described environment: commercial banks were undercapitalized after the burst of the real-estate boom of the early 2000's (IMF, 2011; Hoshi and Kashyap, 2015), while the Spanish government faced substantial default risk at the height of the European sovereign debt crisis in 2011-2013.

To capture the fact that Spanish commercial banks have been undercapitalized since the onset of the financial crisis, we introduce financial frictions as in Gertler and Karadi (2011) 1] Within such a setup, the size of the balance sheet is limited by an endogenous leverage constraint. Commercial banks have a portfolio choice between corporate loans and long term government debt. The introduction of this portfolio choice creates an interconnectedness between the financial system and (potential) fiscal/debt problems of the government (Bocola, 2016, Kirchner and van Wijnbergen, 2016). Long term government bonds are introduced in a way similar to Woodford (1998, 2001) to approximate the average maturity of sovereign debt held by Spanish banks at the time. A longer maturity of government bonds leads to higher potential capital losses for financial

\footnotetext{
${ }^{1}$ Throughout the paper we will interchangeably use the term 'commercial banks' and 'financial intermediaries' to denote the same group of economic agents.
} 
intermediaries, and more pronounced adverse effects on the economy in case of a financial crisis ${ }^{2}$ Sovereign default risk is introduced by postulating a maximum level of taxation that is politically feasible, like in Schabert and van Wijnbergen (2006, 2014) and Corsetti et al. (2013), and similar to the concept of a 'fiscal limit' in Davig et al. (2011). Uncertainty about the exact value of that limit leads to a sovereign debt discount that increases in the size of the public debt

The main contribution of our paper is to highlight a new channel through which the effectiveness of fiscal stimuli is reduced: crowding out of private investment by government purchases is amplified by capital losses on existing holdings of government bonds held by balance-sheetconstrained commercial banks. Our model allows us to quantitatively investigate the extent to which the stimulative effects from expansionary fiscal policy are offset by disruptions to the commercial banking system. The main result is that the cumulative impact on output, measured by the cumulative discounted multiplier (Mountford and Uhlig, 2009), is much reduced and possibly turns negative once government bonds are long term and subject to sovereign default risk, the more so the longer the maturity and the larger the risk of sovereign default. Additional debt issue, necessary to finance the stimulus, increases sovereign default risk, which in turn leads to capital losses on existing government bond holdings of the commercial banking system. And since that is undercapitalized to begin with, lending to the real economy drops, which reduces aggregate investment, thereby offsetting the stimulative effect from additional government purchases. We show that with a better capitalized commercial banking system the country would experience a smaller drop in output, or even an increase, after implementation of a fiscal stimulus. Finally, we find that the effectiveness of fiscal stimuli is equally reduced by weakness in the banking system when monetary policy is exogenous, like in a (small) country belonging to a large monetary union or when a country finds itself at the ZLB.

\section{Related Literature}

Empirical evidence on the effectiveness of fiscal stimuli is mixed. Barro and Redlick (2011) find a multiplier of 0.7 , which increases to unity when they allow for interactions with the unemployment rate. Auerbach and Gorodnichenko (2012a b) and Bachmann and Sims (2012) show that the multiplier is moderate or even negative in expansions, while it is larger than 2 in recessions. Blanchard and Perotti (2002), using a SVAR (Structural Vector Autoregression) approach, find a multiplier of 1 in the U.S. for government purchases. Ilzetzki et al. (2013) find that for countries with debt levels exceeding $60 \%$ of GDP, the impact multiplier is close to zero, and the long run multiplier -3, suggesting that debt sustainability is an important determinant of the output effects of fiscal stimuli. Corsetti et al. (2012) specifically investigate the size of the fiscal multiplier in times of financial crises. They find that the cumulative multiplier is substantially larger than 1 during financial crises, but negative when public finances are strained. Since we focus on the interaction between these two effects, our results are not really at variance

\footnotetext{
${ }^{2}$ We do not try to derive an optimal maturity structure, one would need a very different model for this; instead we more modestly show that exogenously lengthening the maturity structure exacerbates the poisonous link between financial fragility and weakness in the sovereign debt market. Questions concerning the costs and benefits of long term government debt and the optimal maturity structure are discussed in Cole and Kehoe (2000), Chatterjee and Eyigungor (2012), and Arellano and Ramanarayanan (2012).
} 
with their outcomes. Homar and van Wijnbergen (2017) differentiate between crises after which banks have been recapitalized and crises where they have not been recapped and show that for given bank weakness, fiscal policy has no empirically significant impact on the recovery, while bank recapitalizations do. They distinguish between weakly and strongly capitalized banking systems, and distinguish between deficits arising from government purchases and bank recaps.

Our paper connects to the empirical literature on the effects of banks' holdings of sovereign debt on their lending to the real economy, which is the channel through which the effectiveness of fiscal stimuli is undermined in our paper. Becker and Ivashina (2016) find evidence for crowding out of private loans by increased holdings of government bonds. Gennaioli et al. (2014) document that banks' holdings of public bonds are large ( $9 \%$ of assets over a sample including both advanced and emerging economies), and that a one dollar increase in bonds is associated with a 0.60 dollar decrease in bank loans in times of sovereign default.

Theoretically results on the size of the fiscal multiplier have been mixed: standard flexibleprice neoclassical models always have multipliers smaller than unity, while New-Keynesian models usually have a larger multiplier than their neoclassical equivalents, but dependent on the stance of monetary policy, and most of the time below unity as well. Christiano et al. (2011) and Eggertsson (2011) also investigate fiscal stimuli in a relatively standard New-Keynesian model and find that fiscal multipliers are significantly above 1 when the zero lower bound (ZLB) binds. Woodford (2011) shows that the size of the multiplier crucially depends on the duration of the ZLB-regime. Canzoneri et al. (2016) find that fiscal expansions in recessions lead to multipliers larger than two, which is driven by the fact that financial intermediation costs are directly (and inversely) linked to the output gap.

Our paper is also related to the literature in which shocks to the balance sheet of financial intermediaries affect the macroeconomy because of agency problem between deposit holders and bank owners (Gertler and Kiyotaki, 2010; Gertler and Karadi, 2011, 2013). Gertler and Karadi (2013), Bocola (2016), and Kirchner and van Wijnbergen (2016)) allow financial intermediaries to hold government bonds in addition to private loans. While sovereign default risk is exogenous in Bocola (2016), we endogenize the probability of sovereign default, and link it to the level of outstanding bonds. Kollmann et al. (2013) also employ a model with undercapitalized banks and sovereign risk, but in their setup sovereign risk remains exogenous, eliminating the amplification cycle we highlight.

The literature on sovereign defaults distinguishes between strategic defaults (Arellano, 2008), where defaulting is the optimal choice for the government, and non-strategic defaults (Schabert and van Wijnbergen, 2006, 2014, Corsetti et al. 2013) where the government is assumed to be incapable to raise enough funds to honor outstanding liabilities, see Aguiar and Amador (2013) for a survey. These models assume a (stochastic) maximum level of taxation above which the government defaults, which results in a probability of default that is increasing in the level of government debt. We follow the non-strategic default approach. 


\section{Stylized facts}

In this section we motivate several key ingredients of our model with data from Spain, Italy and Portuga 3 . We show first that Southern-European commercial banks have been undercapitalized since the financial crisis of 2007-2009. Subsequently, we document that commercial banks have large holdings of domestic sovereign debt on their balance sheet, and we then show that these bonds were subject to substantial default risk.

IMF (2011) and Hoshi and Kashyap (2015) provide evidence of the extent to which banks were undercapitalized in the Eurozone, and specifically in Southern-Europe. The problem with undercapitalized banks is that they tend to engage in excessive risk shifting. Loans to inefficient firms are renewed, rather than written down, which prevents productive new or expanding firms from obtaining funding. Evidence for this evergreening of bad loans is found in Peek and Rosengren (2005) and Caballero et al. (2008) in the case of Japan. Capital ratios in Southern-Europe have improved since the Great Recession, so one might conclude that excessive risk shifting problems have abated. But figure 1 suggests that commercial banks in Spain, Italy and Portugal are still undercapitalized, despite having higher capital ratios. The figure shows non-performing loans, which are loans on which scheduled payments have not been made for at least 90 days, and which are either in default or close to being in default.

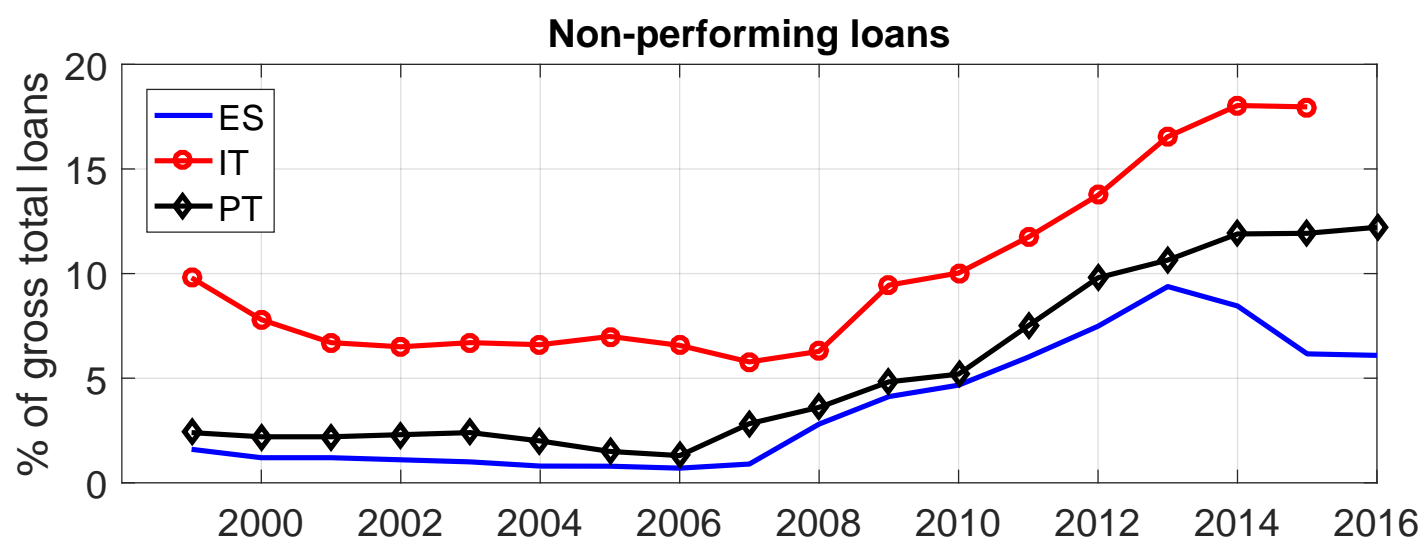

Figure 1: Non-performing loans for the aggregate commercial banking system in Spain (ES), Italy (IT) and Portugal (PT). Source: World Bank (2016).

Even though there is a substantial probability that non-performing loans will not be repaid, banks are under current accounting rules only allowed to take a provision when actual losses have occurred. Evergreening therefore allows banks to keep loans at face value on their balance sheet, despite prospective losses in the future. A marked increase in non-performing loans since 2008 is therefore a good indication of future losses, and is likely to be associated with a commercial banking system that will have to replenish its capital base, or in other words, is effectively

\footnotetext{
${ }^{3}$ We give a more detailed description of the data sources in Appendix $\mathrm{A}$
} 
undercapitalized.

A second feature of the European data that is relevant for our setup is the interconnection between the commercial banking system and the sovereign. Figure2 2 shows domestic government bond holdings of the aggregate commercial banking system as a percentage of aggregate Tier-1 capital at the end of 2011 across the Eurozone. Commercial banks in Southern-Europe clearly have a large exposure to their domestic sovereign. Spanish banks have an exposure to domestic Spanish sovereign debt equivalent to more than $150 \%$ of Tier-1 capital, Italian banks to almost $200 \%$ of Tier-1 capital, while Greek banks have an exposure of almost $250 \%$ of Tier-1 capital to the Greek sovereign at the end of 2011. With the exception of Greece, domestic sovereign debt holdings have been increasing ever since (European Central Bank, 2016). From these numbers it is clear that changes in the (market) value of sovereign debt can have large effects on bank capital.
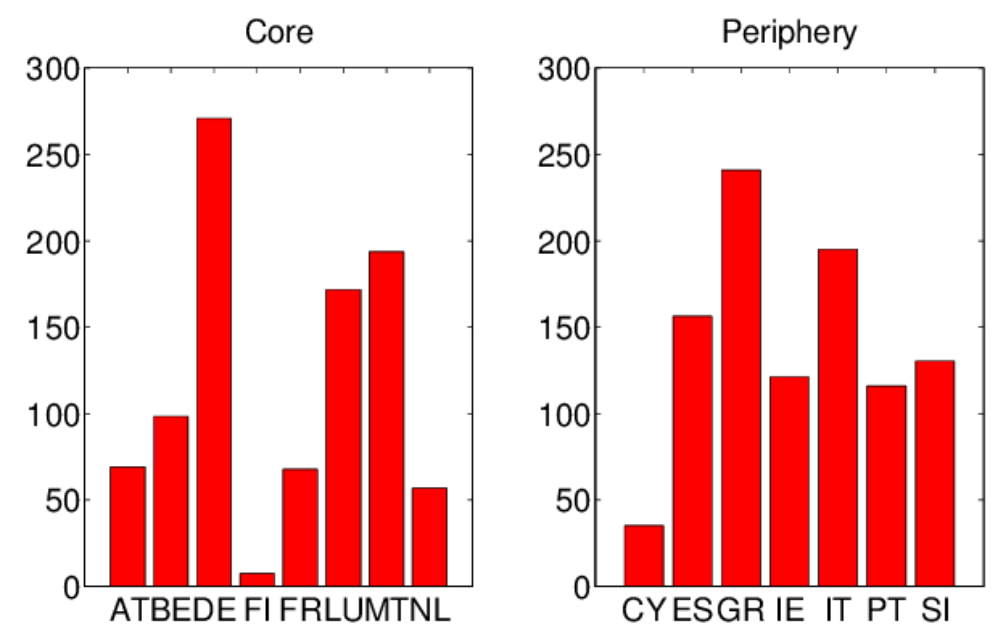

Figure 2: Banks' exposure to domestic sovereign debt (all maturities) as a percentage of their total Tier-1 capital in the core, respectively the periphery of the Eurozone. "AT" refers ro Austria, "BE" to Belgium, "DE" to Germany, "FI" to Finland, "FR" to France, "LU" to Luxemburg, "MT" to Malta, "NL" to Netherlands, "CY" to Cyprus, "ES" to Spain, "GR" to Greece, "IE" to Ireland, "IT" to Italy, "PT" to Portugal, and "SI" to Slovenia. Source: European Banking Authority (2011).

Figure 3 shows that Southern-European countries faced substantial sovereign default risk during the European sovereign debt crisis of 2011-2013. CDS-spreads for Italy and Spain increased from approximately 100 basis points in January 2010 to levels above 400 basis points in 2012 and 2013, reflecting a substantial increase in sovereign default risk. The likelihood of a default by the Portuguese sovereign is even larger, as the CDS premium for Portuguese sovereign debt increased to levels above 1000 basis points at the end of 2011 . 


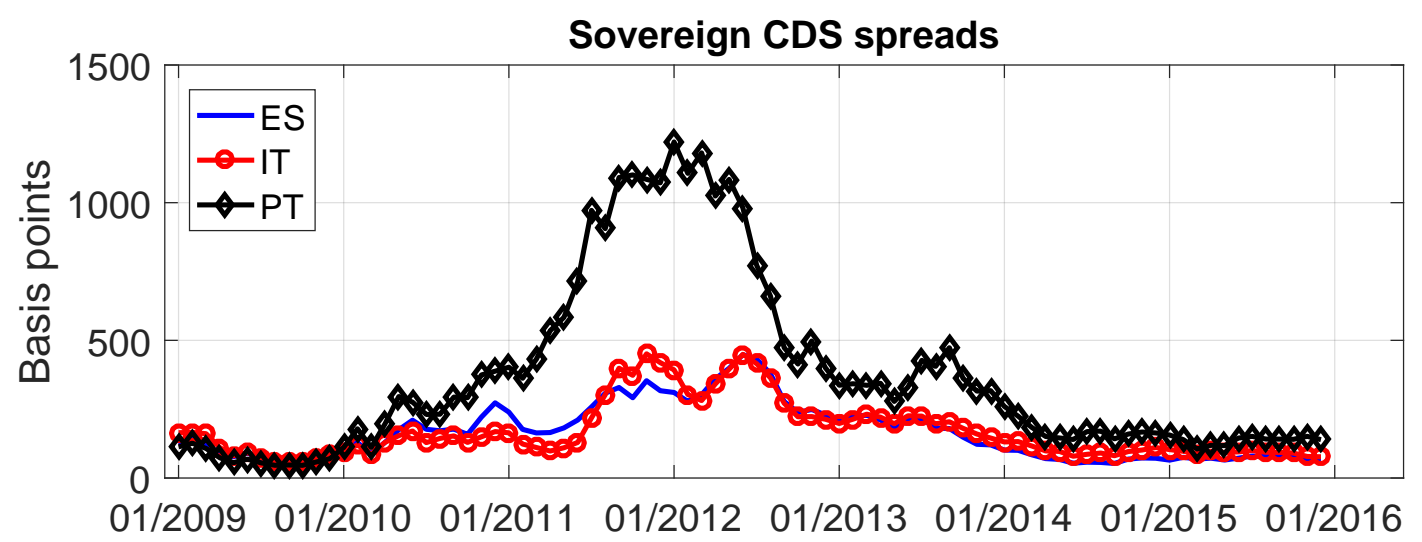

Figure 3: SNR CR 5Y Credit Default Swaps Premium in basis points (monthly) for Spain (ES), Italy (IT) and Portugal (PT). Monthly data were obtained by taking an unweighted average of daily data within a month. Source: Datastream, Thomson Reuters.

\section{Analytical results in a two period model}

In this section we develop a two period model to analytically show that undercapitalized banks cause a (possibly drastic) reduction in the fiscal multiplier through a negative amplification cycle arising from the interaction between undercapitalization of banks, sovereign default risk and the maturity of the public debt. The DSGE model we will estimate and deploy in Section 6 indicates the empirical relevance of these results.

\subsection{Model}

The economy contains periods $t=0$ and $t=1$. There are households, financial intermediaries, production firms and a government. Households supply labor and choose between consumption and saving through deposits in period $t=0$, and consume their income net of lump sum taxes in period $t=1$.

The government enters period $t=0$ with outstanding bonds from period $t=-1$. It pays a coupon on outstanding bonds and refinances outstanding liabilities. In addition, the government purchases goods from production firms. These expenditures are financed by issuing new bonds. In period $t=1$ the government raises lump sum taxes to repay the government bonds. However, the government might not be able to raise enough taxes because of the existence of a (stochastic) maximum level of taxation which arises for political reasons that are not explicitly modeled. This results in a probability of default which is increasing in the level of debt. When taxes to be raised surpass the stochastic maximum level of taxation, the government defaults on all bonds Schabert and van Wijnbergen (2006, 2014); Corsetti et al. (2013). 4

\footnotetext{
${ }^{4}$ Bondholders receive nothing in case of a default, contrary to Section 6 where we introduce a partial default. Incorporating a partial default would make the mathematics more cumbersome while the results rely upon the fact that the probability of not being (fully) repaid affects bond prices in equilibrium. The size of the loss (partial
} 
Production firms produce output in both periods using physical capital and labor as inputs. They enter period $t=0$ with physical capital acquired with funds borrowed from financial intermediaries in period $t=-1$. After production in period $t=0$, they repay their loan and pay wages to workers. They acquire a new loan to purchase physical capital for production in period $t=1$. The market for capital is a perfectly competitive one. Financial intermediaries start period $t=0$ with net worth and attract deposits from households to lend to production firms and purchase government bonds. Financial intermediaries are subject to an incentive compatibility constraint as in Gertler and Karadi (2011), which prevents them from perfectly elastically expanding their balance sheet in case opportunities for arbitrage arise.

\subsubsection{Households}

Households receive utility $u(c)$ from consumption, with $u^{\prime}(c)>0$ and $u^{\prime \prime}(c)<0$, and supply labor which reduces utility by $v(h)$, with $v^{\prime}(h)>0$ and $v^{\prime \prime}(h)>0$. Households discount expected (dis)utility from consumption and labor in period $t=1$ with subjective discount factor $\beta$. In both periods they receive income from labor $w_{t} h_{t}$, from repayment of previous period savings $d_{t-1}$ at financial intermediaries (including interest $r_{t-1}^{d} d_{t-1}$ ), and profits from the firms they own. Income is divided between consumption and savings $d_{0}$ in period $t=0$, while income in period $t=1$ is used for consumption and lump sum taxes.

\subsubsection{Production sector}

The production sector consists of a representative firm which produces output $y_{t}$ in period $t=0$ and $t=1$ using a Cobb-Douglas production function with physical capital $k_{t-1}$ and labor $h_{t}$ as inputs:

$$
y_{t}=k_{t-1}^{\alpha} h_{t}^{1-\alpha}, \quad 0<\alpha<1 .
$$

Labor $h_{t}$ is hired in a perfectly competitive market at wage rate $w_{t}$. After production in period $t=0$, the firm repays the previous period loan $k_{-1}$ (chosen in period $t=-1$ ) to the intermediary, together with a net real return $r_{0}^{k}$. The firm then acquires a new loan $k_{0}$ from financial intermediaries to purchase physical capital $k_{0}$ in a perfectly competitive market, which is used for production in period $t=1$ and afterwards repaid with a net real return $r_{1}^{k}$. The firms are owned by households. Expected profits in period $t=1$ are therefore discounted with the households' subjective discount factor $\beta \Lambda_{0,1}$. The optimization problem of the representative firm in period $t=0$ is given by:

$$
\max _{\left\{k_{0}, h_{0}, h_{1}\right\}}\left(y_{0}-\left(1+r_{0}^{k}\right) k_{-1}-w_{0} h_{0}+E_{0}\left\{\beta \Lambda_{0,1}\left[y_{1}-\left(1+r_{1}^{k}\right) k_{0}-w_{1} h_{1}\right]\right\}\right)
$$

or complete) affects the quantitative rather than the qualitative result. 
which leads to the following first order conditions:

$$
\begin{aligned}
& h_{0}: \quad w_{0}=(1-\alpha) k_{-1}^{\alpha} h_{0}^{-\alpha}, \\
& k_{0}: \quad r_{1}^{k}=\alpha k_{0}^{\alpha-1} h_{1}^{1-\alpha}-1, \\
& h_{1}: \quad w_{1}=(1-\alpha) k_{0}^{\alpha} h_{1}^{-\alpha},
\end{aligned}
$$

where we drop the expectations operator as we will later show that aggregate consumption and labor in period $t=1$ only depend on capital $k_{0}$, which is determined in period $t=0$.

\subsubsection{Government}

Period $t=0$

The government enters period $t=0$ with outstanding government bonds $b_{-1}$ that were issued at the end of period $t=-1$. These bonds pay a coupon $x_{c}$ at the beginning of period $t=0$ and $t=1$, while the principal is repaid at the beginning of period $t=1$. Government bonds issued in period $t=-1$ are traded in period $t=0$ in the secondary market at a price $q_{0}^{b}$. The market value of outstanding government liabilities at the beginning of period $t=0$ is therefore $\left(x_{c}+q_{0}^{b}\right) b_{-1}$. In addition, the government purchases goods $g_{0}$ from the production sector in period $t=0$. To finance expenditures, the government does not rely upon taxes but issues new bonds $b_{0}^{\text {new }}$ at the end of period $t=0$, which pay a coupon $x_{c}$ at the beginning of period $t=1$, and are repaid at the beginning of period $t=1$. The future cashflows from bonds issued in period $t=-1$ and $t=0$ are therefore the same at the end of period $t=0$. Bonds issued at the end of period $t=0$ must therefore trade at the same price $q_{0}^{b}$ as bonds issued at the end of period $t=-1$. Revenues from new debt issue must equal expenditures in period $t=0$ :

$$
q_{0}^{b} b_{0}^{\text {new }}=g_{0}+x_{c} b_{-1} .
$$

Denote the sum of the number of bonds issued in period $t=-1$ and $t=0$ by $b_{0}$. The combined market value of old and new bonds is given by $q_{0}^{b} b_{0}=q_{0}^{b}\left(b_{0}^{\text {new }}+b_{-1}\right)$, which delivers the government budget constraint in period $t=0$ :

$$
q_{0}^{b} b_{0}=g_{0}+\left(x_{c}+q_{0}^{b}\right) b_{-1} .
$$

Period $t=1$

Government liabilities at the beginning of period $t=1$ are equal to $\left(1+x_{c}\right) b_{0}$. To pay bondholders, the government tries to raise lump sum taxes $\tau_{1}=\left(1+x_{c}\right) b_{0}$ from households. However, there is a risk that the government might not be capable to do so, because of the existence of a stochastic maximum level of taxation (Schabert and van Wijnbergen, 2006, 2014, Corsetti et al., 
2013). The probability that taxes $\tau_{1}$ are larger than the maximum level of taxation is increasing in outstanding bonds $b_{0}$. Hence, there is a probability $p\left(b_{0}\right)$ in period $t=0$ that bonds $b_{0}$ will not be repaid in period $t=1$, with $p^{\prime}\left(b_{0}\right)>05$

\subsubsection{Financial intermediaries}

Financial intermediaries enter period $t=0$ with net worth $n_{0}$. They raise deposits $d_{0}$ from households, and purchase government bonds $b_{0}$ at price $q_{0}^{b}$ and acquire claims $k_{0}$ on the representative production firm ${ }^{6}$ The balance sheet of the representative intermediary is then given by:

$$
k_{0}+q_{0}^{b} b_{0}=n_{0}+d_{0}
$$

Claims earn a return $r_{1}^{k}$ net of principal $k_{0}$ at the beginning of period $t=1$. We assume zero depreciation on physical capital. Intermediaries receive a coupon payment $x_{c} b_{0}$ and principal $b_{0}$ at the beginning of period $t=1$ with probability $1-p\left(b_{0}\right)$, while they receive zero euros with probability $p\left(b_{0}\right)$. Financial intermediaries take the probability of default $p\left(b_{0}\right)$ as given when choosing bond holdings $b_{0}$. The net real return on deposits is equal to $r_{0}^{d}$. Expected net worth $n_{1}$ at the beginning of period $t=1$ is given by:

$$
E_{0}\left[n_{1}\right]=\left(1+r_{1}^{k}\right) k_{0}+\left[1-p\left(b_{0}\right)\right]\left(1+x_{c}\right) b_{0}-\left(1+r_{0}^{d}\right) d_{0}
$$

where $E_{0}$ denotes the expectations operator conditional on information available in period $t=0$. Financial intermediaries stop operating after period $t=1$ and pay realized net worth $n_{1}$ to their respective households, as these are the ultimate owners of the intermediaries. Financial intermediaries maximize expected discounted net worth $E_{0}\left[\beta \Lambda_{0,1} n_{1}\right]$, where $\beta \Lambda_{0,1}$ is the households' stochastic discount factor.

However, financial intermediaries face an incentive compatibility constraint as in Gertler and Karadi (2011): after purchasing assets, financial intermediaries have the opportunity to divert assets at the end of period $t=0$. In case an intermediary does so, depositors will force the intermediary into bankruptcy. However, depositors will only be able to recoup a fraction $1-\lambda_{a}$ of asset class $a=\{k, b\}$ that was diverted by the intermediary. This gives rise to an incentive compatibility constraint: depositors will only provide deposits as long as the discounted

\footnotetext{
5 (Schabert and van Wijnbergen, 2006, 2014 Corsetti et al. 2013) assume that there are political reasons which prevent the government from raising sufficient taxes to repay its creditors. These political reasons are not explicitly modeled but captured by a stochastic maximum level of taxes. This 'fiscal limit' is given by a probability density function which is known to investors. Sovereign default is not a strategic decision by the government, as the government would like to repay but is simply incapable of doing so. A different way to introduce sovereign default is to explicitly model the costs and benefits to the government of defaulting on its debt. A decision to default becomes a strategic choice in such a setup. A recent survey of strategic defaults can be found in Aguiar and Amador (2013).

'We assume households do not deposit with bankers belonging to the same household to prevent self-financing, bypassing financial frictions.
} 
continuation value $E_{0}\left[\beta \Lambda_{0,1} n_{1}\right]$ is larger than the value from diverting assets:

$$
E_{0}\left[\beta \Lambda_{0,1} n_{1}\right] \geq \lambda_{k} k_{0}+\lambda_{b} q_{0}^{b} b_{0} .
$$

Because of this incentive compatibility constraint, intermediaries will in equilibrium choose to continue operating rather than divert assets.

Maximization of $E_{0}\left[\beta \Lambda_{0,1} n_{1}\right]$ subject to the incentive compatibility constraint (8) and the balance sheet identity (6) leads to the following first order conditions:

$$
\begin{array}{ll}
k_{0} \quad: \quad E_{0}\left[\beta \Lambda_{0,1}\left(r_{1}^{k}-r_{0}^{d}\right)\right]=\frac{\lambda_{k} \mu_{0}}{1+\mu_{0}}, \\
b_{0}: \quad E_{0}\left[\beta \Lambda_{0,1}\left(\left[1-p\left(b_{0}\right)\right]\left(\frac{1+x_{c}}{q_{0}^{b}}\right)-1-r_{0}^{d}\right)\right]=\frac{\lambda_{b} \mu_{0}}{1+\mu_{0}},
\end{array}
$$

where $\mu_{0}$ is the Lagrangian multiplier on the incentive compatibility constraint (8). A larger return on capital $r_{1}^{k}$ implies a lower stock of physical capital $k_{0}$, see (3). A larger probability of default $p\left(b_{0}\right)$ and/or a higher bond price $q_{0}^{b}$ decrease the expected return on bonds everything else equal. The presence of a binding incentive compatibility constraint (8) $\left(\mu_{0}>0\right)$, implies that financial intermediaries are incapable of perfectly elastically expanding the balance sheet to arbitrage away return differences. As a result, we see from (9) - (10) that an endogenous spread arises between the return on loans and government bonds on the one hand, and deposits on the other.

We show in Appendix B that the incentive compatibiltiy constraint (8) can be rewritten in the following way:

$$
n_{0} \geq\left(\frac{\lambda_{k}}{1+\mu_{0}}\right) k_{0}+\left(\frac{\lambda_{b}}{1+\mu_{0}}\right) q_{0}^{b} b_{0}
$$

The sum of capital $k_{0}$ and government bonds $q_{0}^{b} b_{0}$, weighted by the diversion rates $\lambda_{k}$ and $\lambda_{b}$ respectively, is limited by the amount of net worth $n_{0}$ when (11) is binding. We can interpret (11) as an endogenous leverage constraint.

Since the government does not default on outstanding liabilities in period $t=0$, net worth $n_{0}$ depends upon the bond price $q_{0}^{b}$ in the following way:

$$
n_{0}=\left(1+r_{0}^{k}\right) k_{-1}+x_{c} b_{-1}+q_{0}^{b} b_{-1}-\left(1+r_{-1}^{d}\right) d_{-1}=n_{0}^{e x}+q_{0}^{b} b_{-1},
$$

where $n_{0}^{e x}=\left(1+r_{0}^{k}\right) k_{-1}+x_{c} b_{-1}-\left(1+r_{-1}^{d}\right) d_{-1}$ is the net worth of the financial intermediary excluding the proceeds from selling the long term government bonds $b_{-1}$ in the market at a price $q_{0}^{b}$ in period $t=0$. We observe that $n_{0}^{e x}$ is exogenously given, and not influenced by decisions made in period $t=0$.

The incentive compatibility constraint 111 is binding when net worth $n_{0}$ is sufficiently low. In that case we say that financial intermediaries are undercapitalized, which is the case we focus 
on in this paper. Net worth is in that case the state variable which determines the size of the balance sheet of intermediaries. Also note that a drop in the bond price will reduce net worth $n_{0}$, thereby making the incentive compatibility constraint more binding, and forcing intermediaries to further reduce the size of the balance sheet.

\subsubsection{Aggregate resource constraints}

The aggregate resource constraints in period $t=0$ and $t=1$ are given by:

$$
\begin{aligned}
& y_{0}=c_{0}+k_{0}+g_{0}, \\
& y_{1}=c_{1} .
\end{aligned}
$$

\subsection{A deficit-financed government spending shock}

Consider a deficit-financed government spending shock. We show in Appendix B.1.4 that the change in output $y_{0}$ is given by:

$$
\frac{d y_{0}}{d g_{0}}=\left(\frac{-D_{0}}{1-D_{0}}\right)\left(1+\frac{d k_{0}}{d g_{0}}\right)
$$

where $D_{0}<0$ is a term related to households' labor supply preferences. This expression is derived from combining the aggregate resource constraint (13), households' first order condition for labor, and the production function in period $t=0$. Note that one would also arrive at this expression in a model without financial frictions, in which there is already crowding out $\left(\frac{d k_{0}}{d g_{0}}<0\right)$ and an impact multiplier $\frac{d y_{0}}{d g_{0}}$ smaller than unity. In Appendix B.2.4 we show that the introduction of financial frictions amplifies the contraction in lending $\left.\frac{\partial}{\partial \lambda_{k}}\left(\frac{d k_{0}}{d g_{0}}\right)\right|_{\lambda_{k}=0}<0$ : hence the introduction of financial frictions reduces the effectiveness of deficit-financed fiscal stimuli. We show within a full-fledged DSGE model in Section 6 that the effectiveness of fiscal stimuli is not only reduced upon introduction of financial frictions, but also when comparing the case where $\lambda_{b}>0$ and $\lambda_{k}>0$ with the case where $\lambda_{b}=\lambda_{k}=0$.

We also show in Appendix B.1.4 that the change in output $y_{1}$ is given by:

$$
\frac{d y_{1}}{d g_{0}}=K_{1} \cdot \frac{d k_{0}}{d g_{0}}<0
$$

since $K_{1}>0$. Hence crowding out of capital in period $t=0$ leads to a negative output multiplier in period $t=1$, as firms' production capacity is negatively affected by a government spending shock. In addition, a lower capital stock reduces the marginal product of labor, and therefore reduces labor supply everything else equal, thereby further decreasing output.

As financial frictions affect output through their effect on lending by financial intermediaries to production firms, we now consider the effect of a deficit-financed government spending shock on lending by looking at incentive compatibility constraint (11). Implicit differentiation with 
respect to $g_{0}$ allows us to obtain the following expression for the change in corporate lending with respect to government spending:

$$
\frac{d k_{0}}{d g_{0}}=\underbrace{\left[\frac{\lambda_{b}-B n_{0}\left(\frac{1}{1-D_{0}}\right) \cdot \frac{u^{\prime \prime}\left(c_{0}\right)}{u^{\prime}\left(c_{0}\right)}}{C-\lambda_{k}}\right]}_{\text {Limited balance sheet capacity }}-\underbrace{\left[\frac{\left(1+\mu_{0}-\lambda_{b}\right) b_{-1}}{C-\lambda_{k}}\right] \cdot \frac{d q_{0}^{b}}{d g_{0}}}_{\text {Capital losses on gov't bonds }}<0 .
$$

We derive this expression in Appendix $\mathrm{B}$ and show that $B>0$ and $C<0$.

Expression (17) shows that corporate lending goes down when the government issues new debt to finance additional government consumption $g_{0}$. We can decompose the drop into two effects. The first term denotes crowding out of corporate lending because of limited balance sheet capacity, a point highlighted in Kirchner and van Wijnbergen (2016): corporate lending has to fall to create space on intermediaries' balance sheets to absorb the extra bonds issued by the government.

The second term arises because of capital losses $\frac{d q_{0}^{b}}{d g_{0}}<0$ on intermediaries' existing holdings of government bonds $b_{-1}$, which reduce net worth $n_{0}$. The incentive compatibility constraint 111) becomes more binding, which further reduces the capacity of already balance-sheet-constrained intermediaries to lend to the private sector. To sum up: capital losses on intermediaries' existing holdings of government bonds amplify the crowding out of private lending to the real economy compared with the case of one-period government bonds, in which capital losses would not occur so that the second term is equal to zero.

We can combine the first order conditions for private loans and bonds $(9)-(10)$, and implicitly differentiate the resulting equation with respect to government purchases $g_{0}$ to obtain an expression for the change in the bond price $q_{0}^{b}$ with respect to a change in purchases $g_{0}$ (details can be found in Appendix B. We substitute the resulting expression in equation (17) to obtain the following closed-form expression for $\frac{d k_{0}}{d g_{0}}$ :

$$
\begin{aligned}
\left.\frac{d k_{0}}{d g_{0}}\right|_{L T} ^{\text {default }} & =\underbrace{\left(\frac{\lambda_{b}-B n_{0}\left(\frac{1}{1-D_{0}}\right) \cdot \frac{u^{\prime \prime}\left(c_{0}\right)}{u^{\prime}\left(c_{0}\right)}}{C-\lambda_{k}+\left(1+\mu_{0}-\lambda_{b}\right) q_{0}^{b} b_{-1} Q}\right)}_{\begin{array}{c}
\text { Limited } \\
\text { balance sheet capacity }
\end{array}}-\underbrace{\left(\frac{\left(1+\mu_{0}-\lambda_{b}\right) q_{0}^{b} b_{-1} S}{C-\lambda_{k}+\left(1+\mu_{0}-\lambda_{b}\right) q_{0}^{b} b_{-1} Q}\right)}_{\begin{array}{c}
\text { Capital losses } \\
\text { on existing bondholdings } \\
\text { bue to arbitrage } \\
\text { between loans and bonds }
\end{array}} \\
& -\underbrace{\left(\frac{\left(1+\mu_{0}-\lambda_{b}\right) q_{0}^{b} b_{-1} T}{C-\lambda_{k}+\left(1+\mu_{0}-\lambda_{b}\right) q_{0}^{b} b_{-1} Q}\right)}_{\begin{array}{c}
\text { Capital losses } \\
\text { on existing bondholdings } \\
\text { due to sovereign risk }
\end{array}}<0,
\end{aligned}
$$

where $S<0$ and $T<0$. It turns out that $T$ is linear in $-p^{\prime}\left(b_{0}\right)$. In Appendix $\mathrm{B}$ we show that $C-\lambda_{k}+\left(1+\mu_{0}-\lambda_{b}\right) q_{0}^{b} b_{-1} Q<0$ if the elasticity of the sovereign debt price with respect to the debt level is smaller than one (i.e we are on the rising part of the debt-Laffer curve, empirically 
a plausible assumption for all but the most indebted countries (Claessens, 1990). Equation 18) allows us to disentangle the effect on corporate lending from a drop in bond prices into two effects: the second term on the right hand side of 18 captures an arbitrage effect. A fall in corporate lending reduces physical capital $k_{0}$, which increases the marginal product of capital $r_{1}^{k}$ and the subsequent return on corporate loans. Arbitrage between corporate loans and government bonds leads to a higher (expected) return on bonds, which is achieved through a lower bond price $q_{0}^{b}$. The third term on the right hand side of 18 captures the risk of a sovereign default, and its subsequent impact on the price of bonds. Additional debt issue increases the probability of default $p\left(b_{0}\right)$. Financial intermediaries demand a higher (expected) return to compensate for the higher probability of default associated with holding bonds, which causes a further drop in the bond price and increases capital losses on existing holdings of government bonds.

To sum up: we show that the impact output multiplier of a government spending shock depends on the change in lending to production firms. The contraction in lending, which already occurs in a regular RBC model without financial frictions, is amplified because undercapitalized financial intermediaries suffer capital losses when government bonds are long term and subject to default risk. The contraction in lending does not only reduce investment in the period of the spending shock, but also negatively affects firms' production capacity thereafter. The amplification of the contraction due to the interaction between undercapitalized intermediaries and sovereigns at risk of default therefore not only reduces the impact output multiplier in period $t=0$, but also the output multiplier in period $t=1$. In other words, the negative effects on output extend beyond the period of the spending shock, while the positive effects only occur within the period of the shock. Hence the cumulative impact of an expansion in government purchases might well be negative, something we will investigate quantitatively within an infinite horizon DSGE model in the next sections.

\section{Extension to infinite horizon DSGE model}

In the previous section we established that deficit-financed government purchases crowd out lending to the real economy and a perverse amplification cycle triggered by the diabolic loop between undercapitalized intermediaries and sovereigns at risk of default. In this section we extend the two-period model to an infinite-horizon DSGE model to quantitatively assess to what extent the drop in investment, which is the result of reduced/more expensive lending to the real economy, can offset the positive direct effects on output from higher government purchases, and see which effect dominates by looking at a cumulative discounted multiplier (Mountford and Uhlig, 2009).

Financial intermediaries are again subject to an incentive compatibility constraint as in Gertler and Karadi (2011), but now deposits pay a nominal interest rate which is set according to a standard Taylor-rule by the central bank. The structure of the non financial private sector is relatively standard: capital producing firms buy investment goods and used capital, and convert 
these into new capital that is sold to intermediate goods producers. Intermediate goods producers use capital, for which they need a loan from financial intermediaries, and labor to produce intermediate goods for retail firms. There is perfect competition in the intermediate goods market. After production, intermediate goods firms sell used capital to capital producers, pay wages to workers, and bring the residual to the financial intermediary. The retail firm repackages and sells his unique retail product to the final good producers, while exploiting his (local) monopoly power to charge a mark-up for his product. The final good producers buy these goods and combine them into a single output good. The final good is purchased by households for consumption, by capital producers to convert into capital, and by the government. The household maximizes expected life-time utility subject to a budget constraint, which contains income from deposits, profits from firms, and from labor. Income is used for consumption, lump sum taxes and saving through deposits. The government can intervene and provide the financial sector with new capital (net worth). We only discuss the non-standard parts of the model. The standard parts can be found in Appendix C

\subsection{Households}

There is a continuum of infinitely lived households with identical preferences and asset endowments. A typical household consists of bankers and workers. Every period, a fraction $f$ of the household members is a banker running a financial intermediary. A fraction $1-f$ of the household members is a worker. At the end of every period, all members of the household pool their resources, and every member of the household has the same consumption pattern.

Households earn income from labor, profits from firms' ownership and repayment of short term deposits in financial intermediaries, which are paid back with interest. Households set their nominal wage rate, subject to staggered wage setting, and offer labor services in a monopolistically competitive labor market, in which they supply the amount of labor demanded by labor agencies, which we will explain in Section 4.5. Households' income is used for consumption, lump sum taxes and deposits into financial intermediaries.7 Households' utility function is separable in consumption and labor. There is habit formation in consumption, to capture realistic consumption dynamics (Christiano et al. 2005), and an intertemporal elasticity of substitution of one. Labor disutility is parameterized by the inverse Frisch-elasticity.

\subsection{The Fiscal Authority and the Central Bank}

\section{Fiscal Authority}

The Fiscal Authority (the Government) levies lump sum taxes $\tau_{t}$ on households, issues bonds to finance its (exogeneous) expenditures $g_{t}$ and services outstanding government liabilities. The

\footnotetext{
${ }^{7}$ but not in the ones owned by the family, in order to prevent self-financing.
} 
government can provide the financial sector $n_{t}^{g}$, while $\tilde{n}_{t}^{g}$ denotes repayment of previously administered support. Government bonds are modeled as in Woodford (1998, 2001) to have a parametrisable maturity structure without having to expand the state space dimensionality. $q_{t}^{b}$ is the price of outstanding nominal bonds $B_{t}$ in terms of the consumption good, while the maturity is controlled by the parameter $\rho$. Let $B_{t-1}$ denote the stock of outstanding nominal government debt at the beginning of period $t$. These bonds pay a nominal coupon $x_{c}$ at the beginning of period $t$, a payment $\rho x_{c}$ at the beginning of period $t+1, \rho^{2} x_{c}$ at the beginning of period $t+2$, etc. The no uncertainty duration is therefore equal to $1 /(1-\beta \rho) 8$ The stream of coupon payments from a bond $B_{t-1}$ purchased in period $t-1$ is a fraction $\rho$ of the coupon payments from a bond $B_{t}$ purchased in period $t$. The price of $B_{t-1}$ should therefore be a fraction $\rho$ of the price of $B_{t}$. Outstanding nominal government liabilities at the beginning of period $t$ are therefore equal to $x_{c} B_{t-1}+\rho q_{t}^{b} B_{t-1}$. The government budget constraint in the absence of sovereign default risk, expressed in terms of the domestic price level $P_{t}$, is given by:

$$
q_{t}^{b} b_{t}+\tau_{t}+\tilde{n}_{t}^{g}=g_{t}+n_{t}^{g}+\left(1+r_{t}^{b}\right) q_{t-1}^{b} b_{t-1},
$$

where $b_{t}=B_{t} / P_{t}$ is the real value of government bonds, and $1+r_{t}^{b}$ is given by:

$$
1+r_{t}^{b}=\frac{x_{c}+\rho q_{t}^{b}}{\pi_{t} q_{t-1}^{b}}
$$

with $\pi_{t}=P_{t} / P_{t-1}$ the gross inflation rate.

Now we introduce sovereign default risk in a similar way as in Section 3 there is a stochastic maximum level of taxation, which arises because of the government's inability to raise enough funds to honor outstanding liabilities (Schabert and van Wijnbergen, 2006, 2014, Corsetti et al., 2013). This fiscal limit will be drawn each period from a generalised beta-distribution with parameters $\alpha_{b}, \beta_{b}$ and $\bar{b}_{\max }$ following Corsetti et al. (2013). As a result, we can write the ex ante probability of default $p_{t}^{\text {def }}$ for a given level of government debt $b_{t}$ by the following cumulative distribution function:

$$
p_{t}^{\text {def }}=F_{\beta}\left(\frac{b_{t}}{4 \bar{y}} \frac{1}{b_{\max }} ; \alpha_{b}, \beta_{b}\right) .
$$

When the level of taxes necessary to service outstanding liabilities is above the fiscal limit, the sovereign reduces the coupon payment $x_{c} b_{t-1} / \pi_{t}$ and the principal of the outstanding liabilities $\rho q_{t}^{b} b_{t-1} / \pi_{t}$ by a factor $1-\vartheta_{t} !^{9}$ The haircut $\vartheta_{t}$ depends on whether or not the required level of taxes surpasses the draw for the fiscal limit:

$$
\vartheta_{t}= \begin{cases}\vartheta_{d e f} & \text { with probability } p_{t}^{\text {def }} \\ 0 & \text { with probability } 1-p_{t}^{\text {def }} .\end{cases}
$$

\footnotetext{
${ }^{8}$ Duration is defined as: $\frac{\sum_{j=1}^{\infty} j \beta^{j}\left(\rho^{j-1} x_{c}\right)}{\sum_{j=1}^{\infty} \beta^{j}\left(\rho^{j-1} x_{c}\right)}$

${ }^{9} \mathrm{We}$ assume bondholders know the government's inability to raise sufficient funds, and therefore voluntarily agree to a haircut on the coupon payment and a restructuring of the outstanding government bonds.
} 
The gains $\tau_{t}^{t r}$ from the (partial) default are handed out in randomized fashion to households in the form of lower lump sum taxes. In Appendix C.2 we show that after substitution of the default proceeds $\tau_{t}^{t r}$, the ex post default government budget constraint is the same as in the no default case 19). Sovereign default risk, however, affects the government budget constraint indirectly through bond pricing $q_{t}^{b}$, which incorporates expectations of a sovereign default.

We assume that the government follows a simple fiscal rule for its core tax policy $\tau_{t}$ which responds to deviations from the steady state level of government bonds $\bar{b}$, as in Bohn (1998). Government purchases $\tilde{g}_{t}$ are driven by a standard autoregressive process, which we estimate with Bayesian techniques. We do not attempt to model optimal policy or characterize actual policy, but choose an autoregressive process: its purpose is to provide a benchmark for the fiscal multiplier. Actual government spending $g_{t}$ consists of purchases $\tilde{g}_{t}$ and a response to a financial crisis shock $\lambda_{t}^{k}>0$, to be specified in subsection 4.3 .

$$
g_{t}=\tilde{g}_{t}+\varsigma\left(\lambda_{t-l}^{k}-\bar{\lambda}^{k}\right), \quad \varsigma \geq 0, \quad l \geq 0
$$

The parameter $\varsigma$ determines the size of the response to a financial crisis shock, while $l$ denotes the lags with which the government responds to the financial crisis shock. A more detailed description of the government sector can be found in Appendix C.2.

\section{The Central Bank}

As is commonly assumed in the literature, the Central Bank sets the nominal interest rate on deposits $r_{t}^{n}$ according to a standard Taylor rule which minimizes output and inflation deviations and contains interest rate smoothing, captured by parameter $\rho_{r} \in[0,1)$. To capture Spain's membership of the Eurozone, in which the ECB does not pay attention to Spain as an individual country, we set $\rho_{r}$ close to one in Section ??. Monetary policy follows the Taylor-principle: the central bank raises the nominal interest rate by more than one-for-one with respect to an increase in inflation.

\subsection{Financial intermediaries}

The financial sector is modeled in similar fashion as in Section 3. Intermediary $j$ purchases government bonds $s_{j, t}^{b}$ at a price $q_{t}^{b}$ and obtains claims $s_{j, t}^{k}$ on intermediate goods producers at a price $q_{t}^{k}$. Intermediaries' assets $p_{j, t}$ are funded through net worth $n_{j, t}$ and deposits $d_{j, t}$. The intermediaries' balance sheet is given by:

$$
p_{j, t} \equiv q_{t}^{k} s_{j, t}^{k}+q_{t}^{b} s_{j, t}^{b}=n_{j, t}+d_{j, t}
$$

Claims $s_{j, t}^{k}$ acquired in period $t$ pay a net real return $r_{t+1}^{k}$ at the beginning of period $t+1$. Bonds $s_{j, t}^{b}$ pay a net real return $r_{t+1}^{b *}$ at the beginning of period $t+1$, which includes the impact of a 
possible sovereign default, and pays a net real return on deposits $r_{t+1}^{d}$. The law of motion for net worth of intermediary $j$ is given by:

$$
\begin{aligned}
n_{j, t+1} & =\left(1+r_{t+1}^{k}\right) q_{t}^{k} s_{j, t}^{k}+\left(1+r_{t+1}^{b *}\right) q_{t}^{b} s_{j, t}^{b}-\left(1+r_{t+1}^{d}\right) d_{j, t}+n_{j, t+1}^{g}-\tilde{n}_{j, t+1}^{g} \\
& =\left(r_{t+1}^{k}-r_{t+1}^{d}\right) q_{t}^{k} s_{j, t}^{k}+\left(r_{t+1}^{b *}-r_{t+1}^{d}\right) q_{t}^{b} s_{j, t}^{b}+\left(1+r_{t+1}^{d}\right) n_{j, t}+\tau_{t+1}^{n} n_{j, t}-\tilde{\tau}_{t+1}^{n} n_{j, t}
\end{aligned}
$$

where $n_{j, t+1}^{g}=\tau_{t+1}^{n} n_{j, t}$ denotes net worth provided by the government to financial intermediary $j$ (for example a capital injection). $\tilde{n}_{j, t+1}^{g}=\tilde{\tau}_{t+1}^{n} n_{j, t}$ denotes the repayment of government support received in previous periods.

Intermediary $j$ maximizes expected discounted profits. We follow Gertler and Karadi (2011) by assuming that there is a probability $1-\theta$ that the banker has to exit the financial sector next period, in which case he will bring net worth $n_{j, t+1}$ to his household. He is allowed to continue operating with a probability $\theta$. The banker discounts these outcomes with the household's stochastic discount factor $\beta \Lambda_{t, t+1}$, as his household is the ultimate owner of the financial intermediary. The banker's objective is then given by the following recursive optimization problem:

$$
V_{j, t}=\max E_{t}\left\{\beta \Lambda_{t, t+1}\left[(1-\theta) n_{j, t+1}+\theta V_{j, t+1}\right]\right\},
$$

subject to the incentive compatibility constraint:

$$
V_{j, t} \geq \lambda_{t}^{k} q_{t}^{k} s_{j, t}^{k}+\lambda_{t}^{b} q_{t}^{b} s_{j, t}^{b}
$$

Appendix C.3 shows that the optimization problem leads to the following first order conditions:

$$
\begin{aligned}
\frac{\lambda_{t}^{b}}{\lambda_{t}^{k}} E_{t}\left[\Omega_{t+1}\left(r_{t+1}^{k}-r_{t+1}^{d}\right)\right] & =E_{t}\left[\Omega_{t+1}\left(r_{t+1}^{b *}-r_{t+1}^{d}\right)\right], \\
E_{t}\left[\Omega_{t+1}\left(r_{t+1}^{k}-r_{t+1}^{d}\right)\right] & =\lambda_{t}^{k}\left(\frac{\mu_{t}}{1+\mu_{t}}\right), \\
\eta_{t} & =E_{t}\left[\Omega_{t+1}\left(1+r_{t+1}^{d}+\tau_{t+1}^{n}-\tilde{\tau}_{t+1}^{n}\right)\right],
\end{aligned}
$$

where $\Omega_{t+1}$ can be interpreted as an augmented version of the households' stochastic discount factor incorporating the financial friction, and $\mu_{t}$ the Lagrangian multiplier on the intermediary's incentive compatibility constraint 24).

A financial crisis is modeled as a sudden increase in $\lambda_{t}^{k}$ and $\lambda_{t}^{b}$ (Dedola et al. 2013). $\lambda_{t}^{k}$ is driven by a standard autoregressive process, while $\lambda_{t}^{b}=\left(\bar{\lambda}_{b} / \bar{\lambda}_{k}\right) \lambda_{t}^{k}$.

\subsubsection{Aggregation of financial variables}

Aggregation of most financial variables can be found in Appendix C.3. except for the aggregation of the law of motion for net worth.

At the end of each period, a fraction $\theta$ of current bankers will remain a banker, and retain all net worth to expand the balance sheet of their intermediary. Aggregate net worth of continuing 
bankers at the beginning of period $t$ is equal to:

$$
n_{t}^{e}=\theta\left[\left(r_{t}^{k}-r_{t}^{d}\right) q_{t-1}^{k} s_{t-1}^{k}+\left(r_{t}^{b *}-r_{t}^{d}\right) q_{t-1}^{b} s_{t-1}^{b}+\left(1+r_{t}^{d}\right) n_{t-1}\right]
$$

A fraction $1-\theta$ of bankers will become a worker and bring their intermediary's net worth to the household. They are replaced by another member of their household, who receives starting net worth. Aggregate new net worth is $n_{t}^{n}=\chi p_{t-1}$ (Gertler and Karadi, 2011).

Aggregate net worth is also affected by government support $n_{t}^{g}$ and repayment of government support $\tilde{n}_{t}^{g}$. The gains from default, which were handed out to households in randomized fashion through lower lump sum taxes, and were therefore unanticipated, are used to recapitalize their respective financial intermediary. As the default proceeds are handed out in randomized fashion, some intermediaries will receive a relatively large injection compared to their size, while others receive nothing. The result is that the aggregate law of motion for net worth is unaffected by the occurence of a sovereign default: 10

$$
n_{t}=\theta\left[\left(r_{t}^{k}-r_{t}^{d}\right) q_{t-1}^{k} s_{t-1}^{k}+\left(r_{t}^{b}-r_{t}^{d}\right) q_{t-1}^{b} s_{t-1}^{b}+\left(1+r_{t}^{d}\right) n_{t-1}\right]+\chi p_{t-1}+n_{t}^{g}-\tilde{n}_{t}^{g} .
$$

where $r_{t}^{b *}$ has been replaced by $r_{t}^{b}$, while $n_{t}^{g}$ and $\tilde{n}_{t}^{g}$ are aggregate financial sector support, respectively repayment of earlier financial sector support 11

However, because the recapitalization by households is unanticipated, sovereign default risk will change the equilibrium (Schabert and van Wijnbergen, 2006, 2014, Corsetti et al., 2013), as financial intermediaries ex ante anticipate to loose funds in case of a sovereign default, and adjust their portfolio decisions accordingly.

\subsection{Production side}

There exists a continuum of intermediate goods producers indexed by $i \in[0,1]$. Each of these firms produce a differentiated good. Intermediate goods producers employ a standard CobbDouglas production technology with capital share $\alpha$ and lognormal productivity. Intermediate goods producers acquire physical capital $k_{i, t-1}$ at a price $q_{t-1}^{k}$ at the end of period $t-1$. They borrow from financial intermediaries against future profits, which we assume they can credibly commit (Gertler and Kiyotaki 2010). Intermediate goods producers hire labor $h_{i, t}$ in a perfectly competitive market at wage rate $w_{t}$ after realization of the shocks at the beginning of period $t$. They sell intermediate goods at a relative price $m_{t}$ with respect to the final goods, pay wages, and sell the used capital stock $(1-\delta) k_{i, t}$ for a price $q_{t}^{k}$ to the capital producers. The remaining

\footnotetext{
${ }^{10}$ We do so because otherwise a sovereign default would introduce a discontinuity in intermediaries' net worth, which would force us to solve the model nonlinearily. Because our model contains many state variables, we need to solve the model with first order perturbation approximation, which would not be possible in the presence of nonlinearities.

${ }^{11} \mathrm{We}$ introduce this policy measure because we will later in this paper explore the link between the fiscal multiplier and bank capitalization.
} 
revenues go to financial intermediaries, who receive a net real return $r_{t}^{k}$ :

$$
1+r_{t}^{k}=\frac{\alpha m_{t} y_{i, t} / k_{i, t-1}+q_{t}^{k}(1-\delta)}{q_{t-1}^{k}} .
$$

Capital producers purchase the physical capital stock $(1-\delta) k_{t-1}$ at the end of period $t$ at a price $q_{t}^{k}$, and buy final goods $i_{t}$ from final goods producers, which they combine into new capital $k_{t}$. They sell $k_{t} 1$ at a price $q_{t}^{k}$ to intermediate goods producers who use it for production in period $t+1$. Capital producers face convex adjustment costs that are increasing in the deviation from the level of previous period investment $i_{t-1}$. Hence one unit of investment $i_{t}$ will produce less than one unit of capital $k_{t}$.

Retail firms purchase goods $\left(y_{i, t}\right)$ from intermediate goods producers at a relative price $m_{t}$, convert these one-for-one into retail goods $\left(y_{f, t}=y_{i, t}\right)$, which they sell to final good producers. Retail firms produce a differentiated retail good and operate in a monopolistically competitive market, which allows them to charge a markup over the input price $m_{t}$. Retail firms face staggered pricing like in Calvo (1983) and Yun (1996). There is partial inflation-indexation $\pi_{t-1}^{\gamma_{P}}$ for retail firms that are not allowed to adjust prices.

Final good producers purchase retail goods from all retail firms and employ a CES-production technology. They maximize profits in a perfectly competitive market where they take prices as given and decide period by period on the amount $y_{f, t}$ to purchase from each retail firm. A more elaborate description of the production sector and the resulting first order conditions can be found in Appendix C.5.

\subsection{Labor Market}

\subsubsection{Labor Agencies}

Labor agencies combine differentiated labor $h_{t}(i)$ provided by household $i$ using a CES-aggrgegator with elasticity of substitution $\epsilon_{w}$. They operate in a perfectly competitive market where they take the aggregate nominal wage rate $W_{t}$, the nominal wage rate $W_{t}(i)$ of labor type $i$ and the aggregate labor demand $h_{t}$ as given. They maximize profits by adjusting the demand for labor $h_{t}(i)$ provided by household $i$.

\subsubsection{Household \& Wages}

Households supply labor in a monopolistically competitive market while facing nominal wagestickiness, in spirit similar to price-stickiness in Calvo (1983) and Yun (1996). Household $i$ sets the nominal wage rate $\tilde{W}_{t}(i)$ and supplies any amount of labor demanded by the labor agency at that wage. It takes into account the probability $\psi_{w}$ that it is not allowed to change the wage rate $\tilde{W}_{t}(i)$ next period. In that case, there is partial wage-indexation $\omega_{t}^{a d j}=\omega_{t-1}^{\gamma_{W}}$ with $\omega_{t}=W_{t} / W_{t-1}$ denoting wage-inflation. In setting the nominal wage rate $\tilde{W}_{t}(i)$, the household weighs the expected discounted utility from total future wage income and the anticipated disutility from 
labor:

$$
\max _{\left\{\tilde{W}_{t}(i)\right\}} E_{t}\left\{\sum_{s=0}^{\infty}\left(\beta \psi_{w}\right)\left[\lambda_{t+s} \frac{\tilde{W}_{t}(i)\left(\Pi_{j=1}^{j=s} \omega_{t+j}^{a d j}\right)}{P_{t+s}} h_{t+s}(i)-\chi \frac{h_{t+s}(i)^{1+\varphi}}{1+\varphi}\right]\right\},
$$

where $\lambda_{t+s}$ is the marginal utility of consumption for household $i$, with which household $i$ discounts the future real wage income $\frac{\tilde{W}_{t}(i)\left(\Pi_{j=1}^{j=s} \omega_{t+j}^{a d j}\right)}{P_{t+s}} h_{t+s}(i)$. The labor demand schedule $h_{t}(i)=$ $\left(W_{t}(i) / W_{t}\right)^{-\epsilon_{w}} h_{t}$ constrains the maximization problem, which results in the following first order conditions:

$$
\begin{aligned}
\left(\frac{\tilde{W}_{t}(i)}{W_{t}}\right)^{1+\epsilon_{w} \varphi} & =\left(\frac{\chi \epsilon_{w}}{\epsilon_{w}-1}\right) \frac{\Xi_{1, t}^{w}}{\Xi_{2, t}^{w}} \\
\Xi_{1, t}^{w} & =h_{t}^{1+\varphi}+E_{t}\left[\beta \psi_{w}\left(\omega_{t+1}\right)^{\epsilon_{w}(1+\varphi)}\left(\omega_{t+1}^{a d j}\right)^{-\epsilon_{w}(1+\varphi)} \Xi_{1, t+1}^{w}\right] \\
\Xi_{2, t}^{w} & =\lambda_{t} w_{t} h_{t}+E_{t}\left[\beta \psi_{w}\left(\omega_{t+1}\right)^{\epsilon_{w}-1}\left(\omega_{t+1}^{a d j}\right)^{1-\epsilon_{w}} \Xi_{2, t+1}^{w}\right] .
\end{aligned}
$$

A detailed derivation can be found in Appendix C.6.

\subsection{Market clearing}

Equilibrium requires that the number of claims owned by the financial intermediaries $\left(s_{t}^{k}\right)$ is equal to aggregate capital $\left(k_{t}\right)$, while the number of government bonds owned by the financial sector $\left(s_{t}^{b}\right)$ must equal the number of bonds issued by the government $\left(b_{t}\right)$ :

$$
\begin{aligned}
s_{t}^{k} & =k_{t} \\
s_{t}^{b} & =b_{t}
\end{aligned}
$$

Goods market clearing requires that the aggregate demand equals aggregate supply:

$$
c_{t}+i_{t}+g_{t}=y_{t}
$$

\section{Estimation}

We employ a mix of calibration and estimation with Bayesian methods to match the Spanish economy as closely as possible. Calibration is used to match several key first order moments. As a result, we cannot estimate parameters which affect the steady state values of the first order moments we try to match: changes in these parameters would result in first order moments that differ from the values we try to match. For these parameters we either take the posterior estimates of Burriel et al. (2010) or manually adjust them to match the key first order moments we target. The remaining parameters, which do not affect the steady state and drive the model dynamics, are estimated. 
We start this section by discussing the data, after which we discuss the calibrated parameters and the priors of the variables we are estimating. We conclude by reporting the parameter estimates, which we obtain by using data from the period 2003Q1-2007Q4. Sovereign default risk during this period was negligibly small, which is the reason why we estimate the model version where the probability of default $p_{t}^{d e f}=0$ across all periods.

\section{$5.1 \quad$ Data}

We use three observables for Spain: real output, real consumption and the credit spread between loans to non-financial corporations and deposits. A description of the data can be found in the Appendix. The sample period is 2003Q1-2007Q4. The reason for not choosing a longer period is the fact that the credit spread is only available from 2003Q1, while we do not want to use data after 2007Q4 so as to exclude the Great Recession. We do so as we would like to match the performance of our model economy with the dynamics of the Spanish economy in normal times when financial fragility is not an issue. We detrend the three time series using the HP filter with smoothing parameter equal to 1,600 .

\subsection{Calibration}

We target several key first order moments which can be found in Table 1 . These include the investment-output ratio, the government spending-output ratio, government debt over output ratio, the "maximum" level of debt over output, the fixed cash flow payment on bonds, the average maturity of outstanding Spanish government debt, the credit spread between loans and deposits, the (unweighted) leverage ratio of financial intermediaries, and the labor supply. Parameters that affect these moments in steady state are either set by taking the posterior mean from Burriel et al. (2010), who perform a Bayesian estimation with Spanish data, or are manually adjusted to match the data.

Parameters which are taken from Burriel et al. (2010) are the subjective discount factor $\beta$, the degree of habit formation $v$, the inverse Frisch elasticity $\varphi$, the effective capital share $\alpha$, the elasticity of substitution for goods and labor, respectively $\epsilon$ and $\epsilon_{w}$, the Calvo probability for goods and labor, respectively $\psi$ and $\psi_{w}$, the degree of price-indexation $\gamma_{P}$ and wage-indexation $\gamma_{W}$.

Parameters that are manually adjusted include the maturity parameter of bonds $\rho$, the steady state value of the diversion rate of loans $\bar{\lambda}_{k}$ and bonds $\bar{\lambda}_{b}$, the depreciation parameter $\delta$, the probability of continuing as a banker $\theta$, the disutility weight of labor $\Psi$, the steady state level of lump sum taxes $\bar{\tau}$, the parameter relating previous period assets of dying bankers to start up net worth for new bankers $\chi$, and the parameters $\alpha_{b}, \beta_{b}$ from the default probability function.

Finally we choose $\rho_{\lambda_{k}}$ and $\sigma_{\lambda_{k}}$ for the $\operatorname{AR}(1)$ process that is driving the diversion rate $\lambda_{t}^{k}$. We calibrate these parameters to match the fall in Spanish quarterly output of $1 \%$ after December 2010, and to have the shock die out after approximately 10 quarters. We find $\rho_{\lambda_{k}}=0.7$ and 


\begin{tabular}{llll}
\hline Target & Definition & Value & Data \\
\hline $\bar{i} / \bar{y}$ & Investment ratio & 0.226 & $1994-2008$ average \\
$\bar{g} / \bar{y}$ & Government spending ratio & 0.178 & $1994-2008$ average \\
$\bar{b} / \bar{y}$ & Government debt ratio & 3.2 & December 2010 \\
$b_{\max } / \bar{y}$ & "Maximum" gov't debt ratio & 2.4 & Maastricht criteria \\
$x_{c}$ & Interest rate 10y bonds & $4.1 \%$ & $1998-2008$ average \\
$1 /(1-\beta \rho)$ & Maturity bonds & 25 & $1998-2008$ average \\
$\Gamma$ & Credit spread & 0.0047 & $2003-2007$ average \\
$\phi$ & Leverage ratio & 5.1 & $2001-2008$ average \\
$\bar{h}$ & Labor supply & $1 / 3$ & 8 hours of work per day \\
\hline
\end{tabular}

Table 1: List of steady state calibration targets and source of calibration

$\sigma_{\lambda_{k}}=0.08$. An elaborate description of the calibration can be found in Appendix D.1. In addition, we perform several robustness checks in Appendix E to check that our results do not depend on specific parameter values.

\subsection{Bayesian Estimation of Remaining Parameters}

The remaining parameters affect the dynamics but not the steady state of the model. We can therefore estimate these parameters using Bayesian techniques without affecting the steady state. As a prior for these parameters, we use the the posterior mean and standard deviation of the same parameters that were estimated in Burriel et al. (2010), which can be found in Table 2 These parameters include $\kappa_{b}$, the parameter that governs the feedback from government debt on taxes, $\rho_{g}$, the $\operatorname{AR}(1)$ coefficient for government spending, and the standard deviations for productivity and government spending, $\sigma_{z}$ and $\sigma_{g}$ respectively. We choose the priors for the remaining parameters, namely the investment adjustment cost parameter $\gamma$, and the $\operatorname{AR}(1)$ coefficient for productivity $\rho_{z}$, to be not very informative by choosing a relatively large standard deviation of the prior distribution, as we have no posterior estimates that we can employ.

We explicitly choose not to estimate the monetary policy coefficients $\kappa_{\pi}, \kappa_{y}, \rho_{r}$ and $\sigma_{r}$. The reason is that monetary policy for Spain is conducted by the European Central Bank (ECB), which conducts monetary policy for the euroarea as a whole, rather than for Spain alone. As we work in a closed economy setup, we need a domestic central bank to close the model. But as the monetary policy of the ECB is unlikely to follow a Taylor-rule prescription for the Spanish economy, we decide not to estimate the monetary policy coefficients, but instead perform simulations where monetary policy can be considered exogenous in section ??. We perform a robustness check in the Appendix to check that our results do not depend upon the particular values chosen for the monetary policy coefficients.

Table 2 reports the summary statistics of the posterior distribution of the parameters. After having estimated the model, we applied the convergence statistics proposed by Brooks and Gelman (1998) to check whether convergence was reached. 


\begin{tabular}{|c|c|c|c|c|c|c|c|c|}
\hline & Parameter & Distrib. & Mean & Std. dev. & Mean & $10 \%$ & Mode & $90 \%$ \\
\hline$\kappa_{b}$ & Tax feedback & Gamma & 0.051 & 0.01 & 0.0507 & 0.0346 & 0.0488 & 0.0662 \\
\hline$\gamma$ & Invest. adj. cost & Gamma & 2.5 & 1 & 4.0177 & 2.0509 & 3.7794 & 5.7450 \\
\hline AR coef. & Productivity & Beta & 0.8 & 01 & 0.9848 & 0.9726 & 0.9914 & 0.9981 \\
\hline$\rho_{g}$ & Gov't spending & Beta & 0.979 & 0.01 & 0.9983 & 0.9969 & 0.999 & 0.9997 \\
\hline $\begin{array}{l}\text { Std. dev. } \\
\sigma_{z}\end{array}$ & Productivity & $\begin{array}{l}\text { Inv. } \\
\text { Gamma }\end{array}$ & 0.009 & 0.05 & 0.0234 & 0.0159 & 0.0203 & 0.0302 \\
\hline$\sigma_{g}$ & Gov't spending & $\begin{array}{l}\text { Inv. } \\
\text { Gamma }\end{array}$ & 0.062 & 0.05 & 0.0343 & 0.0229 & 0.0285 & 0.0459 \\
\hline
\end{tabular}

Table 2: Priors (columns 3-5) and posteriors (columns 6-9) of the parameters that are estimated with Bayesian techniques. The results are based on 5 chains, each with 100,000 draws based on the Metropolis-Hastings algorithm.

We find that the both the productivity shock and the government spending shock are quite persistent. The estimated mean and mode for the AR(1) coefficient on government spending and the feedback from government debt on lump sum taxes are close to the respective prior mean. The mean and mode of the investment adjustment cost parameter is around 4, which is higher than the prior mean, and higher than the American equivalent used by Gertler and Karadi (2011).

We note that the standard deviations for productivity is substantially higher than the prior mean, while the standard deviation of government spending is approximately half the prior mean. Apparently the 2003-2007 was a period of highy volatility in Spain in productivity, while the volatility of government spending was lower in the 2003-2007 period than during the 1986-2007 period estimated by Burriel et al. (2010).

\section{The fiscal multiplier, banking fragility and default risk: model results}

In our simulations a financial crisis is triggered by a crisis in confidence, in our context an unanticipated increase in the diversion rates for both assets held by banks, private loans and sovereign debt, $\lambda_{t}^{k}$ and $\lambda_{t}^{b}$ respectively. Both rates are shocked in equal proportion (i.e. their ratio remains the same). We then analyze the output response to an expansionary shift in government expenditures in response to the financial crisis shock $\lambda_{t}^{k}$ to clarify the impact of a weakly capitalized banking system on the effectiveness of such a stimulus program. The stimulus package is announced at the onset of the financial crisis, but implemented only four quarters (one budget year) after its announcement, in line with standard budget procedures. In the first set of policy experiments (Section 6.1), we use the full model, with long term debt held 
on banks' balance sheets and endogenously generated sovereign risk built in. After presenting our core results and the asociated dynamic multiplier patterns, we then decompose the overall weakening of the fiscal multiplier by trimming the model down step by step, so as to find out what is the most significant driver of the weakening of the multiplierresults we obtain on the size of multipliers. We also investigate whether the effectivenss of fiscal stimulus programs increase when commercial banks are better capitalized. In a last section, we check whether fiscal stimuli become more effective when monetary policy is exogenous.

\subsection{The effects of a stimulus package in the presence of financial fra- gility, long term debt and sovereign default risk}

Figure 4 presents the model response to the financial shock with and without a fiscal stimulus package. Without a fiscal stimulus, the increase in the diversion rates for private loans and sovereign debt immediately leads to a tightenening of Intermediaries' leverage constraint (see the blue solid lines in Figure 4). As a consequence, lending to intermediate goods producers is reduced and the spread increases. Therefore the demand for capital falls and the price of capital falls commensurately. And that causes a decline in Intermediaries' net worth, which leads to a further tightening of the leverage constraint and increase in the credit spread. The tightening of intermediaries' leverage constraints and a higher diversion rate for government bonds $\lambda_{t}^{b}=\left(\bar{\lambda}_{b} / \bar{\lambda}_{k}\right) \lambda_{t}^{k}$ lead to a drop in bond prices, which i turn further reduces the value of intermediaries' existing holdings of government bonds. Net worth falls further, and an additional tightening of intermediaries' leverage constraints leads to a second round of interest rate increases. The subsequent rounds of balance sheet deterioration cause the credit spread to increase by almost 400 basispoints, investment to drop by $3 \%$, and output by almost $1 \%$.

The effects of a fiscal stimulus

Now consider the impact of a deficit financed stimulus package that is announced upon the start of the financial crisis, but implemented 4 quarters later (red slotted line in Figure 4). The delay is introduced to repsresent a regular budget cycle. Due to the forward looking nature of financial intermediaries, they immediately anticipate a future increase in government debt. Consequently, they anticipate a future interest rate increase and subsequent bond price drop because of i) a larger supply of bonds and ii) an increase in sovereign default risk because of the higher debt levels. The effects of this anticipated future price drop are propagated through a bond price that is already lowered before the implementation of the fiscal stimulus package begins, which reduces the value of intermediaries' existing holdings of government bonds. The subsequent reduction in net worth today tightens the incentive compatibility constraint of financial intermediaries and makes them more balance-sheet-constrained. To sum up: the anticipation of having to finance riskier debt in the future makes the financial intermediaries immediately more balance-sheet-constrained. The bond price falls by another $3 \%$ with respect to the case of no 

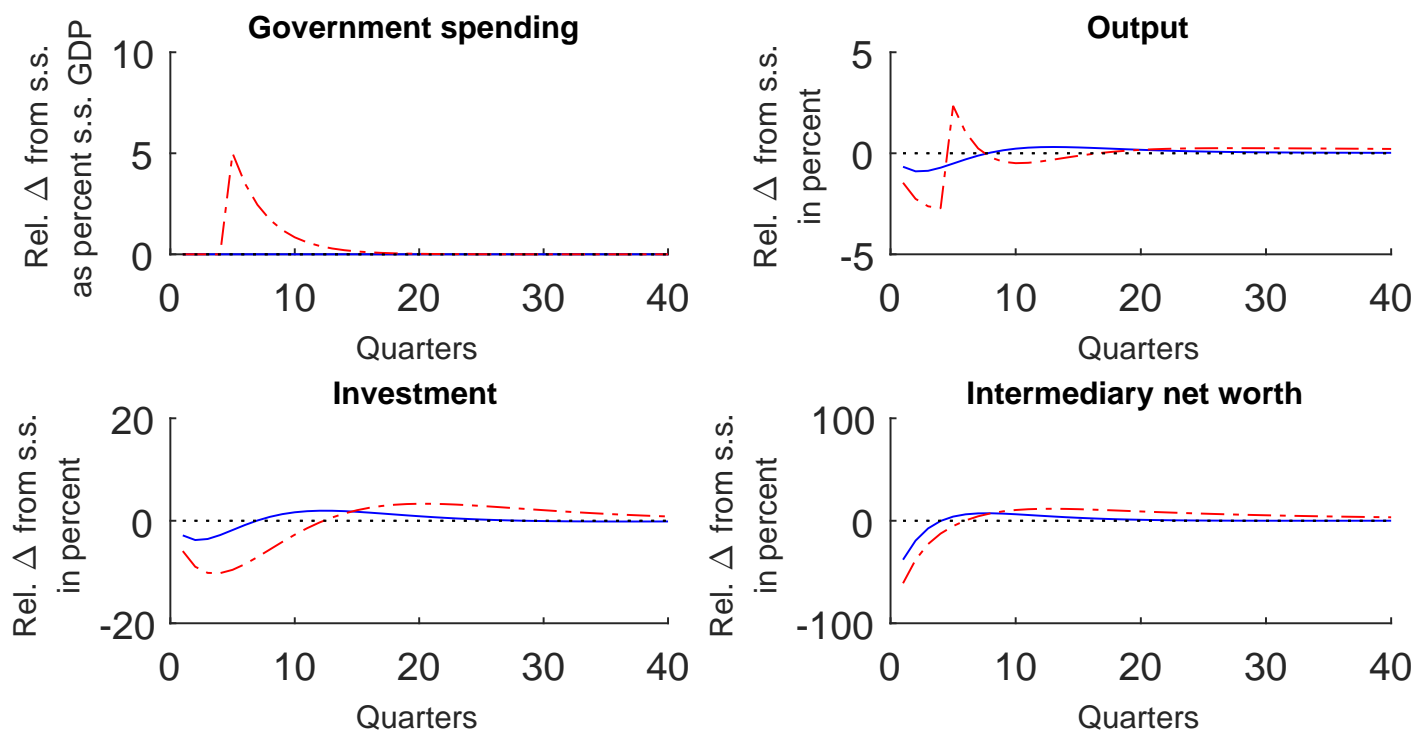

(a)
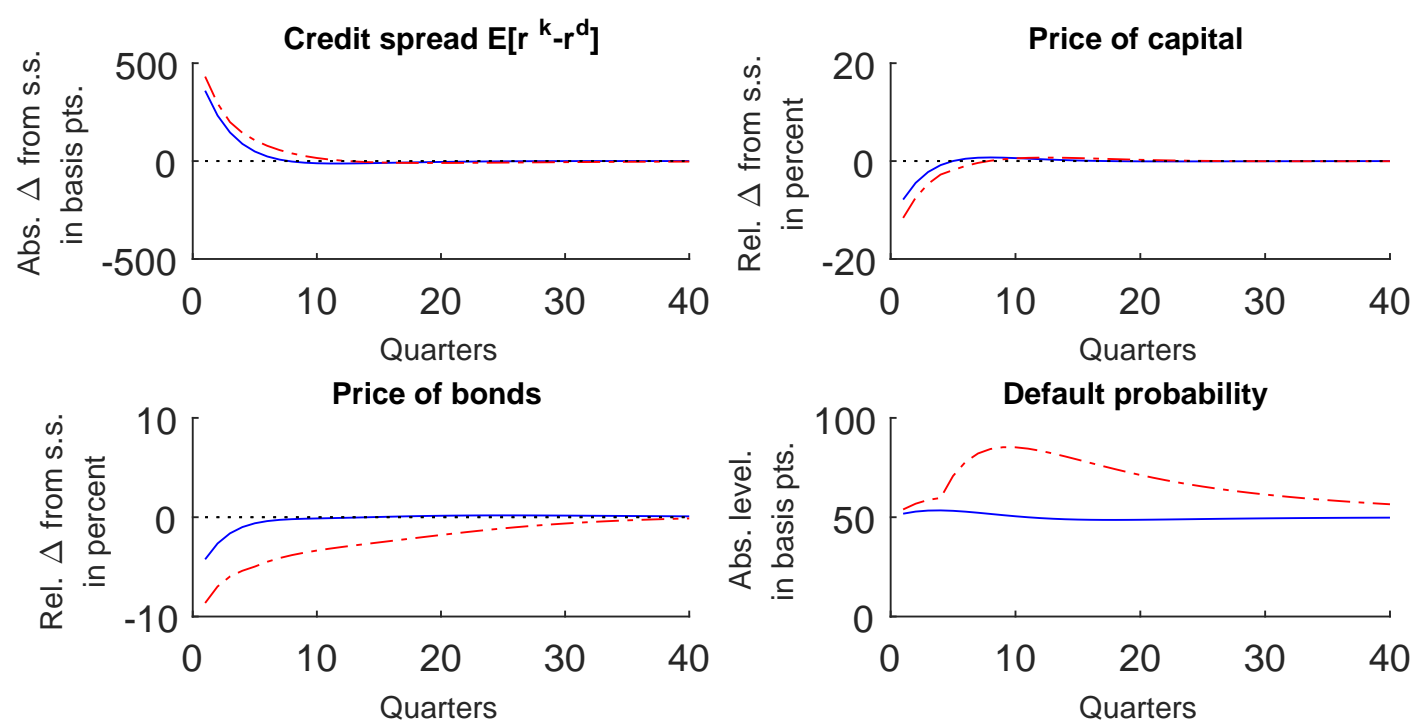

(b)

Figure 4: Plot of the impulse response functions comparing no additional policy (blue, solid) and fiscal stimulus (red, slotted). The stimulus is announced as the crisis hits, and implemented 4 quarters later through additional debt issue, and equal to $1.25 \%$ of annual steady state GDP. The financial crisis is initiated through a shock to the diversion rate of private loans of 8 percent relative to the steady state. 


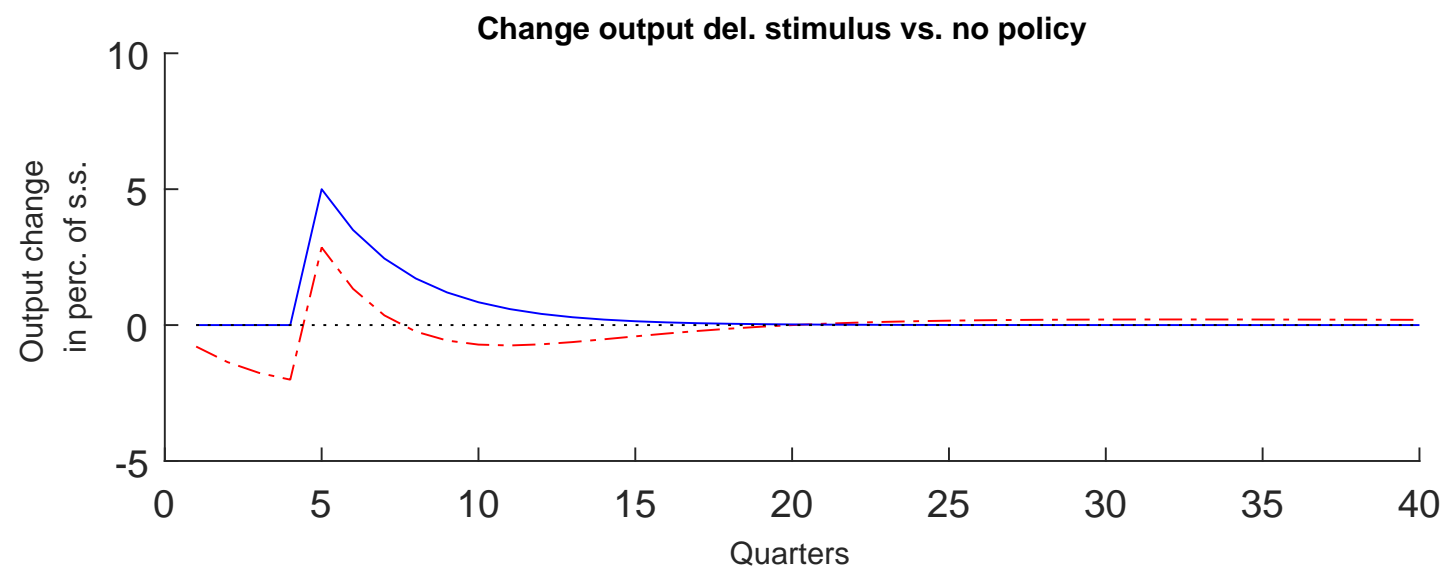

Figure 5: The red slotted line is the fiscal multiplier: the difference between output-withintervention and output-without-stimulus in each quarter. This represents our base case, with sovereign risk, long term (maturity of 25 quarters) debt and deficit financed stimulus package. The solid (blue) line represents the fiscal stimulus itself, expressed as a percentage of quarterly steady state output.

additional government policy, which constitutes almost a doubling in the bond price drop, see Figure 4

A tightening of the incentive compatibility constraint today because of additional capital losses on government bonds also leads to higher interest rates on corporate loans and an immediate reduction in lending to the real economy. So the anticipated future debt issue leads to a drop in lending to the real economy today, with a fall in investment of more than $5 \%$ of steady state investment with respect to the no policy case, and a four times larger decline in the capital stock (not shown) as a consequence. The fall in the demand for physical capital leads to an additional drop in the price of capital, and a further fall in intermediaries' net worth. The anticipation by households of higher future taxes to eventually pay off the additional debt incurred to finance the future fiscal stimulus leads to a drop in consumption (not shown) today. The fall in consumption and investment today cause a sharp fall in output compared with the case of no fiscal stimulus upon impact. Against all that is the positive direct impact of the stimulus package at the time it actually is introduced (cf the positive peak in the top two panels of Figure 4).

Figure 5 shows the net impact over time of all these at times conflicting impact effects on output. The anticipation of future tightening leads to tightening conditions today and thus a negative output effect in the months preceding the actual start of the stimulus program (cf the red slotted line in Figure 5. The net impact turns positive at the start of the implementation, but he negative channels dominate again within a year after the start of the stimulus. The subsequent period of negative impact in the end fizzles out to reach zero after 20 quarters.

The sequence of periods with negative, positive and again negative impact raises the question of whether the cumulative policy impact on output can actually turn negative. To answer that 
question, we calculate a cumulative discounted multiplier (Mountford and Uhlig, 2009). Denoting a variable from the stimulus scenario $x^{s t}$ and from the no-policy-response case $x^{n p}$, the cumulative discounted multiplier is defined as:

$$
\mu_{D}=\frac{\sum_{j} \beta^{j}\left(y_{t+j}^{s t}-y_{t+j}^{n p}\right)}{\sum_{j} \beta^{j}\left(g_{t+j}^{s t}-g_{t+j}^{n p}\right)}
$$

The numerator of $\mu_{D}$ is equal to the cumulative area between the red slotted line and the zero line in Figure 5, with areas below zero having a minus sign, while the denominator is the difference between the solid blue line (which represents additional government spending) and the horizontal zero axis. We see from row $\mathrm{nr} 4$ in Table 3 that the negative effects stemming from deteriorating balance sheets on investment and output eventually offset all the positive direct effects to such an extent that $\mu_{D}$ the cumulative multiplier just about turns negative at -0.02 : the fiscal stimulus eventually becomes self-defeating and thus completely ineffective in the face of tightening balance sheet constraints in the financial intermediary sector (i.e. the banks)!

\subsection{Dissecting \& quantifying the various amplification mechanisms at play}

In this section we quantify in Table 3 the contributions of the different channels to the all-in overall cumulative multiplier effect. We do so by first calculating a base case in which (A) the stimulus is tax-financed so the financial frictions are bypassed, (B) the maturity of government bonds is brought back to one period so there are no capital losses on bonds, and (C) there is no sovereign default risk. This run corresponds to case 1 in the Table below.). Then we introduce step by step debt-financing of the stimulus package (case 2), long term government bonds (case 3 ) and sovereign default risk (which brings us back to case 4, the one analyzed in the previuous section).

In the case where sovereign risk is absent, the maturity of government bonds one period, and the stimulus tax-financed (case 1), the cumulative impact $\mu_{D}$ is positive at 0.54 , not an unusually low value for this type of NK DSGE model. Financing the stimulus through additional debt issue intemediated by the financial intermediaries (case 2) instead of lump sum taxes slightly reduces $\mu_{D}$ from 0.54 to 0.52 . The reason for such a small drop is because the additional debt issue ( $1.25 \%$ of annual GDP) is small compared with intermediaries' existing holdings of sovereign debt ( $80 \%$ of annual GDP in the steady state).

Next we highlight the role of the maturity of government bonds. We see from Table 3 that lengthening the maturity of government bonds from the one quarter asssuemed in case 2 to 25 quarters in case 3 decreases the cumulative multiplier substantially: $\mu_{D}$ falls from 0.52 to 0.20 , which explains $57 \%$ of the total decline of 56 basis points: an increase in the supply of bonds leads to intermediaries demanding a higher (expected) return on bonds, which is achieved through a drop in the bond price. The resulting capital losses on intermediaries' existing bond holdings further tighten leverage constraints. The result is an additional drop in lending, aggregate 
investment and output compared with the case where government bonds have a maturity of one period. This effect corresponds to the second term in expression (18).

Finally we consider the effect of introducing sovereign default risk by comparing case 3 and 4 in Table 3 . The additional drop in $\mu_{D}$ from 0.20 to -0.02 (or about $40 \%$ of the total decline of 56 basis points) is caused by larger capital losses on existing government bond holdings: a deficit financed stimulus not only increases the supply of bonds, but also leads to higher sovereign default risk. This effect is captured by the third term of expression 18].

\begin{tabular}{|l|l|}
\hline Stimulus policy & Discounted cumulative multiplier \\
\hline \hline $\begin{array}{l}\text { 1: Short term debt, stimulus is tax-financed, no } \\
\text { sovereign risk }\end{array}$ & 0.54 \\
\hline $\begin{array}{l}\text { 2: Short term debt, stimulus is debt-financed, no } \\
\text { sovereign risk }\end{array}$ & 0.52 \\
\hline $\begin{array}{l}\text { 3: Long term debt, stimulus is debt-financed, no } \\
\text { sovereign risk }\end{array}$ & 0.20 \\
\hline $\begin{array}{l}\text { 4: Long term debt, stimulus is debt-financed, so- } \\
\text { vereign risk }\end{array}$ & -0.02 \\
\hline
\end{tabular}

Table 3: Table displaying the discounted cumulative dynamic multiplier for listed scenarios. Short term debt are one period bonds (scenario 1 and 2), whereas the expected lifetime of long term debt is equal to 25 quarters in scenario 3 and 4 .

Figure 6 6 also highlights the role of debt maturity for the effectiveness of fiscal stimuli: it shows the decline in the cumulative dynamic multiplier $\mu_{D}$ as a function of average debt maturity of existing and new debt (we recalculate $\rho$ into the more intuitive but equivalent metric of average maturity (duration), measured in quarters). The figure shows a gradual decline of the multiplier as the maturity increases. 


\section{Discounted cumulative multiplier as a function of debt maturity}

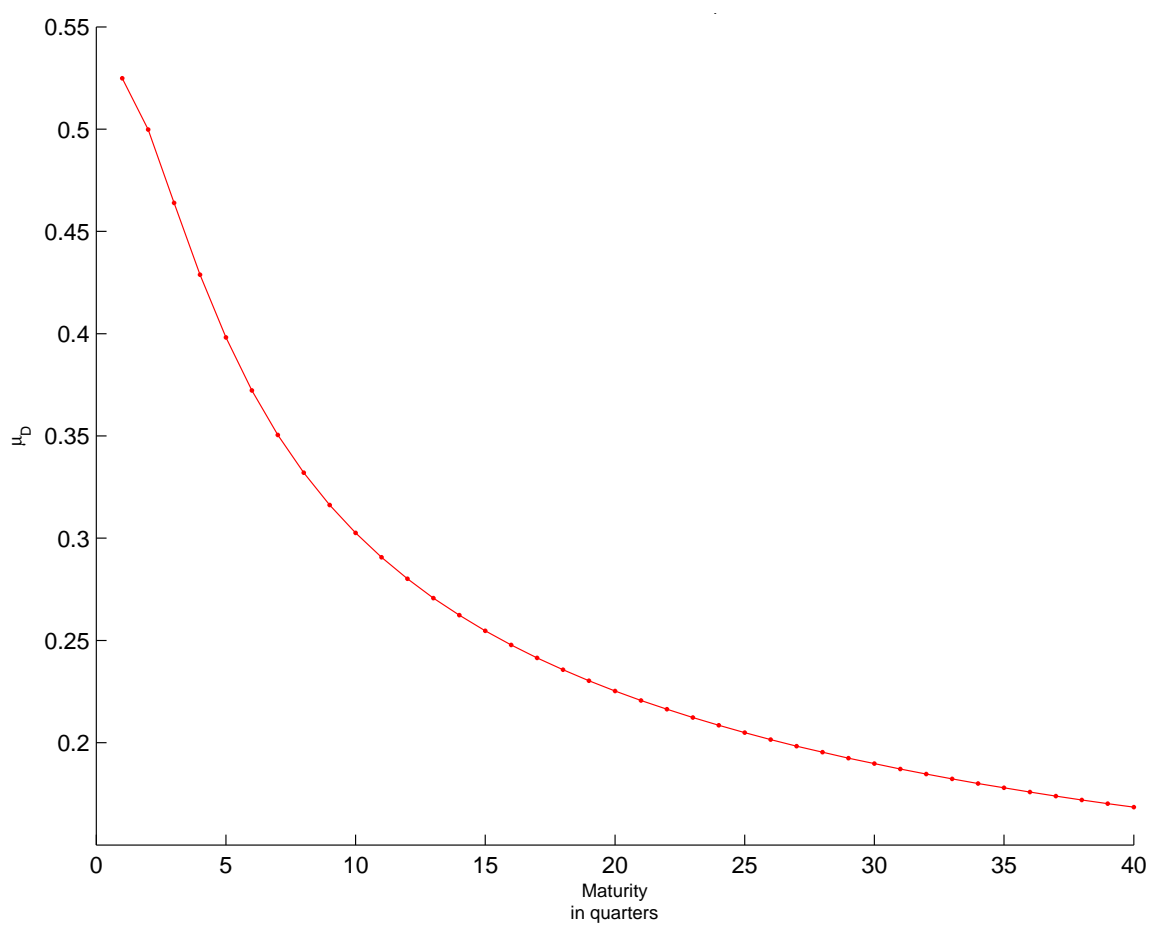

Figure 6: Maturity of government debt vs. discounted cumulative multiplier for the no default economy.

\subsection{Bank capitalization, the ZLB and the effects of a stimulus package}

In previous sections we have seen the damaging impact of the interaction between weakly capitalized banks and capital losses on the sovereign debt they hold on the effectiveness of fiscal policy. So would a better capitalized financial sector be better placed to absorb such capital losses and diminish the negative interaction channel's importance? To answer that question we rerun the model while assuming a fiscal stimulus program accompanied by a concurrently implemented bank recapitalization. Specifically we compare the base case experiment of a fiscal stimulus when banks finance long term government debt subject to sovereign default risk, and compare this with the impact of the same stimulus, but accompanied by a concurrently implemented bank recapitalization equal to $1.25 \%$ of annual steady state GDP, as in Figure 7 .

It is clear from the output response that a better capitalized financial sector significantly improves the response to the fiscal stimulus. The recap alleviates the banks' balance sheet constraint, which explains the decrease in the credit spread. So interest rates come down, and demand for private loans increases. Investment falls less by almost $5 \%$ of the steady state value. Output increases across the entire time path compared to the stimulus_cum_weakly_capitalized_banks scenario, with the troughs up by almost 1 percentage point of steady state output. The cumu- 

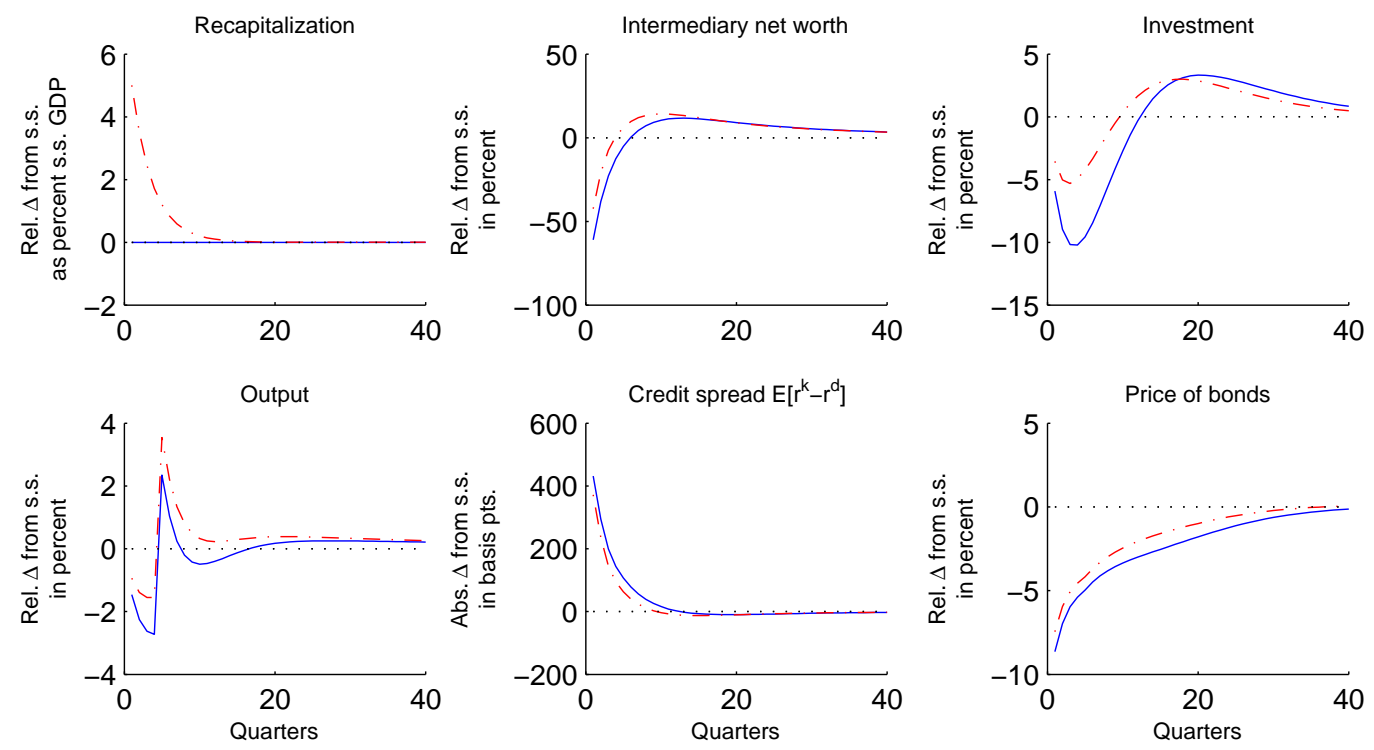

Figure 7: Plot of the impulse response functions comparing a fiscal stimulus for a weakly capitalized banking system (blue, solid), and a better capitalized banking system (red, slotted), in an economy with sovereign default risk. The stimulus is announced as the crisis hits, and implemented 4 quarters later through additional debt issuance, and equal to $1.25 \%$ of annual steady state GDP. A better capitalized banking system is captured by immediately recapitalizing the financial sector as the crisis hits through a tax financed recap of $1.25 \%$ of annual GDP. The financial crisis is initiated through a shock to the diversion rate of private loans of 8 percent relative to the steady state.

lative multiplier increases from -0.02 to 0.92 ! So a fiscal stimulus becomes much more effective when banks are better capitalized before implementation of the stimulus package.

The positive impact of bank recapitalization on the effectiveness of fiscal policy we have just demonstrated might very well explain why the recovery in the US has come much faster than it did in Europe: financial intermediaries were forced to clean up their balance sheets and raise new capital early on after the onset of the crisis. In Europe commercial banks were given much more time to do it and accordingly did not not clean up their balance sheets to a comparable extent. In fact they still carry substantial hidden losses on their balance sheet (IMF, 2011; Hoshi and Kashyap, 2015). Our simulations suggest that failure to improve the capitalization of European banks early on after the onset of the crisis has significantly slowed down the recovery.

So far we have analyzed the impact of fiscal policy assuming a Taylor-rule type "Leaning against the wind" monetary policy. This ignores the realities of the Eurozone: the ECB has obviously not followed a Taylor rule in response to Spanish macrodevelopments alone, Spain is only one of 19 countries belonging to the Eurozone. Changes in the state of the Spanish economy are unlikely to have had a major impact on the monetary policy of the ECB. So from the perspective of Spain, the ECB's monetary policy can better be considered exogenous. We 
capture this exogeneity by setting the interest rate smoothing parameter of the Taylor rule at $\rho_{r}=0.999$, which effectively dampens any "leaning against the wind"Taylor rule behavior and investigate whether bank recapitalizations still increase the effectiveness of fiscal stimuli.

To find out we run the same simulations but now with $\rho_{r}=0.999$ (cf Figure 8). Such a dampening parameter effectively kills any short term response of monetary policy to a nascent recovery and as such should have similar effects as being at the ZLB. The results are clear: although an unresponsive monetary policy like at the ZLB increases the effectiveness of fiscal stimuli, as one would expect, it does so to a much smaller extent when banks are weakly capitalized. So our results carry over to an environment where monetary policy is exogenous, like it pretty miuch is in the smaller Eurozone countries. The cumulative multiplier once again increases, this time from 0.61 (no recap) to 1.52 (with recap). The conclusions regarding the state of the financial sector accordingly remain the same, whether the economy is at the ZLB or not: fiscal stimuli become much more effective when banks are better capitalized.
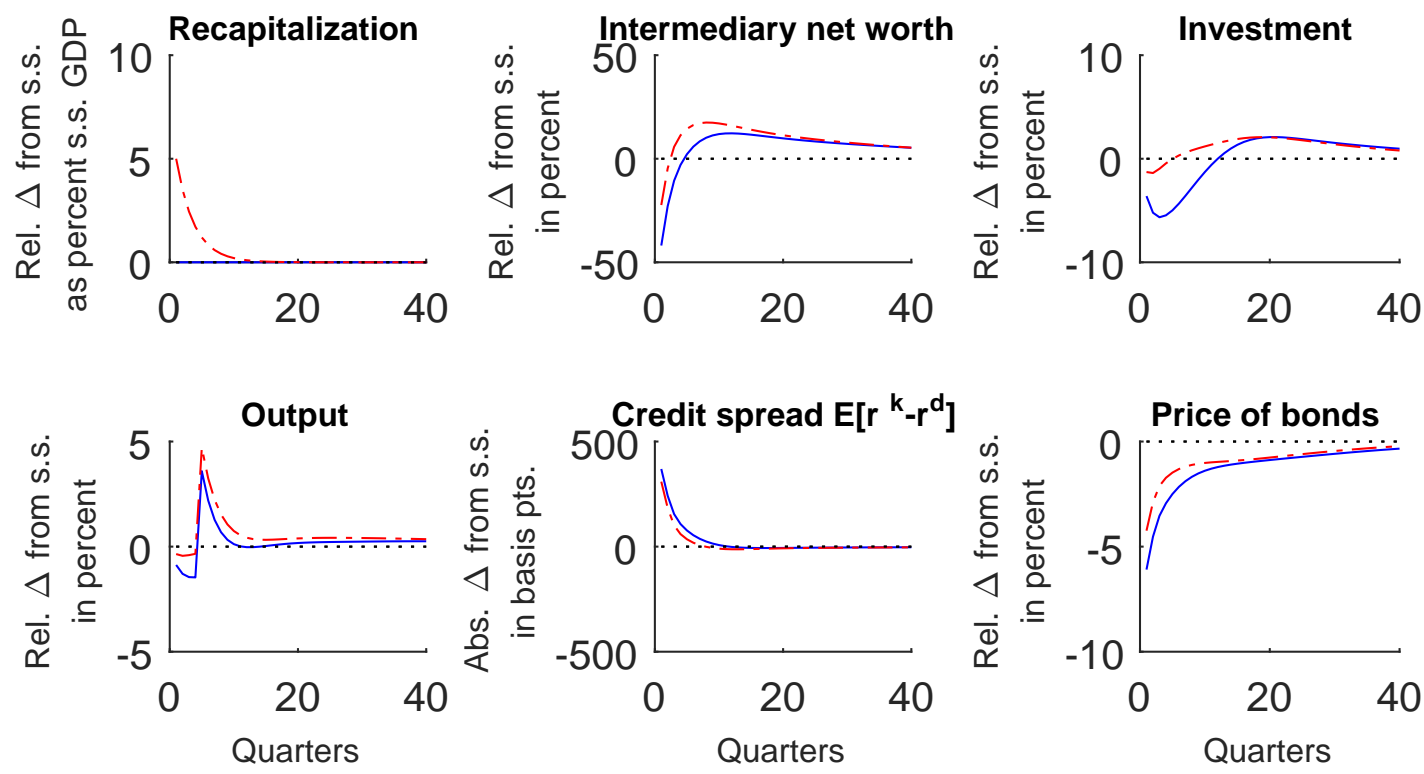

Figure 8: Plot of the impulse response functions comparing a fiscal stimulus for a weakly capitalized banking system (blue, solid), and a better capitalized banking system (red, slotted), in an economy with sovereign default risk but now with exogenous monetary policy $\left(\rho_{r}=0.999\right)$. The stimulus is announced as the crisis hits, and implemented 4 quarters later through additional debt issuance, and equal to $1.25 \%$ of annual steady state GDP. A better capitalized banking system is captured by immediately recapitalizing the financial sector as the crisis hits through a tax financed recap of $1.25 \%$ of annual GDP. The financial crisis is initiated through a shock to the diversion rate of private loans of 8 percent relative to the steady state. 


\section{Conclusion}

In this paper we show that the effectiveness of fiscal stimuli is much reduced in an environment where financial intermediaries are undercapitalized and have large holdings of government bonds on their balance sheets, and the more so when these sovereign debt securities are subject to endogenous sovereign default risk. To make the general point we first construct a simple two period general equilibrium model with leverage constrained banks that finance both loans to the real economy and long term (risky) sovereign debt. We use this model to analytically show that in such circumstances credit provision to the real economy is crowded out by a debt financed fiscal stimulus with crowding out of private investment as a consequence, to such an extent that the overall multiplier may actually turn negative in cumulative terms. In that case a fiscal stimulus would fail to improve output at all after a financial shock. We highlight that crowding out of private investment is amplified i) for longer maturity government debt, and ii) and greater sensitivity of sovereign debt discounts to increasing levels of sovereign debt outstanding (endogenous sovereign default risk). The reason is that these two features introduce capital losses on intermediaries' existing holdings of government bonds after a debt financed fiscal stimulus. These capital losses lead to a deterioration of the intermediaries' balance sheet, tightening leverage constraints and higher credit spreads. As a consequence lending to the real economy is reduced and potential output gains after a fiscal stimulus do not materialize.

To show the empirical relevance of these claims we construct a infinite horizon Neo-Keynesian DSGE incorporating undercapitalized financial intermediaries with corporate loans and long term government bonds subject to endogenous default risk on their balance sheets,. We estimate critical parameters through Bayesian techniques using Spanish data while calibrating on first order moments, also to Spanish data. We confirm in this empirical application that the effectiveness of fiscal policy is indeed substantially reduced when the maturity of government debt is extended to a level that coincides with the average maturity of outstanding Spanish sovereign debt. The cumulative impact even turns negative when sovereign default risk is introduced on top of the longer maturity sovereign debt. In Spain the banking system was severely undercapitalized after the bust of the housing boom of the 2000's, and Spanish sovereign debt holdings were equivalent to $150 \%$ of Tier-1 capital; so our results strongly suggest that a fiscal stimulus to offset the output effects of the Great Financial Crisis would have been counterproductive, at least without simultaneous recapitalization of Spain's distressed banks. These results do not depend on whether monetary policy is best represented by a traditional "Leaning against the wind" Taylor rule, or is exogenous, i.e. without endogenous interest rate response to changes in inflation and output. The latter assumption may be a more accurate description of the situation in Spain; it is unlikely that the ECB's monetary policy responds to economic conditions in Spain.

Our results highlight the importance of cleaning up commercial banks' balance sheets early on in an unfolding financial crisis, and before embarking upon fiscal stimuli. In particular, fiscal stimulus packages would not have been effective in the Eurozone after the GFC since Europe's banks were severely undercapitalized (IMF, 2011; Hoshi and Kashyap, 2015). Fiscal policy would 
have worked better if banks had been recapitalized simultaneously and quickly, like in the US, instead of allowing banks to stretch out this recapitalization process out over many years as was done in Europe.

\section{References}

Aguiar, M. and Amador, M. (2013). Sovereign Debt: A Review. Nber working papers, National Bureau of Economic Research, Inc. 1, 5

Arellano, C. (2008). Default risk and income fluctuations in emerging economies. American Economic Review, 98(3):690-712. 1

Arellano, C. and Ramanarayanan, A. (2012). Default and the maturity structure in sovereign bonds. Journal of Political Economy, 120(2):187 - 232. 2

Auerbach, A. J. and Gorodnichenko, Y. (2012a). Fiscal Multipliers in Recession and Expansion. In Fiscal Policy after the Financial Crisis, NBER Chapters, pages 63-98. National Bureau of Economic Research, Inc. 1

Auerbach, A. J. and Gorodnichenko, Y. (2012b). Measuring the Output Responses to Fiscal Policy. American Economic Journal: Economic Policy, 4(2):1-27. 1

Bachmann, R. and Sims, E. R. (2012). Confidence and the transmission of government spending shocks. Journal of Monetary Economics, 59(3):235-249. 1

Barro, R. J. and Redlick, C. J. (2011). Macroeconomic Effects From Government Purchases and Taxes. The Quarterly Journal of Economics, 126(1):51-102. 1

Becker, B. and Ivashina, V. (2016). Financial repression in the european sovereign debt crisis. 1

Blanchard, O. and Perotti, R. (2002). An Empirical Characterization of the Dynamic Effects of Changes in Government Spending and Taxes on Output. The Quarterly Journal of Economics, 117(4):1329-1368. 1

Bocola, L. (2016). The pass-through of sovereign risk. Journal of Political Economy, 124(4):879-

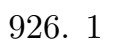

Bohn, H. (1998). The behavior of U.S. public debt and deficits. The Quarterly Journal of Economics, 113(3):949-963. 4.2, C.2, C.2

Brooks, S. P. and Gelman, A. (1998). General methods for Monitoring Convergence of Iterative Simulations. Journal of Computational and Graphical Statistics, (7):434-455. 5.3, D.2, 10

Burriel, P., Fernndez-Villaverde, J., and Rubio-Ramrez, J. (2010). MEDEA: a DSGE model for the Spanish economy. SERIEs: Journal of the Spanish Economic Association, 1(1):175-243. 5, 5.2, $5.3,5.3$, D.1, D.2 
Caballero, R. J., Hoshi, T., and Kashyap, A. K. (2008). Zombie Lending and Depressed Restructuring in Japan. American Economic Review, 98(5):1943-1977. 2

Calvo, G. A. (1983). Staggered prices in a utility-maximizing framework. Journal of Monetary Economics, 12(3):383-398. 4.4, 4.5 .2

Canzoneri, M., Collard, F., Dellas, H., and Diba, B. (2016). Fiscal Multipliers in Recessions. Economic Journal, 126(590):75-108. 1

Chatterjee, S. and Eyigungor, B. (2012). Maturity, indebtedness, and default risk. American Economic Review, 102(6):2674-99. 2

Christiano, L., Eichenbaum, M., and Rebelo, S. (2011). When Is the Government Spending Multiplier Large? Journal of Political Economy, 119(1):78 - 121. 1

Christiano, L. J., Eichenbaum, M., and Evans, C. L. (2005). Nominal rigidities and the dynamic effects of a shock to monetary policy. Journal of Political Economy, 113(1):1-45. 4.1, C.1

Claessens, S. (1990). The debt laffer curve: Some estimates. World Development, 18(12):16711677. 3.2

Cole, H. L. and Kehoe, T. J. (2000). Self-fulfilling debt crises. Review of Economic Studies, 67(1):91-116. 2

Corsetti, G., Kuester, K., Meier, A., and Mller, G. J. (2013). Sovereign Risk, Fiscal Policy, and Macroeconomic Stability. Economic Journal, 0:F99-F132. 1, 3.1, 3.1.3, 5, 4.2, 4.3.1, C.2, D.1

Corsetti, G., Meier, A., and Müller, G. J. (2012). What determines government spending multipliers? Economic Policy, 27(72):521-565. 1

Davig, T., Leeper, E. M., and Walker, T. B. (2011). Inflation and the fiscal limit. European Economic Review, 55(1):31-47. 1

Dedola, L., Karadi, P., and Lombardo, G. (2013). Global implications of national unconventional policies. Journal of Monetary Economics, 60(1):66-85. 4.3, C.3

Eggertsson, G. B. (2011). What Fiscal Policy is Effective at Zero Interest Rates? In NBER Macroeconomics Annual 2010, Volume 25, NBER Chapters, pages 59-112. National Bureau of Economic Research, Inc. 1

European Banking Authority (2011). 2011 eu-wide stress test results. http://www. eba. europa. eu/risk-analysis-and-data/eu-wide-stress-testing/2011/results, 2, A

European Central Bank (2016). http://www.ecb.int. 2, D.1

Eurostat (2014). Quarterly government debt. D.1 
Gennaioli, N., Martin, A., and Rossi, S. (2014). Banks, Government Bonds, and Default; What do the Data Say? Imf working papers, International Monetary Fund. 1

Gertler, M. and Karadi, P. (2011). A model of unconventional monetary policy. Journal of Monetary Economics, 58(1):17-34. 1, 3.1, 3.1.4, 4, 4.3, 4.3.1, 5.3, B.1.2, D.1

Gertler, M. and Karadi, P. (2013). QE 1 vs. 2 vs. 3. . : a framework for analyzing large-scale asset purchases as a monetary policy tool. International Journal of Central Banking, 9(1):5-53. 1. D.1.

Gertler, M. and Kiyotaki, N. (2010). Financial Intermediation and Credit Policy in Business Cycle Analysis. In Friedman, B. M. and Woodford, M., editors, Handbook of Monetary Economics, volume 3 of Handbook of Monetary Economics, chapter 11, pages 547-599. Elsevier. 1. 4.4. C.5.1

Homar, T. and van Wijnbergen, S. (2017). On Zombie Banks and Recessions after Systemic Banking Crises. Journal of Financial Intermediation, Forthcoming. 1

Hoshi, T. and Kashyap, A. K. (2015). Will the U.S. and Europe Avoid a Lost Decade? Lessons from Japans Postcrisis Experience. IMF Economic Review, 63(1):110-163. 1, 2, 6.3, 7

Ilzetzki, E., Mendoza, E. G., and Végh, C. A. (2013). How big (small?) are fiscal multipliers? Journal of Monetary Economics, 60(2):239-254. 1

IMF (2011). "Global Financial Stability Report", Washington D.C. 1, 2, 6.3, 7

Kirchner, M. and van Wijnbergen, S. (2016). Fiscal deficits, financial fragility, and the effectiveness of government policies. Journal of Monetary Economics, 80(C):51-68. 1. 3.2

Kollmann, R., Ratto, M., Roeger, W., and int Veld, J. (2013). Fiscal policy, banks and the financial crisis. Journal of Economic Dynamics and Control, 37(2):387-403. 1

Mountford, A. and Uhlig, H. (2009). What are the effects of fiscal policy shocks? Journal of Applied Econometrics, 24(6):960-992. 1. 4. 6.1

Occhino, F. and Pescatori, A. (2015). Debt overhang in a business cycle model. European Economic Review, 73(C):58-84. 17

Peek, J. and Rosengren, E. S. (2005). Unnatural Selection: Perverse Incentives and the Misallocation of Credit in Japan. American Economic Review, 95(4):1144-1166. 2

Schabert, A. and van Wijnbergen, S. (2006). Debt, Deficits and Destabilizing Monetary Policy in Open Economies. Cepr discussion papers, C.E.P.R. Discussion Papers. 1, 3.1, 3.1.3, $5,4.2$, 4.3.1, C.2 
Schabert, A. and van Wijnbergen, S. J. G. (2014). Sovereign Default and the Stability of InflationTargeting Regimes. IMF Economic Review, 62(2):261-287. 1, 3.1, 3.1.3, 5, 4.2, 4.3.1, B.2.3, C.2

Woodford, M. (1998). Public debt and the price level. unpublished manuscript, Columbia University. 1, 4.2, C.2

Woodford, M. (2001). Fiscal requirements for price stability. Journal of Money, Credit and Banking, 33(3):669-728. 1., 4.2, C.2

Woodford, M. (2011). Simple Analytics of the Government Expenditure Multiplier. American Economic Journal: Macroeconomics, 3(1):1-35. 1

World Bank (2016). http://data.worldbank.org/indicator/FB.AST.NPER.ZS. 1, A

Yun, T. (1996). Nominal price rigidity, money supply endogeneity, and business cycles. Journal of Monetary Economics, 37(2-3):345-370. 4.4, 4.5 .2 


\section{Appendix "Financial Fragility and the Fiscal Mul- tiplier"}

\section{A Data sources introduction}

In this section we describe the data sources that we used in section 2 The data for Figure 1 were directly downloaded from the website of the World Bank (World Bank, 2016), and did not need further processing.

Figure 2 was computed from data from the European Banking Authority European Banking Authority, 2011). We added domestic government bonds of all maturities for all financial institutions that took part in the stress test, and divided by total capital for the financial institutions of this country that participated in the stress tests.

For Figure 3 we downloaded SNR CR Credit Default Swaps Premium Mid in Basis Points from Datastream, Thomson Reuters. We use the raw data, and did not perform any processing. Below we provide the codes for the respective countries:

- Republic of Italy Senior CR 5 Year E, Mnemonic ITG5EAC Code S183RD.

- Republic of Portugal Senior CR 5 Year E, Mnemonic PTG5EAC Code S18446.

- Kingdom of Spain Senior CR 5 Year E, Mnemonic ESG5EAC Code S164NN.

\section{B Derivations Two period model}

\section{B.1 Details model setup}

\section{B.1.1 Household}

We assume a representative household that cares about consumption $c$ in period $t=0$ and $t=1$ because consumption generates utility $u(c)$. The utility function $u(c)$ satisfies the regular conditions $u^{\prime}(c)>0$ and $u^{\prime \prime}(c)<0$. Households supply labor in period $t=0$ and $t=1$. Disutility from labor is captured by $v(h)$ with the regular conditions $v^{\prime}(h)>0$ and $v^{\prime \prime}(h)>0$. The household discounts the expected future cashflow in period $t=1$ by the subjective discount factor $\beta$. The household receives income from labor $h_{t}$ at wage rate $w_{t}$ and repayment of deposits including principal $\left(1+r_{t-1}^{d}\right) d_{t-1}$ in period $t=0$ and $t=1$. In addition it receives profits $\Pi_{t}^{f}$ from production firms. Income in period $t=0$ is divided between consumption $c_{0}$ and savings in the form of deposits $d_{0}$. Upon arrival in period $t=1$, it receives income from repayment of deposits including interest, profits $\Pi_{1}^{f}$ and the payout of the net worth of the financial intermediary it owns. Although the household owns the production firm and the financial intermediary, it is not capable of influencing its production/investment decisions. The household therefore regards profits $\Pi_{1}^{f}$ and net worth $n_{1}$ as a lump sum payment from the 
production firm/financial intermediary. Revenues in period $t=1$ are used for consumption $c_{1}$ and lump sum taxes $\tau_{1}$. The household's optimization problem is now given by:

$$
\max _{\left\{c_{0}, c_{1}, h_{0}, h_{1}, d_{0}\right\}} u\left(c_{0}\right)-v\left(h_{0}\right)+\beta E_{0}\left[u\left(c_{1}\right)-v\left(h_{1}\right)\right]
$$

s.t.

$$
\begin{aligned}
& c_{0}+d_{0}=w_{0} h_{0}+\left(1+r_{-1}^{d}\right) d_{-1}+\Pi_{0}^{f} \\
& c_{1}+\tau_{1}=w_{1} h_{1}+\left(1+r_{0}^{d}\right) d_{0}+n_{1}+\Pi_{1}^{f},
\end{aligned}
$$

where $E_{0}$ is the expectations operator conditional on information in period $t=0$ and $\Pi_{t}^{f}$ profits of the representative production firm in period $t=0,1$. We set up the accompanying Lagrangians for the household's optimization problem:

$$
\begin{aligned}
\mathcal{L}_{0} & =E_{0}\left\{u\left(c_{0}\right)-v\left(h_{0}\right)+\beta u\left(c_{1}\right)-v\left(h_{1}\right)+\lambda_{0}\left(w_{0} h_{0}+\left(1+r_{-1}^{d}\right) d_{-1}+\Pi_{0}^{f}-c_{0}-d_{0}\right)\right. \\
& \left.+\beta \lambda_{1}\left[w_{1} h_{1}+\left(1+r_{0}^{d}\right) d_{0}+n_{1}+\Pi_{1}^{f}-c_{1}-\tau_{1}\right]\right\}
\end{aligned}
$$

and

$$
\mathcal{L}_{1}=u\left(c_{1}\right)-v\left(h_{1}\right)+\lambda_{1}\left[w_{1} h_{1}+\left(1+r_{0}^{d}\right) d_{0}+n_{1}+\Pi_{1}^{f}-c_{1}-\tau_{1}\right]
$$

Once the household arrives in period $t=1$, it will differentiate the Lagrangian $\mathcal{L}_{1}$ with respect to $c_{1}, h_{1}$, which gives the following first order conditions:

$$
\begin{aligned}
& c_{1}: \quad u^{\prime}\left(c_{1}\right)-\lambda_{1}=0 \Rightarrow u^{\prime}\left(c_{1}\right)=\lambda_{1}, \\
& h_{1}: \quad-v^{\prime}\left(h_{1}\right)+\lambda_{1} w_{1}=0 \Rightarrow v^{\prime}\left(h_{1}\right)=\lambda_{1} w_{1},
\end{aligned}
$$

Differentiation of Lagrangian $\mathcal{L}_{0}$ with respect to $c_{0}, h_{0}$ and $d_{0}$ gives the following first order conditions:

$$
\begin{aligned}
c_{0}: & u^{\prime}\left(c_{0}\right)-\lambda_{0}=0 \Rightarrow u^{\prime}\left(c_{0}\right)=\lambda_{0}, \\
h_{0}: & -v^{\prime}\left(h_{0}\right)+\lambda_{0} w_{0}=0 \Rightarrow v^{\prime}\left(h_{0}\right)=\lambda_{0} w_{0}, \\
d_{0}: & -\lambda_{0}+E_{0}\left[\beta \lambda_{1}\left(1+r_{0}^{d}\right)\right]=0 \Rightarrow E_{0}\left[\beta \Lambda_{0,1}\left(1+r_{0}^{d}\right)\right]=1,
\end{aligned}
$$

where $\beta \Lambda_{0,1}=\beta \lambda_{1} / \lambda_{0}$ is the households' stochastic discount factor. 


\section{B.1.2 Financial intermediaries}

Financial intermediaries enter period $t=0$ with net worth $n_{0}$. Financial intermediaries raise deposits $d_{0}$ from households, and use net worth and deposits to lend funds $k_{0}$ to the representative production firm and to purchase government bonds $b_{0}$ at a price $q_{0}^{b}$. The balance sheet of the representative intermediary is then given by:

$$
k_{0}+q_{0}^{b} b_{0}=n_{0}+d_{0},
$$

Lending to production firms earns a net real return $r_{1}^{k}$ in period $t=1$. There is no depreciation on physical capital. The government repays the principal and a coupon payment $x_{c}$ in period $t=1$ on the bonds $b_{0}$ purchased in period $t=0$. As mentioned earlier, the net real return on deposits is equal to $r_{0}^{d}$. Expected net worth in period $t=1$ is given by:

$$
E_{0}\left[n_{1}\right]=\left(1+r_{1}^{k}\right) k_{0}+\left[1-p\left(b_{0}\right)\right]\left(1+x_{c}\right) b_{0}-\left(1+r_{0}^{d}\right) d_{0} .
$$

The objective of the financial intermediary is to maximize expected discounted net worth $E_{0}\left[\beta \Lambda_{0,1} n_{1}\right]$ in period $t=1$, where $\beta \Lambda_{0,1}$ denotes the households' stochastic discount factor. Without any further constraints, the financial intermediary would attract deposits till the point where the difference between the return on loans and government bonds on the one hand, and depsoits on the other has been eliminated through arbitrage. Financial intermediaries, however, face an incentive compatibility constraint as in Gertler and Karadi (2011): hence they cannot perfectly elastically expand the balance sheet to arbitrage away return differences. This generates a spread between the return on loans and government bonds on the one hand, and deposits on the other. We follow Gertler and Karadi (2011), and assume that after purchasing assets in period $t=0$, financial intermediaries have the opportunity to divert assets. Depositors anticipate this possibility, and will provide deposits such that the value of continuing operating is larger than the value gained by diverting assets:

$$
E_{0}\left[\beta \Lambda_{0,1} n_{1}\right] \geq \lambda_{k} k_{0}+\lambda_{b} q_{0}^{b} b_{0}
$$


The objective of the financial intermediary is to maximize 42 subject to the incentive compatibility constraint (43). In mathematical terms:

$$
\begin{array}{cl}
\max _{\left\{k_{0}, b_{0}, d_{0}\right\}} & E_{0}\left[\beta \Lambda_{0,1} n_{1}\right] \\
\text { s.t. } \\
E_{0}\left[\beta \Lambda_{0,1} n_{1}\right] \geq \lambda_{k} k_{0}+\lambda_{b} q_{0}^{b} b_{0} \\
k_{0}+q_{0}^{b} b_{0}=n_{0}+d_{0}
\end{array}
$$

After substituting out net worth in period $t=1$ with the help of the law of motion for net worth (42), we set up the Lagrangian belonging to the intermediary's optimization problem:

$$
\begin{aligned}
\mathcal{L} & =\left(1+\mu_{0}\right) E_{0}\left\{\beta \Lambda_{0,1}\left[\left(1+r_{1}^{k}\right) k_{0}+\left[1-p\left(b_{0}\right)\right]\left(1+x_{c}\right) b_{0}-\left(1+r_{0}^{d}\right) d_{0}\right]\right\} \\
& -\mu_{0}\left(\lambda_{k} k_{0}+\lambda_{b} q_{0}^{b} b_{0}\right)+\chi_{0}\left(n_{0}+d_{0}-k_{0}-q_{0}^{b} b_{0}\right),
\end{aligned}
$$

where $\mu_{0}$ is the Lagrangian multiplier on the incentive compatibility constraint of the commercial bank, and $\chi_{0}$ the Lagrangian multiplier on the balance sheet constraint of the commercial bank. Differentiation with respect to loans, bonds and deposits results in the following first order conditions:

$$
\begin{aligned}
k_{0} & :\left(1+\mu_{0}\right) E_{0}\left[\beta \Lambda_{0,1}\left(1+r_{1}^{k}\right)\right]-\lambda_{k} \mu_{0}-\chi_{0}=0, \\
b_{0}: & \left(1+\mu_{0}\right) E_{0}\left\{\beta \Lambda_{0,1}\left[1-p\left(b_{0}\right)\right]\left(1+x_{c}\right)\right\}-\lambda_{b} q_{0}^{b} \mu_{0}-\chi_{0} q_{0}^{b}=0, \\
d_{0}: & -\left(1+\mu_{0}\right) E_{0}\left[\beta \Lambda_{0,1}\left(1+r_{0}^{d}\right)\right]+\chi_{0}=0 .
\end{aligned}
$$

We can rewrite the first order condition for deposits as $\chi_{0}=\left(1+\mu_{0}\right) E_{0}\left[\beta \Lambda_{0,1}\left(1+r_{0}^{d}\right)\right]$, and substitute in the first order conditions for loans and bonds to get:

$$
\begin{array}{ll}
k_{0} & : \quad E_{0}\left[\beta \Lambda_{0,1}\left(r_{1}^{k}-r_{0}^{d}\right)\right]=\frac{\lambda_{k} \mu_{0}}{1+\mu_{0}}, \\
b_{0} & : \quad E_{0}\left[\beta \Lambda_{0,1}\left(\left[1-p\left(b_{0}\right)\right]\left(\frac{1+x_{c}}{q_{0}^{b}}\right)-1-r_{0}^{d}\right)\right]=\frac{\lambda_{b} \mu_{0}}{1+\mu_{0}},
\end{array}
$$


Let us continue by looking at the law of motion for expected discounted net worth $E_{0}\left[\beta \Lambda_{0,1} n_{1}\right]$ :

$$
\begin{aligned}
E_{0}\left[\beta \Lambda_{0,1} n_{1}\right] & =E_{0}\left\{\beta \Lambda_{0,1}\left[\left(1+r_{1}^{k}\right) k_{0}+\left[1-p\left(b_{0}\right)\right]\left(1+x_{c}\right) b_{0}-\left(1+r_{0}^{d}\right) d_{0}\right]\right\} \\
& =E_{0}\left\{\beta \Lambda_{0,1}\left[\left(1+r_{1}^{k}\right) k_{0}+\left[1-p\left(b_{0}\right)\right]\left(\frac{1+x_{c}}{q_{0}^{b}}\right) q_{0}^{b} b_{0}-\left(1+r_{0}^{d}\right)\left(k_{0}+q_{0}^{b} b_{0}-n_{0}\right)\right]\right\} \\
& =E_{0}\left[\beta \Lambda_{0,1}\left(r_{1}^{k}-r_{0}^{d}\right)\right] k_{0}+E_{0}\left[\beta \Lambda_{0,1}\left(\left[1-p\left(b_{0}\right)\right]\left(\frac{1+x_{c}}{q_{0}^{b}}\right)-1-r_{0}^{d}\right)\right] q_{0}^{b} b_{0} \\
& +E_{0}\left[\beta \Lambda_{0,1}\left(1+r_{0}^{d}\right)\right] n_{0}
\end{aligned}
$$

Now we take a look at the incentive compatibility constraint of the commercial bank 43 . We start by substituting 499 for $E_{0}\left[\beta \Lambda_{0,1} n_{1}\right]$ :

$$
\begin{aligned}
E_{0}\left[\beta \Lambda_{0,1}\left(r_{1}^{k}-r_{0}^{d}\right)\right] k_{0} & +E_{0}\left[\beta \Lambda_{0,1}\left(\left[1-p\left(b_{0}\right)\right]\left(\frac{1+x_{c}}{q_{0}^{b}}\right)-1-r_{0}^{d}\right)\right] q_{0}^{b} b_{0} \\
& +E_{0}\left[\beta \Lambda_{0,1}\left(1+r_{0}^{d}\right)\right] n_{0} \geq \lambda_{k} k_{0}+\lambda_{b} q_{0}^{b} b_{0}
\end{aligned}
$$

Substitution of the first order conditions for loans and bonds 447 - 48 allows us to rewrite 450 in the following way:

$$
\begin{aligned}
\frac{\mu_{0}}{1+\mu_{0}}\left(\lambda_{k} k_{0}+\lambda_{b} q_{0}^{b} b_{0}\right)+E_{0}\left[\beta \Lambda_{0,1}\left(1+r_{0}^{d}\right)\right] n_{0} & \geq \lambda_{k} k_{0}+\lambda_{b} q_{0}^{b} b_{0} \Rightarrow \\
n_{0} & \geq\left(1-\frac{\mu_{0}}{1+\mu_{0}}\right)\left(\lambda_{k} k_{0}+\lambda_{b} q_{0}^{b} b_{0}\right) \Rightarrow \\
\left(1+\mu_{0}\right) n_{0} & \geq \lambda_{k} k_{0}+\lambda_{b} q_{0}^{b} b_{0}
\end{aligned}
$$

where we remember that $E_{0}\left[\beta \Lambda_{0,1}\left(1+r_{0}^{d}\right)\right]=1$ from the households' Euler equation 40 .

\section{B.1.3 Aggregate resource constraints}

In this section we will derive the aggregate resource constraints. For period $t=0$, we start from the households' budget constraint, and subsitute intermediaries' balance sheet constraint $d_{0}=k_{0}+q_{0}^{b} b_{0}-n_{0}$ :

$$
\begin{aligned}
c_{0}+d_{0}=c_{0}+k_{0}+q_{0}^{b} b_{0}-n_{0} & =w_{0} h_{0}+\left(1+r_{-1}^{d}\right) d_{-1}+\Pi_{0}^{f} \\
& =w_{0} h_{0}+\left(1+r_{-1}^{d}\right) d_{-1}+y_{0}-\left(1+r_{0}^{k}\right) k_{-1}-w_{0} h_{0} \\
& =\left(1+r_{-1}^{d}\right) d_{-1}+y_{0}-\left(1+r_{0}^{k}\right) k_{-1} .
\end{aligned}
$$

We remember the law of motion for net worth $n_{0}$ in period $t=0$ :

$$
n_{0}=\left(1+r_{0}^{k}\right) k_{-1}+x_{c} b_{-1}+q_{0}^{b} b_{-1}-\left(1+r_{-1}^{d}\right) d_{-1}
$$


Hence we get the following budget constraint:

$$
\begin{aligned}
c_{0}+k_{0}+q_{0}^{b} b_{0}-\left(1+r_{0}^{k}\right) k_{-1}-x_{c} b_{-1}-q_{0}^{b} b_{-1}+\left(1+r_{-1}^{d}\right) d_{-1} & =\left(1+r_{-1}^{d}\right) d_{-1}+y_{0}-\left(1+r_{0}^{k}\right) k_{-1} \Rightarrow \\
c_{0}+k_{0}+q_{0}^{b} b_{0}-x_{c} b_{-1}-q_{0}^{b} b_{-1} & =y_{0}
\end{aligned}
$$

For total outstanding government bonds $q_{0}^{b} b_{0}$ we substitute the government budget constraint (5) to arrive at the aggregate resource constraint in period $t=0$ :

$$
y_{0}=c_{0}+k_{0}+g_{0} .
$$

For period $t=1$, we again start from the households' budget constraint:

$$
c_{1}+\tau_{1}=w_{1} h_{1}+\left(1+r_{0}^{d}\right) d_{0}+n_{1}+\Pi_{1}^{f}
$$

where $\Pi_{1}^{f}$ denotes the profits of the representative production firm in period $t=1$. We substitute the law of motion for net worth $n_{1}=\left(1+r_{1}^{k}\right) k_{0}+\left(1+x_{c}\right) b_{0} \mathbb{1}_{b}-\left(1+r_{0}^{d}\right) d_{0}$, where $\mathbb{1}_{b}$ is a default indicator, which equals zero if the government defaults and one if the government repays its creditors. In addition, we substitute the profits $\Pi_{1}^{f}=y_{1}-\left(1+r_{1}^{k}\right) k_{0}-w_{1} h_{1}$ of the representative production firm. We get the following law of motion:

$$
\begin{aligned}
c_{1}+\tau_{1} & =w_{1} h_{1}+\left(1+r_{0}^{d}\right) d_{0}+n_{1}+\Pi_{1}^{f} \\
& =w_{1} h_{1}+\left(1+r_{0}^{d}\right) d_{0}+\left(1+r_{1}^{k}\right) k_{0}+\left(1+x_{c}\right) b_{0} \mathbb{1}_{b}-\left(1+r_{0}^{d}\right) d_{0} \\
& +y_{1}-\left(1+r_{1}^{k}\right) k_{0}-w_{1} h_{1} \\
& =\left(1+x_{c}\right) b_{0} \mathbb{1}_{b}+y_{1}
\end{aligned}
$$

We note that lump sum taxes $\tau_{1}=\left(1+x_{c}\right) b_{0} \mathbb{1}_{b}$, and arrive at the following aggregate resource constraint in period $t=1$ :

$$
y_{1}=c_{1}
$$

\section{B.1.4 Some further derivations}

We start by implicitly differentiating the labor supply equation $(39)$ with respect to $g_{0}$ in period $t=0$, where we remember $w_{0}=(1-\alpha) k_{-1}^{\alpha} h_{0}^{-\alpha}$ :

$$
\begin{aligned}
v^{\prime \prime}\left(h_{0}\right) \cdot \frac{d h_{0}}{d g_{0}} & =u^{\prime \prime}\left(c_{0}\right) w_{0} \cdot \frac{d c_{0}}{d g_{0}}-\frac{\alpha u^{\prime}\left(c_{0}\right) w_{0}}{h_{0}} \cdot \frac{d h_{0}}{d g_{0}} \Rightarrow \\
\frac{d h_{0}}{d g_{0}} & =\left(\frac{u^{\prime \prime}\left(c_{0}\right) w_{0}}{v^{\prime \prime}\left(h_{0}\right)+\frac{\alpha v^{\prime}\left(h_{0}\right)}{h_{0}}}\right) \cdot \frac{d c_{0}}{d g_{0}}
\end{aligned}
$$


Now we implicitly differentiate output $y_{0}=k_{-1}^{\alpha} h_{0}^{1-\alpha}$ where we remember that $k_{-1}$ is predetermined:

$$
\frac{d y_{0}}{d g_{0}}=(1-\alpha) k_{-1}^{\alpha} h_{0}^{-\alpha} \cdot \frac{d h_{0}}{d g_{0}}=w_{0} \cdot \frac{d h_{0}}{d g_{0}}
$$

Now we implicitly differentiate the aggregate resource constraint 52 with respect to $g_{0}$ gives the following result:

$$
\begin{aligned}
\frac{d c_{0}}{d g_{0}}+\frac{d k_{0}}{d g_{0}}+1 & =\frac{d y_{0}}{d g_{0}}=w_{0} \cdot \frac{d h_{0}}{d g_{0}}=\left(\frac{u^{\prime \prime}\left(c_{0}\right) w_{0}^{2}}{v^{\prime \prime}\left(h_{0}\right)+\frac{\alpha v^{\prime}\left(h_{0}\right)}{h_{0}}}\right) \cdot \frac{d c_{0}}{d g_{0}}=D_{0} \cdot \frac{d c_{0}}{d g_{0}} \Rightarrow \\
\frac{d c_{0}}{d g_{0}} & =-\left(\frac{1}{1-D_{0}}\right)\left(1+\frac{d k_{0}}{d g_{0}}\right),
\end{aligned}
$$

with $D_{0}$ given by:

$$
D_{0}=\frac{u^{\prime \prime}\left(c_{0}\right) w_{0}^{2}}{v^{\prime \prime}\left(h_{0}\right)+\frac{\alpha v^{\prime}\left(h_{0}\right)}{h_{0}}}<0
$$

Now we use (56) to find an expression for the derivative of output $y_{0}$ with respect to government spending $g_{0}$ :

$$
\frac{d y_{0}}{d g_{0}}=w_{0} \cdot \frac{d h_{0}}{d g_{0}}=\left(\frac{u^{\prime \prime}\left(c_{0}\right) w_{0}^{2}}{v^{\prime \prime}\left(h_{0}\right)+\frac{\alpha v^{\prime}\left(h_{0}\right)}{h_{0}}}\right) \cdot \frac{d c_{0}}{d g_{0}}=D_{0} \cdot \frac{d c_{0}}{d g_{0}}=-\left(\frac{D_{0}}{1-D_{0}}\right)\left(1+\frac{d k_{0}}{d g_{0}}\right) .
$$

As $D_{0}<0$, we observe that $-D_{0} /\left(1-D_{0}\right)<1$. Hence if $\frac{d k_{0}}{d g_{0}}<0$, we see that the government spending multiplier will be smaller than unity. If the drop in lending is large enough, namely $\frac{d k_{0}}{d g_{0}}<-1$, we see that the multiplier turns negative.

Now we move on to period $t=1$ and inspect the labor supply equation (37), which we differentiate with respect to $g_{0}$, where we remember $w_{1}=(1-\alpha) k_{0}^{\alpha} h_{1}^{-\alpha}$ :

$$
\begin{aligned}
v^{\prime \prime}\left(h_{1}\right) \cdot \frac{d h_{1}}{d g_{0}} & =u^{\prime \prime}\left(c_{1}\right) w_{1} \cdot \frac{d c_{1}}{d g_{0}}+\alpha u^{\prime}\left(c_{1}\right) w_{1}\left(\frac{1}{k_{0}} \cdot \frac{d k_{0}}{d g_{0}}-\frac{1}{h_{1}} \cdot \frac{d h_{1}}{d g_{0}}\right) \\
& =u^{\prime \prime}\left(c_{1}\right) w_{1} \cdot \frac{d c_{1}}{d g_{0}}+\alpha v^{\prime}\left(h_{1}\right)\left(\frac{1}{k_{0}} \cdot \frac{d k_{0}}{d g_{0}}-\frac{1}{h_{1}} \cdot \frac{d h_{1}}{d g_{0}}\right) \Rightarrow \\
\left(v^{\prime \prime}\left(h_{1}\right)+\frac{\alpha v^{\prime}\left(h_{1}\right)}{h_{1}}\right) \cdot \frac{d h_{1}}{d g_{0}} & =u^{\prime \prime}\left(c_{0}\right) w_{1} \cdot \frac{d c_{1}}{d g_{0}}+\frac{\alpha v^{\prime}\left(h_{1}\right)}{k_{0}} \cdot \frac{d k_{0}}{d g_{0}} \Rightarrow \\
\frac{d h_{1}}{d g_{0}} & =\left(\frac{u^{\prime \prime}\left(c_{0}\right) w_{1}}{v^{\prime \prime}\left(h_{1}\right)+\frac{\alpha v^{\prime}\left(h_{1}\right)}{h_{1}}}\right) \cdot \frac{d c_{1}}{d g_{0}}+\left(\frac{\alpha v^{\prime}\left(h_{1}\right)}{v^{\prime \prime}\left(h_{1}\right)+\frac{\alpha v^{\prime}\left(h_{1}\right)}{h_{1}}}\right) \cdot \frac{1}{k_{0}} \cdot \frac{d k_{0}}{d g_{0}} .
\end{aligned}
$$

Now we move on to determine an expression for $\frac{d c_{1}}{d g_{0}}$. We remember from the aggregate resource constraint 53 in period $t=1$ that $c_{1}=y_{1}=k_{0}^{\alpha} h_{1}^{1-\alpha}$. Hence we can derive the following 
expression:

$$
\begin{aligned}
\frac{d c_{1}}{d g_{0}}=\frac{d y_{1}}{d g_{0}} & =\alpha k_{0}^{\alpha-1} h_{1}^{1-\alpha} \cdot \frac{d k_{0}}{d g_{0}}+(1-\alpha) k_{0}^{\alpha} h_{1}^{-\alpha} \cdot \frac{d h_{1}}{d g_{0}}=\left(1+r_{1}^{k}\right) \cdot \frac{d k_{0}}{d g_{0}}+w_{1} \cdot \frac{d h_{1}}{d g_{0}} \\
& =\left(1+r_{1}^{k}\right) \cdot \frac{d k_{0}}{d g_{0}}+\left(\frac{u^{\prime \prime}\left(c_{1}\right) w_{1}^{2}}{v^{\prime \prime}\left(h_{1}\right)+\frac{\alpha v^{\prime}\left(h_{1}\right)}{h_{1}}}\right) \cdot \frac{d c_{1}}{d g_{0}}+\left(\frac{\alpha v^{\prime}\left(h_{1}\right) w_{1}}{v^{\prime \prime}\left(h_{1}\right)+\frac{\alpha v^{\prime}\left(h_{1}\right)}{h_{1}}}\right) \cdot \frac{1}{k_{0}} \cdot \frac{d k_{0}}{d g_{0}} \\
& =\left(1+r_{1}^{k}\right) \cdot \frac{d k_{0}}{d g_{0}}+D_{1} \cdot \frac{d c_{1}}{d g_{0}}+\left(\frac{\alpha v^{\prime}\left(h_{1}\right) w_{1}}{v^{\prime \prime}\left(h_{1}\right)+\frac{\alpha v^{\prime}\left(h_{1}\right)}{h_{1}}}\right) \cdot \frac{1}{k_{0}} \cdot \frac{d k_{0}}{d g_{0}} \Rightarrow \\
\frac{d c_{1}}{d g_{0}} & =\left(\frac{1}{1-D_{1}}\right)\left[1+r_{1}^{k}+\left(\frac{\alpha v^{\prime}\left(h_{1}\right) w_{1}}{v^{\prime \prime}\left(h_{1}\right)+\frac{\alpha v^{\prime}\left(h_{1}\right)}{h_{1}}}\right) \cdot \frac{1}{k_{0}}\right] \cdot \frac{d k_{0}}{d g_{0}}=K_{1} \cdot \frac{d k_{0}}{d g_{0}}
\end{aligned}
$$

where $K_{1}$ is given by:

$$
K_{1}=\left(\frac{1}{1-D_{1}}\right)\left[1+r_{1}^{k}+\left(\frac{\alpha v^{\prime}\left(h_{1}\right) w_{1}}{v^{\prime \prime}\left(h_{1}\right)+\frac{\alpha v^{\prime}\left(h_{1}\right)}{h_{1}}}\right) \cdot \frac{1}{k_{0}}\right]>0,
$$

where $D_{1}$ is given by:

$$
D_{1}=\frac{u^{\prime \prime}\left(c_{1}\right) w_{1}^{2}}{v^{\prime \prime}\left(h_{1}\right)+\frac{\alpha v^{\prime}\left(h_{1}\right)}{h_{1}}}<0 .
$$

We get the following expression for the derivative of output in period $t=1$ with respect to government spending $g_{0}$ :

$$
\frac{d y_{1}}{d g_{0}}=\frac{d c_{1}}{d g_{0}}=K_{1} \cdot \frac{d k_{0}}{d g_{0}}
$$

Since $K_{1}>0$, we see that a reduction in physical capital $\left(\frac{d k_{0}}{d g_{0}}<0\right)$ causes output to drop. 
Substitution of 559 in expression 58 gives the following expression for $\frac{d h_{1}}{d g_{0}}$ :

$$
\begin{aligned}
\frac{d h_{1}}{d g_{0}} & =\left(\frac{u^{\prime \prime}\left(c_{0}\right) w_{1}}{v^{\prime \prime}\left(h_{1}\right)+\frac{\alpha v^{\prime}\left(h_{1}\right)}{h_{1}}}\right) \cdot \frac{d c_{1}}{d g_{0}}+\left(\frac{\alpha v^{\prime}\left(h_{1}\right)}{v^{\prime \prime}\left(h_{1}\right)+\frac{\alpha v^{\prime}\left(h_{1}\right)}{h_{1}}}\right) \cdot \frac{1}{k_{0}} \cdot \frac{d k_{0}}{d g_{0}} \\
& =\left(\frac{u^{\prime \prime}\left(c_{0}\right) w_{1}}{v^{\prime \prime}\left(h_{1}\right)+\frac{\alpha v^{\prime}\left(h_{1}\right)}{h_{1}}}\right)\left(\frac{1}{1-D_{1}}\right)\left[1+r_{1}^{k}+\left(\frac{\alpha v^{\prime}\left(h_{1}\right) w_{1}}{v^{\prime \prime}\left(h_{1}\right)+\frac{\alpha v^{\prime}\left(h_{1}\right)}{h_{1}}}\right) \cdot \frac{1}{k_{0}}\right] \cdot \frac{d k_{0}}{d g_{0}} \\
& +\left(\frac{\alpha v^{\prime}\left(h_{1}\right)}{v^{\prime \prime}\left(h_{1}\right)+\frac{\alpha v^{\prime}\left(h_{1}\right)}{h_{1}}}\right) \cdot \frac{1}{k_{0}} \cdot \frac{d k_{0}}{d g_{0}} \\
& =\frac{1}{w_{1}}\left(\frac{u^{\prime \prime}\left(c_{0}\right) w_{1}^{2}}{v^{\prime \prime}\left(h_{1}\right)+\frac{\alpha v^{\prime}\left(h_{1}\right)}{h_{1}}}\right)\left(\frac{1}{1-D_{1}}\right)\left[\alpha k_{0}^{\alpha-1} h_{1}^{1-\alpha}+\left(\frac{\alpha v^{\prime}\left(h_{1}\right) w_{1}}{v^{\prime \prime}\left(h_{1}\right)+\frac{\alpha v^{\prime}\left(h_{1}\right)}{h_{1}}}\right) \cdot \frac{1}{k_{0}}\right] \cdot \frac{d k_{0}}{d g_{0}} \\
& +\left(\frac{\alpha v^{\prime}\left(h_{1}\right)}{v^{\prime \prime}\left(h_{1}\right)+\frac{\alpha v^{\prime}\left(h_{1}\right)}{h_{1}}}\right) \cdot \frac{1}{k_{0}} \cdot \frac{d k_{0}}{d g_{0}} \\
& =\frac{1}{w_{1}}\left(\frac{D_{1}}{1-D_{1}}\right)\left[\alpha k_{0}^{\alpha} h_{1}^{1-\alpha}+\left(\frac{\alpha v^{\prime}\left(h_{1}\right) w_{1}}{v^{\prime \prime}\left(h_{1}\right)+\frac{\alpha v^{\prime}\left(h_{1}\right)}{h_{1}}}\right)\right] \cdot \frac{1}{k_{0}} \cdot \frac{d k_{0}}{d g_{0}} \\
& +\left(\frac{\alpha v^{\prime}\left(h_{1}\right)}{v^{\prime \prime}\left(h_{1}\right)+\frac{\alpha v^{\prime}\left(h_{1}\right)}{h_{1}}}\right) \cdot \frac{1}{k_{0}} \cdot \frac{d k_{0}}{d g_{0}}=E_{1} \cdot \frac{1}{k_{0}} \cdot \frac{d k_{0}}{d g_{0}},
\end{aligned}
$$

where $E_{1}$ is given by:

$$
\begin{aligned}
E_{1} & =\frac{1}{w_{1}}\left(\frac{D_{1}}{1-D_{1}}\right)\left[\alpha k_{0}^{\alpha} h_{1}^{1-\alpha}+\left(\frac{\alpha v^{\prime}\left(h_{1}\right) w_{1}}{v^{\prime \prime}\left(h_{1}\right)+\frac{\alpha v^{\prime}\left(h_{1}\right)}{h_{1}}}\right)\right]+\left(\frac{\alpha v^{\prime}\left(h_{1}\right)}{v^{\prime \prime}\left(h_{1}\right)+\frac{\alpha v^{\prime}\left(h_{1}\right)}{h_{1}}}\right) \\
& =\left(\frac{D_{1}}{1-D_{1}}\right)\left[\frac{\alpha k_{0}^{\alpha} h_{1}^{1-\alpha}}{w_{1}}+\left(\frac{\alpha v^{\prime}\left(h_{1}\right)}{v^{\prime \prime}\left(h_{1}\right)+\frac{\alpha v^{\prime}\left(h_{1}\right)}{h_{1}}}\right)\right]+\left(\frac{\alpha v^{\prime}\left(h_{1}\right)}{v^{\prime \prime}\left(h_{1}\right)+\frac{\alpha v^{\prime}\left(h_{1}\right)}{h_{1}}}\right) \\
& =\left(\frac{D_{1}}{1-D_{1}}\right)\left(\frac{\alpha k_{0}^{\alpha} h_{1}^{1-\alpha}}{(1-\alpha) k_{0}^{\alpha} h_{1}^{-\alpha}}\right)+\left(\frac{D_{1}}{1-D_{1}}\right)\left(\frac{\alpha v^{\prime}\left(h_{1}\right)}{v^{\prime \prime}\left(h_{1}\right)+\frac{\alpha v^{\prime}\left(h_{1}\right)}{h_{1}}}\right)+\left(\frac{\alpha v^{\prime}\left(h_{1}\right)}{v^{\prime \prime}\left(h_{1}\right)+\frac{\alpha v^{\prime}\left(h_{1}\right)}{h_{1}}}\right) \\
& =\left(\frac{D_{1}}{1-D_{1}}\right)\left(\frac{\alpha}{1-\alpha}\right) h_{1}+\left(\frac{1}{1-D_{1}}\right)\left(\frac{\alpha v^{\prime}\left(h_{1}\right)}{v^{\prime \prime}\left(h_{1}\right)+\frac{\alpha v^{\prime}\left(h_{1}\right)}{h_{1}}}\right)
\end{aligned}
$$

Finally, we derive an expression for the derivative of the return on capital $r_{1}^{k}$ with respect to 
government spending $g_{0}$. The return on capital is given by $r_{1}^{k}=\alpha k_{0}^{\alpha-1} h_{1}^{1-\alpha}-1$.

$$
\begin{aligned}
& \frac{d\left(1+r_{1}^{k}\right)}{d g_{0}}=\frac{d r_{1}^{k}}{d g_{0}}=\frac{d}{d g_{0}}\left(\alpha k_{0}^{\alpha-1} h_{1}^{1-\alpha}-1\right) \\
& =\alpha(\alpha-1) k_{0}^{\alpha-2} h_{1}^{1-\alpha} \cdot \frac{d k_{0}}{d g_{0}}+\alpha(1-\alpha) k_{0}^{\alpha-1} h_{1}^{-\alpha} \cdot \frac{d h_{1}}{d g_{0}} \\
& =(\alpha-1) \alpha k_{0}^{\alpha-1} h_{1}^{1-\alpha}\left(\frac{1}{k_{0}} \cdot \frac{d k_{0}}{d g_{0}}-\frac{1}{h_{1}} \cdot \frac{d h_{1}}{d g_{0}}\right) \\
& =(\alpha-1)\left(1+r_{1}^{k}\right)\left(\frac{1}{k_{0}} \cdot \frac{d k_{0}}{d g_{0}}-\frac{1}{h_{1}} \cdot \frac{d h_{1}}{d g_{0}}\right) \\
& =(\alpha-1)\left(1+r_{1}^{k}\right)\left(\frac{1}{k_{0}} \cdot \frac{d k_{0}}{d g_{0}}-\frac{1}{h_{1}} \cdot E_{1} \cdot \frac{1}{k_{0}} \cdot \frac{d k_{0}}{d g_{0}}\right) \\
& =(\alpha-1)\left(1+r_{1}^{k}\right)\left[1-\left(\frac{D_{1}}{1-D_{1}}\right)\left(\frac{\alpha}{1-\alpha}\right)\right. \\
& \left.-\left(\frac{1}{1-D_{1}}\right)\left(\frac{\alpha v^{\prime}\left(h_{1}\right) / h_{1}}{v^{\prime \prime}\left(h_{1}\right)+\frac{\alpha v^{\prime}\left(h_{1}\right)}{h_{1}}}\right)\right] \cdot \frac{1}{k_{0}} \cdot \frac{d k_{0}}{d g_{0}} \\
& =(\alpha-1)\left(1+r_{1}^{k}\right)\left[\left(\frac{1-D_{1}}{1-D_{1}}\right)\left(\frac{v^{\prime \prime}\left(h_{1}\right)+\frac{\alpha v^{\prime}\left(h_{1}\right)}{h_{1}}}{v^{\prime \prime}\left(h_{1}\right)+\frac{\alpha v^{\prime}\left(h_{1}\right)}{h_{1}}}\right)\right. \\
& -\left(\frac{D_{1}}{1-D_{1}}\right)\left(\frac{\alpha}{1-\alpha}\right) \\
& \left.-\left(\frac{1}{1-D_{1}}\right)\left(\frac{\alpha v^{\prime}\left(h_{1}\right) / h_{1}}{v^{\prime \prime}\left(h_{1}\right)+\frac{\alpha v^{\prime}\left(h_{1}\right)}{h_{1}}}\right)\right] \cdot \frac{1}{k_{0}} \cdot \frac{d k_{0}}{d g_{0}} \\
& =\frac{(\alpha-1)\left(1+r_{1}^{k}\right)}{1-D_{1}}\left\{\left[\frac{v^{\prime \prime}\left(h_{1}\right)-D_{1}\left(v^{\prime \prime}\left(h_{1}\right)+\frac{\alpha v^{\prime}\left(h_{1}\right)}{h_{1}}\right)}{v^{\prime \prime}\left(h_{1}\right)+\frac{\alpha v^{\prime}\left(h_{1}\right)}{h_{1}}}\right]\right. \\
& \left.-D_{1}\left(\frac{\alpha}{1-\alpha}\right)\right\} \cdot \frac{1}{k_{0}} \cdot \frac{d k_{0}}{d g_{0}} \\
& =\frac{(\alpha-1)\left(1+r_{1}^{k}\right)}{1-D_{1}}\left[\frac{v^{\prime \prime}\left(h_{1}\right)}{v^{\prime \prime}\left(h_{1}\right)+\frac{\alpha v^{\prime}\left(h_{1}\right)}{h_{1}}}-D_{1}-D_{1}\left(\frac{\alpha}{1-\alpha}\right)\right] \cdot \frac{1}{k_{0}} \cdot \frac{d k_{0}}{d g_{0}} \\
& =\frac{(\alpha-1)\left(1+r_{1}^{k}\right)}{1-D_{1}}\left[\frac{v^{\prime \prime}\left(h_{1}\right)}{v^{\prime \prime}\left(h_{1}\right)+\frac{\alpha v^{\prime}\left(h_{1}\right)}{h_{1}}}+\left(\frac{-D_{1}}{1-\alpha}\right)\right] \cdot \frac{1}{k_{0}} \cdot \frac{d k_{0}}{d g_{0}} \\
& =\left(1+r_{1}^{k}\right) \cdot E_{2} \cdot \frac{d k_{0}}{d g_{0}},
\end{aligned}
$$

where $E_{2}$ is given by:

$$
E_{2}=\left(\frac{\alpha-1}{1-D_{1}}\right)\left[\frac{v^{\prime \prime}\left(h_{1}\right)}{v^{\prime \prime}\left(h_{1}\right)+\frac{\alpha v^{\prime}\left(h_{1}\right)}{h_{1}}}+\left(\frac{-D_{1}}{1-\alpha}\right)\right] \cdot \frac{1}{k_{0}}<0 .
$$

It will be useful to have a direct relationship between the degree by which the incentive 
compatibility constraint of the financial intermediary, captured by the Lagrangian multiplier $\mu_{0}$, is binding, and the level of lending to the real sector $k_{0}$. Such a direct relationship, however, is not directly available, but an indirect one is in the form of equation 477. We can rewrite this relationship between the return on capital and the Lagrangian multiplier on the incentive compatibility constraint in the following way:

$$
\mu_{0}=\frac{E_{0}\left[\beta \Lambda_{0,1}\left(r_{1}^{k}-r_{0}^{d}\right)\right]}{\lambda_{k}-E_{0}\left[\beta \Lambda_{0,1}\left(r_{1}^{k}-r_{0}^{d}\right)\right]}
$$

where $\beta \Lambda_{0,1}=\beta\left(\frac{u^{\prime}\left(c_{1}\right)}{u^{\prime}\left(c_{0}\right)}\right)$ is the households' stochastic discount factor. Now we show that $\mu_{0}>0$ by showing that $\lambda_{k}-E_{0}\left[\beta \Lambda_{0,1}\left(r_{1}^{k}-r_{0}^{d}\right)\right]>0$. To do so, we substitute 477 for $E_{0}\left[\beta \Lambda_{0,1}\left(r_{1}^{k}-r_{0}^{d}\right)\right]$ :

$$
\lambda_{k}-E_{0}\left[\beta \Lambda_{0,1}\left(r_{1}^{k}-r_{0}^{d}\right)\right]=\lambda_{k}-\frac{\lambda_{k} \mu_{0}}{1+\mu_{0}}=\frac{\lambda_{k}}{1+\mu_{0}}>0 .
$$

We now calculate $1+\mu_{0}$ :

$$
1+\mu_{0}=1+\frac{E_{0}\left[\beta \Lambda_{0,1}\left(r_{1}^{k}-r_{0}^{d}\right)\right]}{\lambda_{k}-E_{0}\left[\beta \Lambda_{0,1}\left(r_{1}^{k}-r_{0}^{d}\right)\right]}=\frac{\lambda_{k}}{\lambda_{k}-E_{0}\left[\beta \Lambda_{0,1}\left(r_{1}^{k}-r_{0}^{d}\right)\right]}
$$

We now remember from (53) and (3) that $c_{1}$ and $r_{1}^{k}$ only depend on the stock of capital $k_{0}$ chosen in period $t=0$. Hence we can drop the expectations operator from (67). Now we differentiate $\mu_{0}$ with respect to government spending $g_{0}$ :

$$
\frac{d \mu_{0}}{d g_{0}}=\frac{\left[\beta\left(\frac{u^{\prime}\left(c_{1}\right)}{u^{\prime}\left(c_{0}\right)}\right)\left(r_{1}^{k}-r_{0}^{d}\right)\right]^{\prime}\left[\lambda_{k}-\beta\left(\frac{u^{\prime}\left(c_{1}\right)}{u^{\prime}\left(c_{0}\right)}\right)\left(r_{1}^{k}-r_{0}^{d}\right)\right]-\left[\beta\left(\frac{u^{\prime}\left(c_{1}\right)}{u^{\prime}\left(c_{0}\right)}\right)\left(r_{1}^{k}-r_{0}^{d}\right)\right](-1)\left[\beta\left(\frac{u^{\prime}\left(c_{1}\right)}{u^{\prime}\left(c_{0}\right)}\right)\left(r_{1}^{k}-r_{0}^{d}\right)\right]^{\prime}}{\left[\lambda_{k}-\beta\left(\frac{u^{\prime}\left(c_{1}\right)}{u^{\prime}\left(c_{0}\right)}\right)\left(r_{1}^{k}-r_{0}^{d}\right)\right]^{2}}
$$

where $[\cdot]^{\prime}$ denotes the derivative with respect to $g_{0}$. Hence $d \mu_{0} / d g_{0}$ is equal to:

$$
\begin{aligned}
\frac{d \mu_{0}}{d g_{0}} & =\frac{\lambda_{k}\left[\beta\left(\frac{u^{\prime}\left(c_{1}\right)}{u^{\prime}\left(c_{0}\right)}\right)\left(r_{1}^{k}-r_{0}^{d}\right)\right]^{\prime}}{\left[\lambda_{k}-\beta\left(\frac{u^{\prime}\left(c_{1}\right)}{u^{\prime}\left(c_{0}\right)}\right)\left(r_{1}^{k}-r_{0}^{d}\right)\right]^{2}}=\left(\frac{1+\mu_{0}}{\lambda_{k}-\beta\left(\frac{u^{\prime}\left(c_{1}\right)}{u^{\prime}\left(c_{0}\right)}\right)\left(r_{1}^{k}-r_{0}^{d}\right)}\right)\left[\beta\left(\frac{u^{\prime}\left(c_{1}\right)}{u^{\prime}\left(c_{0}\right)}\right)\left(r_{1}^{k}-r_{0}^{d}\right)\right]^{\prime} \\
& =A\left[\beta\left(\frac{u^{\prime}\left(c_{1}\right)}{u^{\prime}\left(c_{0}\right)}\right)\left(r_{1}^{k}-r_{0}^{d}\right)\right]^{\prime},
\end{aligned}
$$

where $A$ is given by:

$$
A=\left(\frac{1+\mu_{0}}{\lambda_{k}-\beta\left(\frac{u^{\prime}\left(c_{1}\right)}{u^{\prime}\left(c_{0}\right)}\right)\left(r_{1}^{k}-r_{0}^{d}\right)}\right)=\frac{\left(1+\mu_{0}\right)^{2}}{\lambda_{k}}>0
$$


Calculation of the second factor gives us:

$$
\begin{aligned}
& {\left[\beta\left(\frac{u^{\prime}\left(c_{1}\right)}{u^{\prime}\left(c_{0}\right)}\right)\left(r_{1}^{k}-r_{0}^{d}\right)\right]^{\prime}=\left[\beta\left(\frac{u^{\prime}\left(c_{1}\right)}{u^{\prime}\left(c_{0}\right)}\right)\left(1+r_{1}^{k}\right)-1\right]^{\prime}} \\
& =\beta\left(\frac{u^{\prime \prime}\left(c_{1}\right)}{u^{\prime}\left(c_{0}\right)}\right)\left(1+r_{1}^{k}\right) \cdot \frac{d c_{1}}{d g_{0}} \\
& -\beta\left(\frac{u^{\prime}\left(c_{1}\right)}{\left[u^{\prime}\left(c_{0}\right)\right]^{2}}\right)\left(1+r_{1}^{k}\right) u^{\prime \prime}\left(c_{0}\right) \cdot \frac{d c_{0}}{d g_{0}} \\
& +\beta\left(\frac{u^{\prime}\left(c_{1}\right)}{u^{\prime}\left(c_{0}\right)}\right) \cdot \frac{d\left(1+r_{1}^{k}\right)}{d g_{0}} \\
& =\left[\beta\left(\frac{u^{\prime}\left(c_{1}\right)}{u^{\prime}\left(c_{0}\right)}\right)\left(1+r_{1}^{k}\right)\right] \\
& \times \quad\left[\left(\frac{u^{\prime \prime}\left(c_{1}\right)}{u^{\prime}\left(c_{1}\right)}\right) \cdot \frac{d c_{1}}{d g_{0}}-\left(\frac{u^{\prime \prime}\left(c_{0}\right)}{u^{\prime}\left(c_{0}\right)}\right) \cdot \frac{d c_{0}}{d g_{0}}+\left(\frac{1}{1+r_{1}^{k}}\right) \cdot \frac{d\left(1+r_{1}^{k}\right)}{d g_{0}}\right] \\
& =\left[\beta\left(\frac{u^{\prime}\left(c_{1}\right)}{u^{\prime}\left(c_{0}\right)}\right)\left(1+r_{1}^{k}\right)\right] \times\left[\left(\frac{u^{\prime \prime}\left(c_{1}\right)}{u^{\prime}\left(c_{1}\right)}\right) \cdot K_{1} \cdot \frac{d k_{0}}{d g_{0}}\right. \\
& \left.-\left(\frac{u^{\prime \prime}\left(c_{0}\right)}{u^{\prime}\left(c_{0}\right)}\right)\left(\frac{1}{1-D_{0}}\right)\left(-1-\frac{d k_{0}}{d g_{0}}\right)+E_{2} \cdot \frac{d k_{0}}{d g_{0}}\right] \\
& =\left[\beta\left(\frac{u^{\prime}\left(c_{1}\right)}{u^{\prime}\left(c_{0}\right)}\right)\left(1+r_{1}^{k}\right)\right]\left(\frac{1}{1-D_{0}}\right)\left(\frac{u^{\prime \prime}\left(c_{0}\right)}{u^{\prime}\left(c_{0}\right)}\right) \\
& +\left[\beta\left(\frac{u^{\prime}\left(c_{1}\right)}{u^{\prime}\left(c_{0}\right)}\right)\left(1+r_{1}^{k}\right)\right] \\
& \times \quad\left[\left(\frac{u^{\prime \prime}\left(c_{1}\right)}{u^{\prime}\left(c_{1}\right)}\right) \cdot K_{1}+\left(\frac{1}{1-D_{0}}\right)\left(\frac{u^{\prime \prime}\left(c_{0}\right)}{u^{\prime}\left(c_{0}\right)}\right)+E_{2}\right] \cdot \frac{d k_{0}}{d g_{0}}
\end{aligned}
$$

where we used (40), (57) and (59). Hence we get for $d \mu_{0} / d g_{0}$ the following expression:

$$
\begin{aligned}
\frac{d \mu_{0}}{d g_{0}} & =A\left[\beta\left(\frac{u^{\prime}\left(c_{1}\right)}{u^{\prime}\left(c_{0}\right)}\right)\left(1+r_{1}^{k}\right)\right]\left(\frac{1}{1-D_{0}}\right) \cdot \frac{u^{\prime \prime}\left(c_{0}\right)}{u^{\prime}\left(c_{0}\right)} \\
& +A\left[\beta\left(\frac{u^{\prime}\left(c_{1}\right)}{u^{\prime}\left(c_{0}\right)}\right)\left(1+r_{1}^{k}\right)\right]\left[\left(\frac{u^{\prime \prime}\left(c_{1}\right)}{u^{\prime}\left(c_{1}\right)}\right) \cdot K_{1}+\left(\frac{1}{1-D_{0}}\right) \cdot \frac{u^{\prime \prime}\left(c_{0}\right)}{u^{\prime}\left(c_{0}\right)}+E_{2}\right] \cdot \frac{d k_{0}}{d g_{0}} \\
& =B\left\{\left(\frac{1}{1-D_{0}}\right) \cdot \frac{u^{\prime \prime}\left(c_{0}\right)}{u^{\prime}\left(c_{0}\right)}+\left[\left(\frac{u^{\prime \prime}\left(c_{1}\right)}{u^{\prime}\left(c_{1}\right)}\right) \cdot K_{1}+\left(\frac{1}{1-D_{0}}\right) \cdot \frac{u^{\prime \prime}\left(c_{0}\right)}{u^{\prime}\left(c_{0}\right)}+E_{2}\right] \cdot \frac{d k_{0}}{d g_{0}}\right\}(71)
\end{aligned}
$$

with $B$ given by:

$$
B=A\left[\beta\left(\frac{u^{\prime}\left(c_{1}\right)}{u^{\prime}\left(c_{0}\right)}\right)\left(1+r_{1}^{k}\right)\right]=\frac{\left(1+\mu_{0}\right)^{2}}{\lambda_{k}}\left[\beta\left(\frac{u^{\prime}\left(c_{1}\right)}{u^{\prime}\left(c_{0}\right)}\right)\left(1+r_{1}^{k}\right)\right]>0 .
$$




\section{B.2 Analysis of the equilibrium}

\section{B.2.1 Case 1: one-period bonds and no sovereign risk: establishing crowding out of physical capital by government bonds}

We obtain the case of no sovereign default risk by setting $p\left(b_{0}\right)=0$. Switching from long-term government debt to one-period bonds implies that at the beginning of period $t=0$ the government has to repay outstanding government bonds $b_{-1}$, instead of rolling them over. Outstanding government liabilities at the beginning of period $t=0$ are now equal to $\left(1+x_{c}\right) b_{-1}$ instead of $\left(q_{0}^{b}+x_{c}\right) b_{-1}$. Hence the government budget constraint in period $t=0$ becomes:

$$
q_{0}^{b} b_{0}=g_{0}+\left(1+x_{c}\right) b_{-1} .
$$

Since the principal of government bonds $b_{-1}$ is repaid at the beginning of period $t=0$ to financial intermediaries, there are no capital losses on their existing holdings of government bonds $b_{-1}$. Net worth $n_{0}$ is therefore exogenous and not affected by a shock to $g_{0}$.

To evaluate the effect of a marginal increase in government spending $g_{0}$, we perform an implicit differentiation of intermediaries' incentive compatibility constraint [51, which we assume to be binding, with respect to $g_{0}$ :

$$
n_{0} \frac{d \mu_{0}}{d g_{0}}=\lambda_{k} \frac{d k_{0}}{d g_{0}}+\lambda_{b} \frac{d\left(q_{0}^{b} b_{0}\right)}{d g_{0}}
$$

Substitution of 71 gives the following expression:

$n_{0} \cdot B\left\{\left(\frac{1}{1-D_{0}}\right) \cdot \frac{u^{\prime \prime}\left(c_{0}\right)}{u^{\prime}\left(c_{0}\right)}+\left[\left(\frac{u^{\prime \prime}\left(c_{1}\right)}{u^{\prime}\left(c_{1}\right)}\right) \cdot K_{1}+\left(\frac{1}{1-D_{0}}\right) \cdot \frac{u^{\prime \prime}\left(c_{0}\right)}{u^{\prime}\left(c_{0}\right)}+E_{2}\right] \cdot \frac{d k_{0}}{d g_{0}}\right\}=\lambda_{k} \frac{d k_{0}}{d g_{0}}+\lambda_{b}$.

Isolating $\frac{d k_{0}}{d g_{0}}$ gives the following expression:

$$
\begin{aligned}
\left.\frac{d k_{0}}{d g_{0}}\right|_{S T} & =\frac{\lambda_{b}-B n_{0}\left(\frac{1}{1-D_{0}}\right) \cdot \frac{u^{\prime \prime}\left(c_{0}\right)}{u^{\prime}\left(c_{0}\right)}}{\left\{B n_{0}\left[\left(\frac{u^{\prime \prime}\left(c_{1}\right)}{u^{\prime}\left(c_{1}\right)}\right) \cdot K_{1}+\left(\frac{1}{1-D_{0}}\right) \cdot \frac{u^{\prime \prime}\left(c_{0}\right)}{u^{\prime}\left(c_{0}\right)}+E_{2}\right]-\lambda_{k}\right\}} \\
& =\frac{\lambda_{b}-B n_{0}\left(\frac{1}{1-D_{0}}\right) \cdot \frac{u^{\prime \prime}\left(c_{0}\right)}{u^{\prime}\left(c_{0}\right)}}{C-\lambda_{k}}<0,
\end{aligned}
$$

since $C<0$, as it is given by:

$$
C=B n_{0}\left[\left(\frac{u^{\prime \prime}\left(c_{1}\right)}{u^{\prime}\left(c_{1}\right)}\right) \cdot K_{1}+\left(\frac{1}{1-D_{0}}\right) \cdot \frac{u^{\prime \prime}\left(c_{0}\right)}{u^{\prime}\left(c_{0}\right)}+E_{2}\right]<0 .
$$

Hence we see a crowding out of physical capital by government bonds. As the financial intermediary has to finance the additional debt issue in equilibrium, there is less space on the intermediary's balance sheet to purchase physical capital for lending to production firms. 


\section{B.2.2 Case 2: long term bonds: establishing a further fall in lending due to capital losses on government bonds}

The only difference compared with the main text is that the probability of default is equal to zero, $p\left(b_{0}\right)=0$. Again, we implicitly differentiate the (binding) incentive compatibility constraint (51) of the financial intermediary with resepct to $g_{0}$. However, $n_{0}$ now depends on the bond price $q_{0}^{b}$, which in turn is affected by a change in government spending $g_{0}$. Hence this term will not drop out anymore after implicit differentiation. We obtain the following expression:

$$
n_{0} \frac{d \mu_{0}}{d g_{0}}+\left(1+\mu_{0}\right) \frac{d n_{0}}{d g_{0}}=\lambda_{k} \cdot \frac{d k_{0}}{d g_{0}}+\lambda_{b} \cdot \frac{d\left(q_{0}^{b} b_{0}\right)}{d g_{0}}
$$

Implicit differentiation of the government budget constraint (5) gives the following expression:

$$
\frac{d\left(q_{0}^{b} b_{0}\right)}{d g_{0}}=1+b_{-1} \cdot \frac{d q_{0}^{b}}{d g_{0}}
$$

After rewriting we obtain the following expression for 74 :

$$
n_{0} \cdot \frac{d \mu_{0}}{d g_{0}}+\left(1+\mu_{0}\right) \cdot \frac{d n_{0}}{d q_{0}^{b}} \cdot \frac{d q_{0}^{b}}{d g_{0}}=\lambda_{k} \cdot \frac{d k_{0}}{d g_{0}}+\lambda_{b}\left(1+b_{-1} \cdot \frac{d q_{0}^{b}}{d g_{0}}\right)
$$

We know that the first derivative of net worth $n_{0}$ with respect to a change in the bond price is equal to $b_{-1}$ :

$$
\frac{d n_{0}}{d q_{0}^{b}}=b_{-1}>0
$$

Taking together the terms for $\frac{d k_{0}}{d g_{0}}$ and $\frac{d q_{0}^{b}}{d g_{0}}$ gives the following expression:

$$
\begin{aligned}
\lambda_{b} & =B n_{0}\left\{\left(\frac{1}{1-D_{0}}\right) \cdot \frac{u^{\prime \prime}\left(c_{0}\right)}{u^{\prime}\left(c_{0}\right)}+\left[\left(\frac{u^{\prime \prime}\left(c_{1}\right)}{u^{\prime}\left(c_{1}\right)}\right) \cdot K_{1}+\left(\frac{1}{1-D_{0}}\right) \cdot \frac{u^{\prime \prime}\left(c_{0}\right)}{u^{\prime}\left(c_{0}\right)}+E_{2}\right] \cdot \frac{d k_{0}}{d g_{0}}\right\} \\
& -\lambda_{k} \cdot \frac{d k_{0}}{d g_{0}}+\left(1+\mu_{0}-\lambda_{b}\right) b_{-1} \cdot \frac{d q_{0}^{b}}{d g_{0}}
\end{aligned}
$$

Rearranging gives:

$$
\lambda_{b}-B n_{0}\left(\frac{1}{1-D_{0}}\right) \cdot \frac{u^{\prime \prime}\left(c_{0}\right)}{u^{\prime}\left(c_{0}\right)}=\left(C-\lambda_{k}\right) \cdot \frac{d k_{0}}{d g_{0}}+\left(1+\mu_{0}-\lambda_{b}\right) b_{-1} \cdot \frac{d q_{0}^{b}}{d g_{0}}
$$

Compared with the case of short term government bonds, a third term containing the change in the bond price emerges. Now combine the first order conditions for physical capital (47) and government bonds 48 while we remember that we can drop the expectations operator since $c_{1}$ and $r_{1}^{k}$ are determined in period $t=0$ :

$$
\beta\left(\frac{u^{\prime}\left(c_{1}\right)}{u^{\prime}\left(c_{0}\right)}\right)\left(\frac{1+x_{c}}{q_{0}^{b}}-1-r_{0}^{d}\right)=\frac{\lambda_{b}}{\lambda_{k}} \beta\left(\frac{u^{\prime}\left(c_{1}\right)}{u^{\prime}\left(c_{0}\right)}\right)\left(r_{1}^{k}-r_{0}^{d}\right) .
$$


Using the households' first order condition for deposits 40, and substituting the expressions for the return on capital and the return on government bonds (with $p\left(b_{0}\right)=0$ ), we get:

$$
\begin{aligned}
\beta\left(\frac{u^{\prime}\left(c_{1}\right)}{u^{\prime}\left(c_{0}\right)}\right)\left(\frac{1+x_{c}}{q_{0}^{b}}\right)-1 & =\frac{\lambda_{b}}{\lambda_{k}} \beta\left(\frac{u^{\prime}\left(c_{1}\right)}{u^{\prime}\left(c_{0}\right)}\right)\left(1+r_{1}^{k}\right)-\frac{\lambda_{b}}{\lambda_{k}} \Rightarrow \\
\beta\left(\frac{u^{\prime}\left(c_{1}\right)}{u^{\prime}\left(c_{0}\right)}\right)\left(\frac{1+x_{c}}{q_{0}^{b}}\right)-\left(1-\frac{\lambda_{b}}{\lambda_{k}}\right) & =\frac{\lambda_{b}}{\lambda_{k}} \beta\left(\frac{u^{\prime}\left(c_{1}\right)}{u^{\prime}\left(c_{0}\right)}\right)\left(1+r_{1}^{k}\right) .
\end{aligned}
$$

Differentiation with respect to $g_{0}$ yields the following result for the left hand side of 79p:

$$
\begin{aligned}
{\left[\beta\left(\frac{u^{\prime}\left(c_{1}\right)}{u^{\prime}\left(c_{0}\right)}\right)\left(\frac{1+x_{c}}{q_{0}^{b}}\right)-\left(1-\frac{\lambda_{b}}{\lambda_{k}}\right)\right]^{\prime} } & =\beta \frac{u^{\prime}\left(c_{1}\right)}{u^{\prime}\left(c_{0}\right)}\left(\frac{1+x_{c}}{q_{0}^{b}}\right)\left[\frac{u^{\prime \prime}\left(c_{1}\right)}{u^{\prime}\left(c_{1}\right)} \cdot \frac{d c_{1}}{d g_{0}}-\frac{u^{\prime \prime}\left(c_{0}\right)}{u^{\prime}\left(c_{0}\right)} \cdot \frac{d c_{0}}{d g_{0}}-\frac{1}{q_{0}^{b}} \cdot \frac{d q_{0}^{b}}{d g_{0}}\right] \\
& =\beta \frac{u^{\prime}\left(c_{1}\right)}{u^{\prime}\left(c_{0}\right)}\left(\frac{1+x_{c}}{q_{0}^{b}}\right) \\
& \times\left\{\left(\frac{1}{1-D_{0}}\right) \cdot \frac{u^{\prime \prime}\left(c_{0}\right)}{u^{\prime}\left(c_{0}\right)}\right. \\
& \left.+\left[\frac{u^{\prime \prime}\left(c_{1}\right)}{u^{\prime}\left(c_{1}\right)} \cdot K_{1}+\left(\frac{1}{1-D_{0}}\right) \cdot \frac{u^{\prime \prime}\left(c_{0}\right)}{u^{\prime}\left(c_{0}\right)}\right] \cdot \frac{d k_{0}}{d g_{0}}-\frac{1}{q_{0}^{b}} \cdot \frac{d q_{0}^{b}}{d g_{0}}\right\}
\end{aligned}
$$

Similarly we differentiate the right hand side of 79 :

$$
\begin{aligned}
{\left[\frac{\lambda_{b}}{\lambda_{k}} \beta\left(\frac{u^{\prime}\left(c_{1}\right)}{u^{\prime}\left(c_{0}\right)}\right)\left(1+r_{1}^{k}\right)\right]^{\prime} } & =\frac{\lambda_{b}}{\lambda_{k}} \beta\left(\frac{u^{\prime}\left(c_{1}\right)}{u^{\prime}\left(c_{0}\right)}\right)\left(1+r_{1}^{k}\right) \\
& \times\left[\frac{u^{\prime \prime}\left(c_{1}\right)}{u^{\prime}\left(c_{1}\right)} \cdot \frac{d c_{1}}{d g_{0}}-\frac{u^{\prime \prime}\left(c_{0}\right)}{u^{\prime}\left(c_{0}\right)} \cdot \frac{d c_{0}}{d g_{0}}+\frac{1}{1+r_{1}^{k}} \cdot \frac{d\left(1+r_{1}^{k}\right)}{d g_{0}}\right] \\
& =\frac{\lambda_{b}}{\lambda_{k}} \beta\left(\frac{u^{\prime}\left(c_{1}\right)}{u^{\prime}\left(c_{0}\right)}\right)\left(1+r_{1}^{k}\right) \times\left\{\left(\frac{1}{1-D_{0}}\right) \cdot \frac{u^{\prime \prime}\left(c_{0}\right)}{u^{\prime}\left(c_{0}\right)}\right. \\
& \left.+\left[\frac{u^{\prime \prime}\left(c_{1}\right)}{u^{\prime}\left(c_{1}\right)} \cdot K_{1}+\left(\frac{1}{1-D_{0}}\right) \cdot \frac{u^{\prime \prime}\left(c_{0}\right)}{u^{\prime}\left(c_{0}\right)}+E_{2}\right] \cdot \frac{d k_{0}}{d g_{0}}\right\}
\end{aligned}
$$

Combining (80) and 81) results in the following equation:

$$
\begin{aligned}
& \left\{\left(\frac{1}{1-D_{0}}\right) \cdot \frac{u^{\prime \prime}\left(c_{0}\right)}{u^{\prime}\left(c_{0}\right)}+\left[\frac{u^{\prime \prime}\left(c_{1}\right)}{u^{\prime}\left(c_{1}\right)} \cdot K_{1}+\left(\frac{1}{1-D_{0}}\right) \cdot \frac{u^{\prime \prime}\left(c_{0}\right)}{u^{\prime}\left(c_{0}\right)}\right] \cdot \frac{d k_{0}}{d g_{0}}\right\} \\
\times & \left\{\beta\left(\frac{u^{\prime}\left(c_{1}\right)}{u^{\prime}\left(c_{0}\right)}\right)\left(\frac{1+x_{c}}{q_{0}^{b}}\right)-\frac{\lambda_{b}}{\lambda_{k}} \beta\left(\frac{u^{\prime}\left(c_{1}\right)}{u^{\prime}\left(c_{0}\right)}\right)\left(1+r_{1}^{k}\right)\right\} \\
- & \beta\left(\frac{u^{\prime}\left(c_{1}\right)}{u^{\prime}\left(c_{0}\right)}\right)\left(\frac{1+x_{c}}{q_{0}^{b}}\right) \frac{1}{q_{0}^{b}} \cdot \frac{d q_{0}^{b}}{d g_{0}}=\frac{\lambda_{b}}{\lambda_{k}} \beta\left(\frac{u^{\prime}\left(c_{1}\right)}{u^{\prime}\left(c_{0}\right)}\right)\left(1+r_{1}^{k}\right) \cdot E_{2} \cdot \frac{d k_{0}}{d g_{0}}
\end{aligned}
$$


This can be rewritten in the following way:

$$
\begin{aligned}
\beta\left(\frac{u^{\prime}\left(c_{1}\right)}{u^{\prime}\left(c_{0}\right)}\right)\left(\frac{1+x_{c}}{q_{0}^{b}}\right) \frac{1}{q_{0}^{b}} \cdot \frac{d q_{0}^{b}}{d g_{0}} & =-\frac{\lambda_{b}}{\lambda_{k}} \beta\left(\frac{u^{\prime}\left(c_{1}\right)}{u^{\prime}\left(c_{0}\right)}\right)\left(1+r_{1}^{k}\right) \cdot E_{2} \cdot \frac{d k_{0}}{d g_{0}} \\
& +\left\{\left(\frac{1}{1-D_{0}}\right) \cdot \frac{u^{\prime \prime}\left(c_{0}\right)}{u^{\prime}\left(c_{0}\right)}\right. \\
& \left.+\left[\frac{u^{\prime \prime}\left(c_{1}\right)}{u^{\prime}\left(c_{1}\right)} \cdot K_{1}+\left(\frac{1}{1-D_{0}}\right) \cdot \frac{u^{\prime \prime}\left(c_{0}\right)}{u^{\prime}\left(c_{0}\right)}\right] \cdot \frac{d k_{0}}{d g_{0}}\right\}\left(1-\frac{\lambda_{b}}{\lambda_{k}}\right) \\
& =\left(1-\frac{\lambda_{b}}{\lambda_{k}}\right)\left(\frac{1}{1-D_{0}}\right) \cdot \frac{u^{\prime \prime}\left(c_{0}\right)}{u^{\prime}\left(c_{0}\right)} \\
& +\left\{-\frac{\lambda_{b}}{\lambda_{k}} \beta\left(\frac{u^{\prime}\left(c_{1}\right)}{u^{\prime}\left(c_{0}\right)}\right)\left(1+r_{1}^{k}\right) \cdot E_{2}\right. \\
& \left.+\left(1-\frac{\lambda_{b}}{\lambda_{k}}\right)\left[\frac{u^{\prime \prime}\left(c_{1}\right)}{u^{\prime}\left(c_{1}\right)} \cdot K_{1}+\left(\frac{1}{1-D_{0}}\right) \cdot \frac{u^{\prime \prime}\left(c_{0}\right)}{u^{\prime}\left(c_{0}\right)}\right]\right\} \cdot \frac{d k_{0}}{d g_{0}} \Rightarrow \\
\frac{d q_{0}^{b}}{d g_{0}} & =q_{0}^{b} F+q_{0}^{b} G \cdot \frac{d k_{0}}{d g_{0}},
\end{aligned}
$$

where $F$ is given by:

$$
F=\frac{\left(1-\frac{\lambda_{b}}{\lambda_{k}}\right)\left(\frac{1}{1-D_{0}}\right) \cdot \frac{u^{\prime \prime}\left(c_{0}\right)}{u^{\prime}\left(c_{0}\right)}}{\beta\left(\frac{u^{\prime}\left(c_{1}\right)}{u^{\prime}\left(c_{0}\right)}\right)\left(\frac{1+x_{c}}{q_{0}^{b}}\right)}<0,
$$

since we assume $\lambda_{b}<\lambda_{k}$. Meanwhile $G$ is given by:

$$
G=\frac{-\frac{\lambda_{b}}{\lambda_{k}} \beta\left(\frac{u^{\prime}\left(c_{1}\right)}{u^{\prime}\left(c_{0}\right)}\right)\left(1+r_{1}^{k}\right) \cdot E_{2}+\left(1-\frac{\lambda_{b}}{\lambda_{k}}\right)\left[\frac{u^{\prime \prime}\left(c_{1}\right)}{u^{\prime}\left(c_{1}\right)} \cdot K_{1}+\left(\frac{1}{1-D_{0}}\right) \cdot \frac{u^{\prime \prime}\left(c_{0}\right)}{u^{\prime}\left(c_{0}\right)}\right]}{\beta\left(\frac{u^{\prime}\left(c_{1}\right)}{u^{\prime}\left(c_{0}\right)}\right)\left(\frac{1+x_{c}}{q_{0}^{b}}\right)}
$$

Substitution of 82 in 78 gives the following expression.

$$
\lambda_{b}-B n_{0}\left(\frac{1}{1-D_{0}}\right) \cdot \frac{u^{\prime \prime}\left(c_{0}\right)}{u^{\prime}\left(c_{0}\right)}=\left(C-\lambda_{k}\right) \cdot \frac{d k_{0}}{d g_{0}}+\left(1+\mu_{0}-\lambda_{b}\right) q_{0}^{b} b_{-1}\left(F+G \cdot \frac{d k_{0}}{d g_{0}}\right)
$$

This gives the following expression for the change in private investment:

$$
\left.\frac{d k_{0}}{d g_{0}}\right|_{L T}=\underbrace{\left(\frac{\lambda_{b}-B n_{0}\left(\frac{1}{1-D_{0}}\right) \cdot \frac{u^{\prime \prime}\left(c_{0}\right)}{u^{\prime}\left(c_{0}\right)}}{C-\lambda_{k}+\left(1+\mu_{0}-\lambda_{b}\right) q_{0}^{b} b_{-1} G}\right)}_{\text {Case 1: one-period bonds }}-\underbrace{\left(\frac{\left(1+\mu_{0}-\lambda_{b}\right) q_{0}^{b} b_{-1} F}{C-\lambda_{k}+\left(1+\mu_{0}-\lambda_{b}\right) q_{0}^{b} b_{-1} G}\right)}_{\text {Capital losses on existing bondholdings }}<0 .
$$

We see that $\left.\frac{d k_{0}}{d g_{0}}\right|_{L T}<0$ when $C-\lambda_{k}+\left(1+\mu_{0}-\lambda_{b}\right) q_{0}^{b} b_{-1} G<0$. In that case we have that private investment is crowded out by additional government spending $g_{0}$. The reason is that the presence of existing holdings of government bonds $b_{-1}$ on the balance sheet of the financial intermediary 
has a negative effect on net worth $n_{0}$ in period $t=0$ : an increase in government spending $g_{0}$ induces a fall in the bond price $q_{0}^{b}$, which reduces net worth $n_{0}$. As the size of the balance sheet is limited by the amount of net worth, see equation (51), this fall in the bond prices leads to an additional reduction in physical capital $k_{0}$. A proof that $C-\lambda_{k}+\left(1+\mu_{0}-\lambda_{b}\right) q_{0}^{b} b_{-1} G<0$ can be found in Appendix B.2.3.

\section{B.2.3 Case 3: long term bonds \& sovereign default risk: an additional fall in lending due to capital losses on government bonds}

Implicit differentiation of the incentive compatibility constraint with respect to $g_{0}$ yields the same expression as for the case when sovereign risk is absent:

$$
\lambda_{b}-B n_{0}\left(\frac{1}{1-D_{0}}\right) \cdot \frac{u^{\prime \prime}\left(c_{0}\right)}{u^{\prime}\left(c_{0}\right)}=\left(C-\lambda_{k}\right) \cdot \frac{d k_{0}}{d g_{0}}+\left(1+\mu_{0}-\lambda_{b}\right) b_{-1} \cdot \frac{d q_{0}^{b}}{d g_{0}}
$$

Again we combine the first order conditions for physical capital 477) and government bonds 448, but now do so without setting $p\left(b_{0}\right)=0$. We remember that we can drop the expectations operator since $c_{1}$ and $r_{1}^{k}$ are determined in period $t=0$ :

$$
\beta\left(\frac{u^{\prime}\left(c_{1}\right)}{u^{\prime}\left(c_{0}\right)}\right)\left\{\left[1-p\left(b_{0}\right)\right]\left(\frac{1+x_{c}}{q_{0}^{b}}\right)-1-r_{0}^{d}\right\}=\frac{\lambda_{b}}{\lambda_{k}} \beta\left(\frac{u^{\prime}\left(c_{1}\right)}{u^{\prime}\left(c_{0}\right)}\right)\left(r_{1}^{k}-r_{0}^{d}\right) .
$$

Again applying the households' first order condition for deposits 40p to substitute in the expressions for the return on capital and the return on government bonds, we get:

$$
\begin{aligned}
\beta\left(\frac{u^{\prime}\left(c_{1}\right)}{u^{\prime}\left(c_{0}\right)}\right)\left[1-p\left(b_{0}\right)\right]\left(\frac{1+x_{c}}{q_{0}^{b}}\right)-1 & =\frac{\lambda_{b}}{\lambda_{k}} \beta\left(\frac{u^{\prime}\left(c_{1}\right)}{u^{\prime}\left(c_{0}\right)}\right)\left(1+r_{1}^{k}\right)-\frac{\lambda_{b}}{\lambda_{k}} \Rightarrow \\
\beta\left(\frac{u^{\prime}\left(c_{1}\right)}{u^{\prime}\left(c_{0}\right)}\right)\left[1-p\left(b_{0}\right)\right]\left(\frac{1+x_{c}}{q_{0}^{b}}\right)-\left(1-\frac{\lambda_{b}}{\lambda_{k}}\right) & =\frac{\lambda_{b}}{\lambda_{k}} \beta\left(\frac{u^{\prime}\left(c_{1}\right)}{u^{\prime}\left(c_{0}\right)}\right)\left(1+r_{1}^{k}\right) .
\end{aligned}
$$

Differentiation with respect to $g_{0}$ yields the following result for the left hand side of 88 :

$$
\begin{aligned}
& {\left[\beta\left(\frac{u^{\prime}\left(c_{1}\right)}{u^{\prime}\left(c_{0}\right)}\right)\left[1-p\left(b_{0}\right)\right]\left(\frac{1+x_{c}}{q_{0}^{b}}\right)-\left(1-\frac{\lambda_{b}}{\lambda_{k}}\right)\right]^{\prime}=} \\
= & \beta \frac{u^{\prime}\left(c_{1}\right)}{u^{\prime}\left(c_{0}\right)}\left[1-p\left(b_{0}\right)\right]\left(\frac{1+x_{c}}{q_{0}^{b}}\right)\left[\frac{u^{\prime \prime}\left(c_{1}\right)}{u^{\prime}\left(c_{1}\right)} \cdot \frac{d c_{1}}{d g_{0}}-\frac{u^{\prime \prime}\left(c_{0}\right)}{u^{\prime}\left(c_{0}\right)} \cdot \frac{d c_{0}}{d g_{0}}-\frac{p^{\prime}\left(b_{0}\right)}{1-p\left(b_{0}\right)} \cdot \frac{d b_{0}}{d g_{0}}-\frac{1}{q_{0}^{b}} \cdot \frac{d q_{0}^{b}}{d g_{0}}\right] \\
= & \beta \frac{u^{\prime}\left(c_{1}\right)}{u^{\prime}\left(c_{0}\right)}\left[1-p\left(b_{0}\right)\right]\left(\frac{1+x_{c}}{q_{0}^{b}}\right)\left\{\left(\frac{1}{1-D_{0}}\right) \cdot \frac{u^{\prime \prime}\left(c_{0}\right)}{u^{\prime}\left(c_{0}\right)}-\frac{p^{\prime}\left(b_{0}\right)}{1-p\left(b_{0}\right)} \cdot \frac{1}{q_{0}^{b}}\right. \\
+ & {\left.\left[\frac{u^{\prime \prime}\left(c_{1}\right)}{u^{\prime}\left(c_{1}\right)} \cdot K_{1}+\left(\frac{1}{1-D_{0}}\right) \cdot \frac{u^{\prime \prime}\left(c_{0}\right)}{u^{\prime}\left(c_{0}\right)}\right] \cdot \frac{d k_{0}}{d g_{0}}-\left[1-\left(b_{0}-b_{-1}\right) \frac{p^{\prime}\left(b_{0}\right)}{1-p\left(b_{0}\right)}\right] \frac{1}{q_{0}^{b}} \cdot \frac{d q_{0}^{b}}{d g_{0}}\right\} }
\end{aligned}
$$


To derive the above result, we differentiate the government budget constraint in period $t=0$ with respect to $g_{0}$ to arrive at:

$$
\begin{aligned}
\frac{d}{d g_{0}}\left(q_{0}^{b} b_{0}\right) \equiv b_{0} \cdot \frac{d q_{0}^{b}}{d g_{0}}+q_{0}^{b} \cdot \frac{d b_{0}}{d g_{0}} & =1+b_{-1} \cdot \frac{d q_{0}^{b}}{d g_{0}} \Rightarrow \\
\frac{d b_{0}}{d g_{0}} & =\frac{1}{q_{0}^{b}}\left[1-\left(b_{0}-b_{-1}\right) \frac{d q_{0}^{b}}{d g_{0}}\right]
\end{aligned}
$$

We differentiate the right hand side of 88 , which is exactly equal to 81):

$$
\begin{aligned}
{\left[\frac{\lambda_{b}}{\lambda_{k}} \beta\left(\frac{u^{\prime}\left(c_{1}\right)}{u^{\prime}\left(c_{0}\right)}\right)\left(1+r_{1}^{k}\right)\right]^{\prime} } & =\frac{\lambda_{b}}{\lambda_{k}} \beta\left(\frac{u^{\prime}\left(c_{1}\right)}{u^{\prime}\left(c_{0}\right)}\right)\left(1+r_{1}^{k}\right) \times\left\{\left(\frac{1}{1-D_{0}}\right) \cdot \frac{u^{\prime \prime}\left(c_{0}\right)}{u^{\prime}\left(c_{0}\right)}\right. \\
& \left.+\left[\frac{u^{\prime \prime}\left(c_{1}\right)}{u^{\prime}\left(c_{1}\right)} \cdot K_{1}+\left(\frac{1}{1-D_{0}}\right) \cdot \frac{u^{\prime \prime}\left(c_{0}\right)}{u^{\prime}\left(c_{0}\right)}+E_{2}\right] \cdot \frac{d k_{0}}{d g_{0}}\right\}
\end{aligned}
$$

Combining (89) and (91) results in the following equation:

$$
\begin{aligned}
& \left\{\left(\frac{1}{1-D_{0}}\right) \cdot \frac{u^{\prime \prime}\left(c_{0}\right)}{u^{\prime}\left(c_{0}\right)}+\left[\frac{u^{\prime \prime}\left(c_{1}\right)}{u^{\prime}\left(c_{1}\right)} \cdot K_{1}+\left(\frac{1}{1-D_{0}}\right) \cdot \frac{u^{\prime \prime}\left(c_{0}\right)}{u^{\prime}\left(c_{0}\right)}\right] \cdot \frac{d k_{0}}{d g_{0}}\right\} \\
\times & \left\{\beta\left(\frac{u^{\prime}\left(c_{1}\right)}{u^{\prime}\left(c_{0}\right)}\right)\left[1-p\left(b_{0}\right)\right]\left(\frac{1+x_{c}}{q_{0}^{b}}\right)-\frac{\lambda_{b}}{\lambda_{k}} \beta\left(\frac{u^{\prime}\left(c_{1}\right)}{u^{\prime}\left(c_{0}\right)}\right)\left(1+r_{1}^{k}\right)\right\} \\
- & \beta\left(\frac{u^{\prime}\left(c_{1}\right)}{u^{\prime}\left(c_{0}\right)}\right)\left[1-p\left(b_{0}\right)\right]\left(\frac{1+x_{c}}{q_{0}^{b}}\right)\left\{\frac{p^{\prime}\left(b_{0}\right)}{1-p\left(b_{0}\right)} \cdot \frac{1}{q_{0}^{b}}+\left[1-\left(b_{0}-b_{-1}\right) \frac{p^{\prime}\left(b_{0}\right)}{1-p\left(b_{0}\right)}\right] \frac{1}{q_{0}^{b}} \cdot \frac{d q_{0}^{b}}{d g_{0}}\right\} \\
= & \frac{\lambda_{b}}{\lambda_{k}} \beta\left(\frac{u^{\prime}\left(c_{1}\right)}{u^{\prime}\left(c_{0}\right)}\right)\left(1+r_{1}^{k}\right) \cdot E_{2} \cdot \frac{d k_{0}}{d g_{0}}
\end{aligned}
$$

This can be rewritten in the following way:

$$
\begin{aligned}
& \beta\left(\frac{u^{\prime}\left(c_{1}\right)}{u^{\prime}\left(c_{0}\right)}\right)\left[1-p\left(b_{0}\right)\right]\left(\frac{1+x_{c}}{q_{0}^{b}}\right)\left\{\frac{p^{\prime}\left(b_{0}\right)}{1-p\left(b_{0}\right)} \cdot \frac{1}{q_{0}^{b}}+\left[1-\left(b_{0}-b_{-1}\right) \frac{p^{\prime}\left(b_{0}\right)}{1-p\left(b_{0}\right)}\right] \frac{1}{q_{0}^{b}} \cdot \frac{d q_{0}^{b}}{d g_{0}}\right\} \\
= & -\frac{\lambda_{b}}{\lambda_{k}} \beta\left(\frac{u^{\prime}\left(c_{1}\right)}{u^{\prime}\left(c_{0}\right)}\right)\left(1+r_{1}^{k}\right) \cdot E_{2} \cdot \frac{d k_{0}}{d g_{0}} \\
+ & \left\{\left(\frac{1}{1-D_{0}}\right) \cdot \frac{u^{\prime \prime}\left(c_{0}\right)}{u^{\prime}\left(c_{0}\right)}+\left[\frac{u^{\prime \prime}\left(c_{1}\right)}{u^{\prime}\left(c_{1}\right)} \cdot K_{1}+\left(\frac{1}{1-D_{0}}\right) \cdot \frac{u^{\prime \prime}\left(c_{0}\right)}{u^{\prime}\left(c_{0}\right)}\right] \cdot \frac{d k_{0}}{d g_{0}}\right\}\left(1-\frac{\lambda_{b}}{\lambda_{k}}\right)
\end{aligned}
$$

While further rearranging yields the following expression:

$$
\begin{aligned}
& \beta\left(\frac{u^{\prime}\left(c_{1}\right)}{u^{\prime}\left(c_{0}\right)}\right)\left[1-p\left(b_{0}\right)\right]\left(\frac{1+x_{c}}{q_{0}^{b}}\right)\left[1-\left(b_{0}-b_{-1}\right) \frac{p^{\prime}\left(b_{0}\right)}{1-p\left(b_{0}\right)}\right] \frac{1}{q_{0}^{b}} \cdot \frac{d q_{0}^{b}}{d g_{0}} \\
= & \left(1-\frac{\lambda_{b}}{\lambda_{k}}\right)\left(\frac{1}{1-D_{0}}\right) \cdot \frac{u^{\prime \prime}\left(c_{0}\right)}{u^{\prime}\left(c_{0}\right)}-\beta\left(\frac{u^{\prime}\left(c_{1}\right)}{u^{\prime}\left(c_{0}\right)}\right)\left[1-p\left(b_{0}\right)\right]\left(\frac{1+x_{c}}{q_{0}^{b}}\right) \frac{p^{\prime}\left(b_{0}\right)}{1-p\left(b_{0}\right)} \cdot \frac{1}{q_{0}^{b}} \\
+ & \left\{-\frac{\lambda_{b}}{\lambda_{k}} \beta\left(\frac{u^{\prime}\left(c_{1}\right)}{u^{\prime}\left(c_{0}\right)}\right)\left(1+r_{1}^{k}\right) \cdot E_{2}+\left(1-\frac{\lambda_{b}}{\lambda_{k}}\right)\left[\frac{u^{\prime \prime}\left(c_{1}\right)}{u^{\prime}\left(c_{1}\right)} \cdot K_{1}+\left(\frac{1}{1-D_{0}}\right) \cdot \frac{u^{\prime \prime}\left(c_{0}\right)}{u^{\prime}\left(c_{0}\right)}\right]\right\} \cdot \frac{d k_{0}}{d g_{0}}
\end{aligned}
$$


We can summarize this result in the following way:

$$
\frac{d q_{0}^{b}}{d g_{0}}=q_{0}^{b} P+q_{0}^{b} Q \cdot \frac{d k_{0}}{d g_{0}}
$$

where $P$ is given by:

$$
\begin{aligned}
P & =\frac{\left(1-\frac{\lambda_{b}}{\lambda_{k}}\right)\left(\frac{1}{1-D_{0}}\right) \cdot \frac{u^{\prime \prime}\left(c_{0}\right)}{u^{\prime}\left(c_{0}\right)}-\beta\left(\frac{u^{\prime}\left(c_{1}\right)}{u^{\prime}\left(c_{0}\right)}\right)\left[1-p\left(b_{0}\right)\right]\left(\frac{1+x_{c}}{q_{0}^{b}}\right) \frac{p^{\prime}\left(b_{0}\right)}{1-p\left(b_{0}\right)} \cdot \frac{1}{q_{0}^{b}}}{\beta\left(\frac{u^{\prime}\left(c_{1}\right)}{u^{\prime}\left(c_{0}\right)}\right)\left[1-p\left(b_{0}\right)\right]\left(\frac{1+x_{c}}{q_{0}^{b}}\right)\left[1-\left(b_{0}-b_{-1}\right) \frac{p^{\prime}\left(b_{0}\right)}{1-p\left(b_{0}\right)}\right]} \\
& =\frac{\frac{p^{\prime}\left(b_{0}\right)}{1-p\left(b_{0}\right)} \cdot \frac{1}{q_{0}^{b}}}{\left[1-p\left(b_{0}\right)\right]\left[1-\left(b_{0}-b_{-1}\right) \frac{p^{\prime}\left(b_{0}\right)}{1-p\left(b_{0}\right)}\right]}-\frac{p^{\prime}}{\left[1-\left(b_{0}-b_{-1}\right) \frac{\left.p_{0}\right)}{1-p\left(b_{0}\right)}\right]}<0,
\end{aligned}
$$

conditional on $\left(b_{0}-b_{-1}\right) \frac{p^{\prime}\left(b_{0}\right)}{1-p\left(b_{0}\right)}<1$. Schabert and van Wijnbergen 2014 refer to $b_{0}\left(\frac{p^{\prime}\left(b_{0}\right)}{1-p\left(b_{0}\right)}\right)$ as the default elasticity, and set it at 0.01 . Since $\left(b_{0}-b_{-1}\right)\left(\frac{p^{\prime}\left(b_{0}\right)}{1-p\left(b_{0}\right)}\right)<b_{0}\left(\frac{p^{\prime}\left(b_{0}\right)}{1-p\left(b_{0}\right)}\right)$ we know that the condition $\left(b_{0}-b_{-1}\right)\left(\frac{p^{\prime}\left(b_{0}\right)}{1-p\left(b_{0}\right)}\right)<1$ will hold in that case. Now we remember that $F<0$ and rewrite $P$ in the following way:

$$
P=S+T
$$

with $S$ and $T$ given by:

$$
\begin{aligned}
S & =\frac{F}{\left[1-p\left(b_{0}\right)\right]\left[1-\left(b_{0}-b_{-1}\right) \frac{p^{\prime}\left(b_{0}\right)}{1-p\left(b_{0}\right)}\right]}<0, \\
T & =-\frac{\frac{p^{\prime}\left(b_{0}\right)}{1-p\left(b_{0}\right)} \cdot \frac{1}{q_{0}^{b}}}{\left[1-\left(b_{0}-b_{-1}\right) \frac{p^{\prime}\left(b_{0}\right)}{1-p\left(b_{0}\right)}\right]}<0 .
\end{aligned}
$$

Meanwhile $Q$ is given by:

$$
\begin{aligned}
Q & =\frac{-\frac{\lambda_{b}}{\lambda_{k}} \beta\left(\frac{u^{\prime}\left(c_{1}\right)}{u^{\prime}\left(c_{0}\right)}\right)\left(1+r_{1}^{k}\right) \cdot E_{2}+\left(1-\frac{\lambda_{b}}{\lambda_{k}}\right)\left[\frac{u^{\prime \prime}\left(c_{1}\right)}{u^{\prime}\left(c_{1}\right)} \cdot K_{1}+\left(\frac{1}{1-D_{0}}\right) \cdot \frac{u^{\prime \prime}\left(c_{0}\right)}{u^{\prime}\left(c_{0}\right)}\right]}{\beta\left(\frac{u^{\prime}\left(c_{1}\right)}{u^{\prime}\left(c_{0}\right)}\right)\left[1-p\left(b_{0}\right)\right]\left(\frac{1+x_{c}}{q_{0}^{b}}\right)\left[1-\left(b_{0}-b_{-1}\right) \frac{p^{\prime}\left(b_{0}\right)}{1-p\left(b_{0}\right)}\right]} \\
& =\frac{G}{\left[1-p\left(b_{0}\right)\right]\left[1-\left(b_{0}-b_{-1}\right) \frac{p^{\prime}\left(b_{0}\right)}{1-p\left(b_{0}\right)}\right]},
\end{aligned}
$$

where $G$ is the case where sovereign default risk is absent. We also see that if we shut down sovereign risk by setting $p\left(b_{0}\right)=p^{\prime}\left(b_{0}\right)=0$, we get $P=F$ and $Q=G$, as we would expect. Substitution of 92 in 87 gives the following expression.

$$
\lambda_{b}-B n_{0}\left(\frac{1}{1-D_{0}}\right) \cdot \frac{u^{\prime \prime}\left(c_{0}\right)}{u^{\prime}\left(c_{0}\right)}=\left(C-\lambda_{k}\right) \cdot \frac{d k_{0}}{d g_{0}}+\left(1+\mu_{0}-\lambda_{b}\right) q_{0}^{b} b_{-1}\left(P+Q \cdot \frac{d k_{0}}{d g_{0}}\right)
$$


This gives the following expression for the change in private investment:

$$
\begin{aligned}
\left.\frac{d k_{0}}{d g_{0}}\right|_{L T} ^{\text {default }} & =\underbrace{\left(\frac{\left.\lambda_{b}-B n_{0}\left(\frac{1}{1-D_{0}}\right) \cdot \frac{u^{\prime \prime}\left(c_{0}\right)}{u^{\prime}\left(c_{0}\right)}\right)}{C-\lambda_{k}+\left(1+\mu_{0}-\lambda_{b}\right) q_{0}^{b} b_{-1} Q}\right)}_{\begin{array}{c}
\text { Case 1: limited } \\
\text { balance sheet capacity }
\end{array}}-\underbrace{\left(\frac{\left(1+\mu_{0}-\lambda_{b}\right) q_{0}^{b} b_{-1} S}{C-\lambda_{k}+\left(1+\mu_{0}-\lambda_{b}\right) q_{0}^{b} b_{-1} Q}\right)}_{\begin{array}{c}
\text { Case 2: capital losses } \\
\text { on existing bondholdings } \\
\text { due to arbitrage } \\
\text { between loans and bonds }
\end{array}} \\
& -\underbrace{\left(\frac{\left(1+\mu_{0}-\lambda_{b}\right) q_{0}^{b} b_{-1} T}{C-\lambda_{k}+\left(1+\mu_{0}-\lambda_{b}\right) q_{0}^{b} b_{-1} Q}\right)}_{\begin{array}{c}
\text { Case 3: capital losses } \\
\text { onisting bondholdings } \\
\text { due to sovereign risk }
\end{array}}<0 .
\end{aligned}
$$

We see that $\left.\frac{d k_{0}}{d g_{0}}\right|_{L T} ^{\text {default }}<0$ when $C-\lambda_{k}+\left(1+\mu_{0}-\lambda_{b}\right) q_{0}^{b} b_{-1} Q<0$. In that case private investment is crowded out by additional government spending $g_{0}$. So it remains to prove that $C-\lambda_{k}+\left(1+\mu_{0}-\lambda_{b}\right) q_{0}^{b} b_{-1} Q<0$.

Of all the terms in $C-\lambda_{k}+\left(1+\mu_{0}-\lambda_{b}\right) q_{0}^{b} b_{-1} Q$, only the sign of $Q$ is ambiguous. We start by rewriting $Q$, given by expression (94), in the following way:

$$
Q=Q_{1}+Q_{2}
$$

where $Q_{1}$ and $Q_{2}$ are given by:

$$
\begin{aligned}
Q_{1} & =\frac{-\frac{\lambda_{b}}{\lambda_{k}} \beta\left(\frac{u^{\prime}\left(c_{1}\right)}{u^{\prime}\left(c_{0}\right)}\right)\left(1+r_{1}^{k}\right) \cdot E_{2}}{\beta\left(\frac{u^{\prime}\left(c_{1}\right)}{u^{\prime}\left(c_{0}\right)}\right)\left[1-p\left(b_{0}\right)\right]\left(\frac{1+x_{c}}{q_{0}^{b}}\right)\left[1-\left(b_{0}-b_{-1}\right) \frac{p^{\prime}\left(b_{0}\right)}{1-p\left(b_{0}\right)}\right]}>0, \\
Q_{2} & =\frac{\left(1-\frac{\lambda_{b}}{\lambda_{k}}\right)\left[\frac{u^{\prime \prime}\left(c_{1}\right)}{u^{\prime}\left(c_{1}\right)} \cdot K_{1}+\left(\frac{1}{1-D_{0}}\right) \cdot \frac{u^{\prime \prime}\left(c_{0}\right)}{u^{\prime}\left(c_{0}\right)}\right]}{\beta\left(\frac{u^{\prime}\left(c_{1}\right)}{u^{\prime}\left(c_{0}\right)}\right)\left[1-p\left(b_{0}\right)\right]\left(\frac{1+x_{c}}{q_{0}^{b}}\right)\left[1-\left(b_{0}-b_{-1}\right) \frac{p^{\prime}\left(b_{0}\right)}{1-p\left(b_{0}\right)}\right]}<0,
\end{aligned}
$$

since $1-\left(b_{0}-b_{-1}\right) \frac{p^{\prime}\left(b_{0}\right)}{1-p\left(b_{0}\right)}>0$. We observe that $\left(1+\mu_{0}-\lambda_{b}\right) q_{0}^{b} b_{-1} Q_{1}$ is the only positive term in $C-\lambda_{k}+\left(1+\mu_{0}-\lambda_{b}\right) q_{0}^{b} b_{-1} Q$, while all other terms are negative. We also observe that $\left(1+\mu_{0}\right) q_{0}^{b} b_{-1} Q_{1}>0$, while $-\lambda_{b} q_{0}^{b} b_{-1} Q_{1}<0$.

We now decompose $C$ into the following three terms:

$$
C=B n_{0}\left[\frac{u^{\prime \prime}\left(c_{1}\right)}{u^{\prime}\left(c_{0}\right)} \cdot K_{1}+\left(\frac{1}{1-D_{0}}\right) \cdot \frac{u^{\prime \prime}\left(c_{0}\right)}{u^{\prime}\left(c_{0}\right)}+E_{2}\right]=C_{1}+C_{2}+C_{3},
$$


where $C_{1}, C_{2}$ and $C_{3}$ are given by:

$$
\begin{aligned}
& C_{1}=B n_{0} \cdot \frac{u^{\prime \prime}\left(c_{1}\right)}{u^{\prime}\left(c_{1}\right)} \cdot K_{1}<0, \\
& C_{2}=B n_{0} \cdot\left(\frac{1}{1-D_{0}}\right) \cdot \frac{u^{\prime \prime}\left(c_{0}\right)}{u^{\prime}\left(c_{0}\right)}<0, \\
& C_{3}=B n_{0} \cdot E_{2}<0,
\end{aligned}
$$

since $B>0$. We now prove that the sum of $C_{3}$ and $\left(1+\mu_{0}\right) q_{0}^{b} b_{-1} Q_{1}$ is negative. In that case, we know for sure that $C-\lambda_{k}+\left(1+\mu_{0}-\lambda_{b}\right) q_{0}^{b} b_{-1} Q<0$, as all the other terms are negative.

We use equation 88 to rewrite the first factor in the denominator of $Q_{1}$ in the following way:

$$
\beta\left(\frac{u^{\prime}\left(c_{1}\right)}{u^{\prime}\left(c_{0}\right)}\right)\left[1-p\left(b_{0}\right)\right]\left(\frac{1+x_{c}}{q_{0}^{b}}\right)=1+\frac{\lambda_{b}}{\lambda_{k}} \beta\left(\frac{u^{\prime}\left(c_{1}\right)}{u^{\prime}\left(c_{0}\right)}\right)\left(r_{1}^{k}-r_{0}^{d}\right)
$$

Now we look at the sum of $C_{3}$ and $\left(1+\mu_{0}\right) q_{0}^{b} b_{-1} Q_{1}$ :

$$
\begin{aligned}
& C_{3}+\left(1+\mu_{0}\right) q_{0}^{b} b_{-1} Q_{1}=B n_{0} \cdot E_{2}+\left(1+\mu_{0}\right) q_{0}^{b} b_{-1} Q_{1} \\
= & \frac{\left(1+\mu_{0}\right)^{2}}{\lambda_{k}} \beta\left(\frac{u^{\prime}\left(c_{1}\right)}{u^{\prime}\left(c_{0}\right)}\right)\left(1+r_{1}^{k}\right) n_{0} \cdot E_{2} \\
+ & \left(1+\mu_{0}\right) q_{0}^{b} b_{-1}\left\{\frac{-\frac{\lambda_{b}}{\lambda_{k}} \beta\left(\frac{u^{\prime}\left(c_{1}\right)}{u^{\prime}\left(c_{0}\right)}\right)\left(1+r_{1}^{k}\right) \cdot E_{2}}{\left[1+\frac{\lambda_{b}}{\lambda_{k}} \beta\left(\frac{u^{\prime}\left(c_{1}\right)}{u^{\prime}\left(c_{0}\right)}\right)\left(r_{1}^{k}-r_{0}^{d}\right)\right]\left[1-\left(b_{0}-b_{-1}\right) \frac{p^{\prime}\left(b_{0}\right)}{1-p\left(b_{0}\right)}\right]}\right\} \\
= & \frac{\left(\frac{1+\mu_{0}}{\lambda_{k}}\right) \beta\left(\frac{u^{\prime}\left(c_{1}\right)}{u^{\prime}\left(c_{0}\right)}\right)\left(1+r_{1}^{k}\right) \cdot E_{2}}{\left[1+\frac{\lambda_{b}}{\lambda_{k}} \beta\left(\frac{u^{\prime}\left(c_{1}\right)}{u^{\prime}\left(c_{0}\right)}\right)\left(r_{1}^{k}-r_{0}^{d}\right)\right]\left[1-\left(b_{0}-b_{-1}\right) \frac{p^{\prime}\left(b_{0}\right)}{1-p\left(b_{0}\right)}\right]} \\
\times & \left\{\left(1+\mu_{0}\right) n_{0}\left[1+\frac{\lambda_{b}}{\lambda_{k}} \beta\left(\frac{u^{\prime}\left(c_{1}\right)}{u^{\prime}\left(c_{0}\right)}\right)\left(r_{1}^{k}-r_{0}^{d}\right)\right]\left[1-\left(b_{0}-b_{-1}\right) \frac{p^{\prime}\left(b_{0}\right)}{1-p\left(b_{0}\right)}\right]-\lambda_{b} q_{0}^{b} b_{-1}\right\}<0 .
\end{aligned}
$$

We prove this by substitution of the first order condition for intermediaries' loan holdings (47) and intermediaries' incentive compatibility constraint 51 in 103 . We observe that the expression outside the curly brackets is negative, so we only have to prove that the expression inside the 
curly brackets is larger than zero:

$$
\begin{aligned}
& \left(1+\mu_{0}\right) n_{0}\left[1+\frac{\lambda_{b}}{\lambda_{k}} \beta\left(\frac{u^{\prime}\left(c_{1}\right)}{u^{\prime}\left(c_{0}\right)}\right)\left(r_{1}^{k}-r_{0}^{d}\right)\right]\left[1-\left(b_{0}-b_{-1}\right) \frac{p^{\prime}\left(b_{0}\right)}{1-p\left(b_{0}\right)}\right]-\lambda_{b} q_{0}^{b} b_{-1} \\
& =\left(1+\mu_{0}\right) n_{0}\left[1+\frac{\lambda_{b}}{\lambda_{k}}\left(\frac{\lambda_{k} \mu_{0}}{1+\mu_{0}}\right)\right]\left[1-\left(b_{0}-b_{-1}\right) \frac{p^{\prime}\left(b_{0}\right)}{1-p\left(b_{0}\right)}\right]-\lambda_{b} q_{0}^{b} b_{-1} \\
& =\left(1+\mu_{0}\right) n_{0}\left[1+\lambda_{b}\left(\frac{\mu_{0}}{1+\mu_{0}}\right)\right]\left[1-\left(b_{0}-b_{-1}\right) \frac{p^{\prime}\left(b_{0}\right)}{1-p\left(b_{0}\right)}\right]-\lambda_{b} q_{0}^{b} b_{-1} \\
& =\left(1+\mu_{0}\right) n_{0}\left[1-\left(b_{0}-b_{-1}\right) \frac{p^{\prime}\left(b_{0}\right)}{1-p\left(b_{0}\right)}\right]+\lambda_{b} \mu_{0} n_{0}\left[1-\left(b_{0}-b_{-1}\right) \frac{p^{\prime}\left(b_{0}\right)}{1-p\left(b_{0}\right)}\right]-\lambda_{b} q_{0}^{b} b_{-1} \\
& =\lambda_{b} \mu_{0} n_{0}\left[1-\left(b_{0}-b_{-1}\right) \frac{p^{\prime}\left(b_{0}\right)}{1-p\left(b_{0}\right)}\right]+\left(1+\mu_{0}\right) n_{0}\left[1-\left(b_{0}-b_{-1}\right) \frac{p^{\prime}\left(b_{0}\right)}{1-p\left(b_{0}\right)}\right]-\lambda_{b} q_{0}^{b} b_{-1} \\
& =\lambda_{b} \mu_{0} n_{0}\left[1-\left(b_{0}-b_{-1}\right) \frac{p^{\prime}\left(b_{0}\right)}{1-p\left(b_{0}\right)}\right]+\left(\lambda_{k} k_{0}+\lambda_{b} q_{0}^{b} b_{0}\right)\left[1-\left(b_{0}-b_{-1}\right) \frac{p^{\prime}\left(b_{0}\right)}{1-p\left(b_{0}\right)}\right]-\lambda_{b} q_{0}^{b} b_{-1} \\
& =\lambda_{b} \mu_{0} n_{0}\left[1-\left(b_{0}-b_{-1}\right) \frac{p^{\prime}\left(b_{0}\right)}{1-p\left(b_{0}\right)}\right]+\lambda_{k} k_{0}\left[1-\left(b_{0}-b_{-1}\right) \frac{p^{\prime}\left(b_{0}\right)}{1-p\left(b_{0}\right)}\right] \\
& +\lambda_{b} q_{0}^{b} b_{0}\left[1-\left(b_{0}-b_{-1}\right) \frac{p^{\prime}\left(b_{0}\right)}{1-p\left(b_{0}\right)}\right]-\lambda_{b} q_{0}^{b} b_{-1} \\
& =\lambda_{b} \mu_{0} n_{0}\left[1-\left(b_{0}-b_{-1}\right) \frac{p^{\prime}\left(b_{0}\right)}{1-p\left(b_{0}\right)}\right]+\lambda_{k} k_{0}\left[1-\left(b_{0}-b_{-1}\right) \frac{p^{\prime}\left(b_{0}\right)}{1-p\left(b_{0}\right)}\right] \\
& +\quad \lambda_{b} q_{0}^{b} b_{0}-\lambda_{b} q_{0}^{b} b_{0}\left(b_{0}-b_{-1}\right) \frac{p^{\prime}\left(b_{0}\right)}{1-p\left(b_{0}\right)}-\lambda_{b} q_{0}^{b} b_{-1} \\
& =\lambda_{b} \mu_{0} n_{0}\left[1-\left(b_{0}-b_{-1}\right) \frac{p^{\prime}\left(b_{0}\right)}{1-p\left(b_{0}\right)}\right]+\lambda_{k} k_{0}\left[1-\left(b_{0}-b_{-1}\right) \frac{p^{\prime}\left(b_{0}\right)}{1-p\left(b_{0}\right)}\right] \\
& +\lambda_{b} q_{0}^{b}\left(b_{0}-b_{-1}\right)-\lambda_{b} q_{0}^{b} b_{0}\left(b_{0}-b_{-1}\right) \frac{p^{\prime}\left(b_{0}\right)}{1-p\left(b_{0}\right)} \\
& =\lambda_{b} \mu_{0} n_{0}\left[1-\left(b_{0}-b_{-1}\right) \frac{p^{\prime}\left(b_{0}\right)}{1-p\left(b_{0}\right)}\right]+\lambda_{k} k_{0}\left[1-\left(b_{0}-b_{-1}\right) \frac{p^{\prime}\left(b_{0}\right)}{1-p\left(b_{0}\right)}\right] \\
& +\lambda_{b} q_{0}^{b}\left(b_{0}-b_{-1}\right)\left[1-b_{0} \cdot \frac{p^{\prime}\left(b_{0}\right)}{1-p\left(b_{0}\right)}\right]>0 .
\end{aligned}
$$

We can now prove that $C-\lambda_{k}+\left(1+\mu_{0}-\lambda_{b}\right) q_{0}^{b} b_{-1} G<0$ in Appendix B.2.2 by setting $p\left(b_{0}\right)$ and $p^{\prime}\left(b_{0}\right)$ equal to zero, as in that case $Q$ becomes equal to $G$.

\section{B.2.4 The role of financial frictions}

To properly assess the role that financial frictions play, we show that the drop in lending increases when financial frictions are introduced. We therefore take the partial derivative of 96 with respect to $\lambda_{k}$, and evaluate the resulting expression at $\lambda_{k}=0 . \lambda_{k}$ is a measure for the financial friction: the larger $\lambda_{k}$, the larger the fraction of assets that can be diverted, and the more binding the incentive compatibility constraint becomes. For ease of computation, we assume that $\frac{\lambda_{b}}{\lambda_{k}}$ remains constant. Hence an increase in $\lambda_{k}$ also increases $\lambda_{b}$. We start by taking the 
partial derivative of 96 with respect to $\lambda_{k}$. To do so, we rewrite 96 in the following way:

$$
\frac{d k_{0}}{d g_{0}}=A_{1}-A_{2}
$$

where $A_{1}$ and $A_{2}$ are given by:

$$
\begin{aligned}
& A_{1}=\frac{\lambda_{b}-B n_{0}\left(\frac{1}{1-D_{0}}\right) \cdot \frac{u^{\prime \prime}\left(c_{0}\right)}{u^{\prime}\left(c_{0}\right)}}{C-\lambda_{k}+\left(1+\mu_{0}-\lambda_{b}\right) q_{0}^{b} b_{-1} Q}, \\
& A_{2}=\frac{\left(1+\mu_{0}-\lambda_{b}\right) q_{0}^{b} b_{-1}(S+T)}{C-\lambda_{k}+\left(1+\mu_{0}-\lambda_{b}\right) q_{0}^{b} b_{-1} Q},
\end{aligned}
$$

By assuming that the ratio $\frac{\lambda_{b}}{\lambda_{k}}$ is constant when differentiating, we have that $\frac{\partial Q}{\partial \lambda_{k}}=\frac{\partial S}{\partial \lambda_{k}}=\frac{\partial T}{\partial \lambda_{k}}=$ $\frac{\partial D_{0}}{\partial \lambda_{k}}=0$. We can rewrite $B$ in the following way:

$$
B=\frac{\left(1+\mu_{0}\right)^{2}}{\lambda_{k}} \cdot \beta \cdot \frac{u^{\prime}\left(c_{1}\right)}{u^{\prime}\left(c_{0}\right)} \cdot\left(1+r_{1}^{k}\right)=\frac{M}{\lambda_{k}},
$$

where $M$ is given by:

$$
M=\left(1+\mu_{0}\right)^{2} \cdot \beta \cdot \frac{u^{\prime}\left(c_{1}\right)}{u^{\prime}\left(c_{0}\right)} \cdot\left(1+r_{1}^{k}\right)>0 .
$$

we observe that $\frac{\partial M}{\partial \lambda_{k}}=0$. Similarly, we can rewrite $C$ :

$$
C=\frac{\left(1+\mu_{0}\right)^{2}}{\lambda_{k}} \cdot \beta \cdot \frac{u^{\prime}\left(c_{1}\right)}{u^{\prime}\left(c_{0}\right)} \cdot\left(1+r_{1}^{k}\right) n_{0}\left[\left(\frac{u^{\prime \prime}\left(c_{1}\right)}{u^{\prime}\left(c_{1}\right)}\right) \cdot K_{1}+\left(\frac{1}{1-D_{0}}\right) \cdot \frac{u^{\prime \prime}\left(c_{0}\right)}{u^{\prime}\left(c_{0}\right)}+E_{2}\right]=\frac{N}{\lambda_{k}},
$$

where $N$ is given by:

$$
\begin{aligned}
N & =\left(1+\mu_{0}\right)^{2} \beta \cdot \frac{u^{\prime}\left(c_{1}\right)}{u^{\prime}\left(c_{0}\right)} \cdot\left(1+r_{1}^{k}\right) n_{0}\left[\left(\frac{u^{\prime \prime}\left(c_{1}\right)}{u^{\prime}\left(c_{1}\right)}\right) \cdot K_{1}+\left(\frac{1}{1-D_{0}}\right) \cdot \frac{u^{\prime \prime}\left(c_{0}\right)}{u^{\prime}\left(c_{0}\right)}+E_{2}\right] \\
& =M n_{0} \cdot\left[\left(\frac{u^{\prime \prime}\left(c_{1}\right)}{u^{\prime}\left(c_{1}\right)}\right) \cdot K_{1}+\left(\frac{1}{1-D_{0}}\right) \cdot \frac{u^{\prime \prime}\left(c_{0}\right)}{u^{\prime}\left(c_{0}\right)}+E_{2}\right]<0 .
\end{aligned}
$$

we observe that $\frac{\partial N}{\partial \lambda_{k}}=0$ since $\frac{\partial K_{1}}{\partial \lambda_{k}}=\frac{\partial E_{2}}{\partial \lambda_{k}}=0$. With this knowledge, we rewrite $A_{1}$ and $A_{2}$ in the following way:

$$
\begin{aligned}
& A_{1}=\frac{\left(\frac{\lambda_{b}}{\lambda_{k}}\right) \lambda_{k}-\frac{M}{\lambda_{k}} \cdot n_{0}\left(\frac{1}{1-D_{0}}\right) \cdot \frac{u^{\prime \prime}\left(c_{0}\right)}{u^{\prime}\left(c_{0}\right)}}{\frac{N}{\lambda_{k}}-\lambda_{k}+\left[1+\mu_{0}-\left(\frac{\lambda_{b}}{\lambda_{k}}\right) \lambda_{k}\right] q_{0}^{b} b_{-1} Q}=\frac{X_{1}}{Z}, \\
& A_{2}=\frac{\left(1+\mu_{0}-\left(\frac{\lambda_{b}}{\lambda_{k}}\right) \lambda_{k}\right) q_{0}^{b} b_{-1}(S+T)}{\frac{N}{\lambda_{k}}-\lambda_{k}+\left[1+\mu_{0}-\left(\frac{\lambda_{b}}{\lambda_{k}}\right) \lambda_{k}\right] q_{0}^{b} b_{-1} Q}=\frac{X_{2}}{Z},
\end{aligned}
$$


where $X_{1}, X_{2}$ and $Z$ are given by:

$$
\begin{aligned}
X_{1} & =\left(\frac{\lambda_{b}}{\lambda_{k}}\right) \lambda_{k}-\frac{M}{\lambda_{k}} \cdot n_{0}\left(\frac{1}{1-D_{0}}\right) \cdot \frac{u^{\prime \prime}\left(c_{0}\right)}{u^{\prime}\left(c_{0}\right)} \\
X_{2} & =\left[1+\mu_{0}-\left(\frac{\lambda_{b}}{\lambda_{k}}\right) \lambda_{k}\right] q_{0}^{b} b_{-1}(S+T), \\
Z & =\frac{N}{\lambda_{k}}-\lambda_{k}+\left[1+\mu_{0}-\left(\frac{\lambda_{b}}{\lambda_{k}}\right) \lambda_{k}\right] q_{0}^{b} b_{-1} Q=\frac{\tilde{Z}}{\lambda_{k}}
\end{aligned}
$$

where $\tilde{Z}$ is given by:

$$
\tilde{Z}=N-\lambda_{k}^{2}+\lambda_{k}\left[1+\mu_{0}-\left(\frac{\lambda_{b}}{\lambda_{k}}\right) \lambda_{k}\right] q_{0}^{b} b_{-1} Q
$$

Therefore the partial derivative of $X_{1}, X_{2}$ and $Z$ with respect to $\lambda_{k}$ is equal to:

$$
\begin{aligned}
\frac{\partial X_{1}}{\partial \lambda_{k}} & =\left(\frac{\lambda_{b}}{\lambda_{k}}\right)+\frac{M}{\lambda_{k}^{2}} \cdot n_{0}\left(\frac{1}{1-D_{0}}\right) \cdot \frac{u^{\prime \prime}\left(c_{0}\right)}{u^{\prime}\left(c_{0}\right)}=\frac{1}{\lambda_{k}^{2}}\left[\left(\frac{\lambda_{b}}{\lambda_{k}}\right) \lambda_{k}^{2}+M \cdot n_{0}\left(\frac{1}{1-D_{0}}\right) \cdot \frac{u^{\prime \prime}\left(c_{0}\right)}{u^{\prime}\left(c_{0}\right)}\right] \\
\frac{\partial X_{2}}{\partial \lambda_{k}} & =-\left(\frac{\lambda_{b}}{\lambda_{k}}\right) q_{0}^{b} b_{-1}(S+T)=-\frac{1}{\lambda_{k}^{2}}\left[\left(\frac{\lambda_{b}}{\lambda_{k}}\right) \lambda_{k}^{2} q_{0}^{b} b_{-1}(S+T)\right] \\
\frac{\partial Z}{\partial \lambda_{k}} & =-\frac{N}{\lambda_{k}^{2}}-1-\left(\frac{\lambda_{b}}{\lambda_{k}}\right) q_{0}^{b} b_{-1} Q=-\frac{1}{\lambda_{k}^{2}}\left[N+\lambda_{k}^{2}+\left(\frac{\lambda_{b}}{\lambda_{k}}\right) \lambda_{k}^{2} q_{0}^{b} b_{-1} Q\right] .
\end{aligned}
$$


We are now ready to take the partial derivative of $A_{1}$ with respect to $\lambda_{k}$ :

$$
\begin{aligned}
\frac{\partial A_{1}}{\partial \lambda_{k}}= & \frac{1}{Z^{2}}\left\{\left[\left(\frac{\lambda_{b}}{\lambda_{k}}\right)+\frac{M}{\lambda_{k}^{2}} \cdot n_{0}\left(\frac{1}{1-D_{0}}\right) \cdot \frac{u^{\prime \prime}\left(c_{0}\right)}{u^{\prime}\left(c_{0}\right)}\right]\left[\frac{N}{\lambda_{k}}-\lambda_{k}+\left(1+\mu_{0}-\left(\frac{\lambda_{b}}{\lambda_{k}}\right) \lambda_{k}\right) q_{0}^{b} b_{-1} Q\right]\right. \\
+ & {\left.\left[\left(\frac{\lambda_{b}}{\lambda_{k}}\right) \lambda_{k}-\frac{M}{\lambda_{k}} \cdot n_{0}\left(\frac{1}{1-D_{0}}\right) \cdot \frac{u^{\prime \prime}\left(c_{0}\right)}{u^{\prime}\left(c_{0}\right)}\right]\left[\frac{N}{\lambda_{k}^{2}}+1+\left(\frac{\lambda_{b}}{\lambda_{k}}\right) q_{0}^{b} b_{-1} Q\right]\right\} } \\
= & \frac{1}{\lambda_{k} Z^{2}}\left\{\left[\left(\frac{\lambda_{b}}{\lambda_{k}}\right) \lambda_{k}+\frac{M}{\lambda_{k}} \cdot n_{0}\left(\frac{1}{1-D_{0}}\right) \cdot \frac{u^{\prime \prime}\left(c_{0}\right)}{u^{\prime}\left(c_{0}\right)}\right]\left[\frac{N}{\lambda_{k}}-\lambda_{k}+\left(1+\mu_{0}-\left(\frac{\lambda_{b}}{\lambda_{k}}\right) \lambda_{k}\right) q_{0}^{b} b_{-1} Q\right]\right. \\
+ & {\left.\left[\left(\frac{\lambda_{b}}{\lambda_{k}}\right) \lambda_{k}-\frac{M}{\lambda_{k}} \cdot n_{0}\left(\frac{1}{1-D_{0}}\right) \cdot \frac{u^{\prime \prime}\left(c_{0}\right)}{u^{\prime}\left(c_{0}\right)}\right]\left[\frac{N}{\lambda_{k}}+\lambda_{k}+\left(\frac{\lambda_{b}}{\lambda_{k}}\right) \lambda_{k} q_{0}^{b} b_{-1} Q\right]\right\} } \\
= & \frac{1}{\lambda_{k} Z^{2}}\left\{2\left(\frac{\lambda_{b}}{\lambda_{k}}\right) N-2 M \cdot n_{0}\left(\frac{1}{1-D_{0}}\right) \cdot \frac{u^{\prime \prime}\left(c_{0}\right)}{u^{\prime}\left(c_{0}\right)}\right. \\
+ & {\left[\left(\frac{\lambda_{b}}{\lambda_{k}}\right) \lambda_{k}+\frac{M}{\lambda_{k}} \cdot n_{0}\left(\frac{1}{1-D_{0}}\right) \cdot \frac{u^{\prime \prime}\left(c_{0}\right)}{u^{\prime}\left(c_{0}\right)}\right]\left(1+\mu_{0}\right) q_{0}^{b} b_{-1} Q } \\
- & \left.2 M \cdot n_{0}\left(\frac{1}{1-D_{0}}\right) \cdot \frac{u^{\prime \prime}\left(c_{0}\right)}{u^{\prime}\left(c_{0}\right)}\left(\frac{\lambda_{b}}{\lambda_{k}}\right) q_{0}^{b} b_{-1} Q\right\} \\
= & \frac{\lambda_{k}}{(\tilde{Z})^{2}}\left\{2\left(\frac{\lambda_{b}}{\lambda_{k}}\right) N-2 M \cdot n_{0}\left(\frac{1}{1-D_{0}}\right) \cdot \frac{u^{\prime \prime}\left(c_{0}\right)}{u^{\prime}\left(c_{0}\right)}\right. \\
+ & {\left[\left(\frac{\lambda_{b}}{\lambda_{k}}\right) \lambda_{k}+\frac{M}{\lambda_{k}} \cdot n_{0}\left(\frac{1}{1-D_{0}}\right) \cdot \frac{u^{\prime \prime}\left(c_{0}\right)}{u^{\prime}\left(c_{0}\right)}\right]\left(1+\mu_{0}\right) q_{0}^{b} b_{-1} Q } \\
- & \left.2 M \cdot n_{0}\left(\frac{1}{1-D_{0}}\right) \cdot \frac{u^{\prime \prime}\left(c_{0}\right)}{u^{\prime}\left(c_{0}\right)}\left(\frac{\lambda_{b}}{\lambda_{k}}\right) q_{0}^{b} b_{-1} Q\right\} \\
= & \frac{1}{(\tilde{Z})^{2}}\left\{2\left(\frac{\lambda_{b}}{\lambda_{k}}\right) \lambda_{k} N-2 M \lambda_{k} \cdot n_{0}\left(\frac{1}{1-D_{0}}\right) \cdot \frac{u^{\prime \prime}\left(c_{0}\right)}{u^{\prime}\left(c_{0}\right)}\right. \\
+ & {\left[\left(\frac{\lambda_{b}}{\lambda_{k}}\right) \lambda_{k}^{2}+M \cdot n_{0}\left(\frac{1}{1-D_{0}}\right) \cdot \frac{u^{\prime \prime}\left(c_{0}\right)}{u^{\prime}\left(c_{0}\right)}\right]\left(1+\mu_{0}\right) q_{0}^{b} b_{-1} Q } \\
- & \left.2 M \cdot n_{0}\left(\frac{1}{1-D_{0}}\right) \cdot \frac{u^{\prime \prime}\left(c_{0}\right)}{u^{\prime}\left(c_{0}\right)}\left(\frac{\lambda_{b}}{\lambda_{k}}\right) \lambda_{k} q_{0}^{b} b_{-1} Q\right\} \\
&
\end{aligned}
$$


Similarly, we can calculate the partial derivative of $A_{2}$ with respect to $\lambda_{k}$ :

$$
\begin{aligned}
\frac{\partial A_{2}}{\partial \lambda_{k}} & =\frac{1}{Z^{2}}\left\{\left[-\left(\frac{\lambda_{b}}{\lambda_{k}}\right) q_{0}^{b} b_{-1}(S+T)\right]\left[\frac{N}{\lambda_{k}}-\lambda_{k}+\left(1+\mu_{0}-\left(\frac{\lambda_{b}}{\lambda_{k}}\right) \lambda_{k}\right) q_{0}^{b} b_{-1} Q\right]\right. \\
& \left.+\left[\left(1+\mu_{0}-\left(\frac{\lambda_{b}}{\lambda_{k}}\right) \lambda_{k}\right) q_{0}^{b} b_{-1}(S+T)\right]\left[\frac{N}{\lambda_{k}^{2}}+1+\left(\frac{\lambda_{b}}{\lambda_{k}}\right) q_{0}^{b} b_{-1} Q\right]\right\} \\
& =\frac{1}{\lambda_{k} Z^{2}}\left\{\left[-\left(\frac{\lambda_{b}}{\lambda_{k}}\right) \lambda_{k} q_{0}^{b} b_{-1}(S+T)\right]\left[\frac{N}{\lambda_{k}}-\lambda_{k}+\left(1+\mu_{0}-\left(\frac{\lambda_{b}}{\lambda_{k}}\right) \lambda_{k}\right) q_{0}^{b} b_{-1} Q\right]\right. \\
& \left.+\left[\left(1+\mu_{0}-\left(\frac{\lambda_{b}}{\lambda_{k}}\right) \lambda_{k}\right) q_{0}^{b} b_{-1}(S+T)\right]\left[\frac{N}{\lambda_{k}}+\lambda_{k}+\left(\frac{\lambda_{b}}{\lambda_{k}}\right) \lambda_{k} q_{0}^{b} b_{-1} Q\right]\right\} \\
& =\frac{1}{\lambda_{k} Z^{2}}\left\{\left[-\left(\frac{\lambda_{b}}{\lambda_{k}}\right) \lambda_{k} q_{0}^{b} b_{-1}(S+T)\right]\left(1+\mu_{0}\right) q_{0}^{b} b_{-1} Q-2 N\left(\frac{\lambda_{b}}{\lambda_{k}}\right) q_{0}^{b} b_{-1}(S+T)\right. \\
& \left.+\left(1+\mu_{0}\right) q_{0}^{b} b_{-1}(S+T)\left[\frac{N}{\lambda_{k}}+\lambda_{k}+\left(\frac{\lambda_{b}}{\lambda_{k}}\right) \lambda_{k} q_{0}^{b} b_{-1} Q\right]\right\} \\
= & \frac{1}{\lambda_{k} Z^{2}}\left\{-\left(\frac{\lambda_{b}}{\lambda_{k}}\right) \lambda_{k} q_{0}^{b} b_{-1}(S+T)\left(1+\mu_{0}\right) q_{0}^{b} b_{-1} Q-2 N\left(\frac{\lambda_{b}}{\lambda_{k}}\right) q_{0}^{b} b_{-1}(S+T)\right. \\
+ & \left.\left(1+\mu_{0}\right) q_{0}^{b} b_{-1}(S+T)\left[\frac{N}{\lambda_{k}}+\lambda_{k}\right]+\left(1+\mu_{0}\right) q_{0}^{b} b_{-1}(S+T)\left(\frac{\lambda_{b}}{\lambda_{k}}\right) \lambda_{k} q_{0}^{b} b_{-1} Q\right\} \\
= & \frac{1}{\lambda_{k} Z^{2}}\left\{-2 N\left(\frac{\lambda_{b}}{\lambda_{k}}\right) q_{0}^{b} b_{-1}(S+T)+\left(1+\mu_{0}\right) q_{0}^{b} b_{-1}(S+T)\left[\frac{N}{\lambda_{k}}+\lambda_{k}\right]\right\} \\
= & \frac{\lambda_{k}}{(\tilde{Z})^{2}}\left\{-2 N\left(\frac{\lambda_{b}}{\lambda_{k}}\right) q_{0}^{b} b_{-1}(S+T)+\left(1+\mu_{0}\right) q_{0}^{b} b_{-1}(S+T)\left[\frac{N}{\lambda_{k}}+\lambda_{k}\right]\right\} \\
= & \frac{1}{(\tilde{Z})^{2}}\left\{-2 N\left(\frac{\lambda_{b}}{\lambda_{k}}\right) \lambda_{k} q_{0}^{b} b_{-1}(S+T)+\left(1+\mu_{0}\right) q_{0}^{b} b_{-1}(S+T)\left[N+\lambda_{k}^{2}\right]\right\}
\end{aligned}
$$

Now that we have calculated the partial derivatives of $A_{1}$ and $A_{2}$, we are in a position to calculate the partial derivative of the change in lending due to a government spending shock with respect 
to the diversion parameter $\lambda_{k}$ :

$$
\begin{aligned}
\frac{\partial}{\partial \lambda_{k}}\left(\frac{d k_{0}}{d g_{0}}\right) & =\frac{\partial A_{1}}{\partial \lambda_{k}}-\frac{\partial A_{2}}{\partial \lambda_{k}} \\
& =\frac{1}{(\tilde{Z})^{2}}\left\{2\left(\frac{\lambda_{b}}{\lambda_{k}}\right) \lambda_{k} N-2 M \lambda_{k} \cdot n_{0}\left(\frac{1}{1-D_{0}}\right) \cdot \frac{u^{\prime \prime}\left(c_{0}\right)}{u^{\prime}\left(c_{0}\right)}\right. \\
& +\left[\left(\frac{\lambda_{b}}{\lambda_{k}}\right) \lambda_{k}^{2}+M \cdot n_{0}\left(\frac{1}{1-D_{0}}\right) \cdot \frac{u^{\prime \prime}\left(c_{0}\right)}{u^{\prime}\left(c_{0}\right)}\right]\left(1+\mu_{0}\right) q_{0}^{b} b_{-1} Q \\
& \left.-2 M \cdot n_{0}\left(\frac{1}{1-D_{0}}\right) \cdot \frac{u^{\prime \prime}\left(c_{0}\right)}{u^{\prime}\left(c_{0}\right)}\left(\frac{\lambda_{b}}{\lambda_{k}}\right) \lambda_{k} q_{0}^{b} b_{-1} Q\right\} \\
& -\frac{1}{(\tilde{Z})^{2}}\left\{-2 N\left(\frac{\lambda_{b}}{\lambda_{k}}\right) \lambda_{k} q_{0}^{b} b_{-1}(S+T)+\left(1+\mu_{0}\right) q_{0}^{b} b_{-1}(S+T)\left[N+\lambda_{k}^{2}\right]\right\} \\
& =\frac{1}{(\tilde{Z})^{2}}\left\{2\left(\frac{\lambda_{b}}{\lambda_{k}}\right) \lambda_{k} N-2 M \lambda_{k} \cdot n_{0}\left(\frac{1}{1-D_{0}}\right) \cdot \frac{u^{\prime \prime}\left(c_{0}\right)}{u^{\prime}\left(c_{0}\right)}\right. \\
& +\left[\left(\frac{\lambda_{b}}{\lambda_{k}}\right) \lambda_{k}^{2}+M \cdot n_{0}\left(\frac{1}{1-D_{0}}\right) \cdot \frac{u^{\prime \prime}\left(c_{0}\right)}{u^{\prime}\left(c_{0}\right)}\right]\left(1+\mu_{0}\right) q_{0}^{b} b_{-1} Q \\
& -2 M \cdot n_{0}\left(\frac{1}{1-D_{0}}\right) \cdot \frac{u^{\prime \prime}\left(c_{0}\right)}{u^{\prime}\left(c_{0}\right)}\left(\frac{\lambda_{b}}{\lambda_{k}}\right) \lambda_{k} q_{0}^{b} b_{-1} Q \\
& \left.+2 N\left(\frac{\lambda_{b}}{\lambda_{k}}\right) \lambda_{k} q_{0}^{b} b_{-1}(S+T)-\left(1+\mu_{0}\right) q_{0}^{b} b_{-1}(S+T)\left[N+\lambda_{k}^{2}\right]\right\}
\end{aligned}
$$

Now we can prove that the introduction of financial frictions deteriorate the drop in lending by evaluating expression 105:

$$
\begin{aligned}
\left.\frac{\partial}{\partial \lambda_{k}}\left(\frac{d k_{0}}{d g_{0}}\right)\right|_{\lambda_{k}=0} & =\frac{1}{N^{2}}\left\{M \cdot n_{0}\left(\frac{1}{1-D_{0}}\right) \cdot \frac{u^{\prime \prime}\left(c_{0}\right)}{u^{\prime}\left(c_{0}\right)}\left(1+\mu_{0}\right) q_{0}^{b} b_{-1} Q-N\left(1+\mu_{0}\right) q_{0}^{b} b_{-1}(S+T)\right\} \\
& =\frac{\left(1+\mu_{0}\right) q_{0}^{b} b_{-1}}{N^{2}}\left\{M \cdot n_{0}\left(\frac{1}{1-D_{0}}\right) \cdot \frac{u^{\prime \prime}\left(c_{0}\right)}{u^{\prime}\left(c_{0}\right)} \cdot Q-N(S+T)\right\} \\
& =\frac{\left(1+\mu_{0}\right) q_{0}^{b} b_{-1}}{N^{2}} \cdot L<0
\end{aligned}
$$

where $L$ is given by:

$$
L=M \cdot n_{0}\left(\frac{1}{1-D_{0}}\right) \cdot \frac{u^{\prime \prime}\left(c_{0}\right)}{u^{\prime}\left(c_{0}\right)} \cdot Q-N(S+T)<0 .
$$


To prove that the derivative is smaller than zero, we have to prove that the expression inside the brackets is negative. We start by rewriting $Q, S$ and $T$ in the following way:

$$
\begin{aligned}
Q & =Q_{1}+Q_{2}=\frac{Y_{1}}{V}+\frac{Y_{2}}{V}, \\
S & =\frac{\tilde{S}}{V} \\
T & =\frac{\tilde{T}}{V}
\end{aligned}
$$

where $Y_{1}, Y_{2}, V, \tilde{S}$ and $\tilde{T}$ are given by the following expressions:

$$
\begin{aligned}
Y_{1} & =-\frac{\lambda_{b}}{\lambda_{k}} \beta\left(\frac{u^{\prime}\left(c_{1}\right)}{u^{\prime}\left(c_{0}\right)}\right)\left(1+r_{1}^{k}\right) \cdot E_{2}>0, \\
Y_{2} & =\left(1-\frac{\lambda_{b}}{\lambda_{k}}\right)\left[\frac{u^{\prime \prime}\left(c_{1}\right)}{u^{\prime}\left(c_{1}\right)} \cdot K_{1}+\left(\frac{1}{1-D_{0}}\right) \cdot \frac{u^{\prime \prime}\left(c_{0}\right)}{u^{\prime}\left(c_{0}\right)}\right]<0, \\
V & =\beta\left(\frac{u^{\prime}\left(c_{1}\right)}{u^{\prime}\left(c_{0}\right)}\right)\left[1-p\left(b_{0}\right)\right]\left(\frac{1+x_{c}}{q_{0}^{b}}\right)\left[1-\left(b_{0}-b_{-1}\right) \frac{p^{\prime}\left(b_{0}\right)}{1-p\left(b_{0}\right)}\right]>0, \\
\tilde{S} & =\left(1-\frac{\lambda_{b}}{\lambda_{k}}\right)\left(\frac{1}{1-D_{0}}\right) \cdot \frac{u^{\prime \prime}\left(c_{0}\right)}{u^{\prime}\left(c_{0}\right)}<0, \\
\tilde{T} & =-\beta\left(\frac{u^{\prime}\left(c_{1}\right)}{u^{\prime}\left(c_{0}\right)}\right)\left[1-p\left(b_{0}\right)\right]\left(\frac{1+x_{c}}{q_{0}^{b}}\right) \frac{p^{\prime}\left(b_{0}\right)}{1-p\left(b_{0}\right)} \cdot \frac{1}{q_{0}^{b}}<0,
\end{aligned}
$$


We rewrite $L$ in 106 in the following way:

$$
\begin{aligned}
L & =M \cdot n_{0}\left(\frac{1}{1-D_{0}}\right) \cdot \frac{u^{\prime \prime}\left(c_{0}\right)}{u^{\prime}\left(c_{0}\right)} \cdot Q-N(S+T) \\
& =M \cdot n_{0}\left(\frac{1}{1-D_{0}}\right) \cdot \frac{u^{\prime \prime}\left(c_{0}\right)}{u^{\prime}\left(c_{0}\right)}\left(\frac{Y_{1}+Y_{2}}{V}\right) \\
& -M \cdot n_{0} \cdot\left[\left(\frac{u^{\prime \prime}\left(c_{1}\right)}{u^{\prime}\left(c_{1}\right)}\right) \cdot K_{1}+\left(\frac{1}{1-D_{0}}\right) \cdot \frac{u^{\prime \prime}\left(c_{0}\right)}{u^{\prime}\left(c_{0}\right)}+E_{2}\right]\left(\frac{\tilde{S}}{V}+\frac{\tilde{T}}{V}\right) \\
& =\frac{M \cdot n_{0}}{V}\left\{\left(\frac{1}{1-D_{0}}\right) \cdot \frac{u^{\prime \prime}\left(c_{0}\right)}{u^{\prime}\left(c_{0}\right)} \cdot Y_{1}\right. \\
& +\left(\frac{1}{1-D_{0}}\right) \cdot \frac{u^{\prime \prime}\left(c_{0}\right)}{u^{\prime}\left(c_{0}\right)} \cdot\left(1-\frac{\lambda_{b}}{\lambda_{k}}\right)\left[\frac{u^{\prime \prime}\left(c_{1}\right)}{u^{\prime}\left(c_{1}\right)} \cdot K_{1}+\left(\frac{1}{1-D_{0}}\right) \cdot \frac{u^{\prime \prime}\left(c_{0}\right)}{u^{\prime}\left(c_{0}\right)}\right] \\
& -\left[\left(\frac{u^{\prime \prime}\left(c_{1}\right)}{u^{\prime}\left(c_{1}\right)}\right) \cdot K_{1}+\left(\frac{1}{1-D_{0}}\right) \cdot \frac{u^{\prime \prime}\left(c_{0}\right)}{u^{\prime}\left(c_{0}\right)}+E_{2}\right] \cdot\left(1-\frac{\lambda_{b}}{\lambda_{k}}\right)\left(\frac{1}{1-D_{0}}\right) \cdot \frac{u^{\prime \prime}\left(c_{0}\right)}{u^{\prime}\left(c_{0}\right)} \\
& \left.-\left[\left(\frac{u^{\prime \prime}\left(c_{1}\right)}{u^{\prime}\left(c_{1}\right)}\right) \cdot K_{1}+\left(\frac{1}{1-D_{0}}\right) \cdot \frac{u^{\prime \prime}\left(c_{0}\right)}{u^{\prime}\left(c_{0}\right)}+E_{2}\right] \cdot \tilde{T}\right\} \\
& =\frac{M \cdot n_{0}}{V}\left\{\left(\frac{1}{1-D_{0}}\right) \cdot \frac{u^{\prime \prime}\left(c_{0}\right)}{u^{\prime}\left(c_{0}\right)} \cdot Y_{1}-\left(1-\frac{\lambda_{b}}{\lambda_{k}}\right)\left(\frac{1}{1-D_{0}}\right) \cdot \frac{u^{\prime \prime}\left(c_{0}\right)}{u^{\prime}\left(c_{0}\right)} \cdot E_{2}\right. \\
& \left.-\left[\left(\frac{u^{\prime \prime}\left(c_{1}\right)}{u^{\prime}\left(c_{1}\right)}\right) \cdot K_{1}+\left(\frac{1}{1-D_{0}}\right) \cdot \frac{u^{\prime \prime}\left(c_{0}\right)}{u^{\prime}\left(c_{0}\right)}+E_{2}\right] \cdot \tilde{T}\right\}<0 .
\end{aligned}
$$

\section{Derivations: infinite-horizon DSGE model}

\section{C.1 Households}

There is a continuum of infinitely lived households with identical preferences and asset endowments. A typical household consists of bankers and workers. Every period, a fraction $f$ of the household members is a banker running a financial intermediary. A fraction $1-f$ of the household members is a worker. At the end of every period, all members of the household pool their resources, and every member of the household has the same consumption pattern. Hence there is perfect insurance within the household, and the representative agent representation is preserved. Every period, the household earns income from the labor of the working members and the profits of the firms that are owned by the household. In addition, households keep short term deposits in commercial banks, which are paid back with interest. The household faces a perfectly competitive monopolistic labor market, in which it sets the nominal wage rate, and supplies as much labor as demanded by the labor agencies, which we will explain in section 4.5 . The household uses these incoming cashflows to buy consumption goods which are immediately consumed upon purchase, and make new deposits into financial intermediaries ${ }^{12}$ The household members derive utility from consumption and leisure, with habit formation in consumption, in

\footnotetext{
${ }^{12}$ but not in the ones owned by the family, in order to prevent self-financing.
} 
order to capture realistic consumption dynamics (Christiano et al., 2005). Households optimize expected discounted utility:

$\max _{\left\{c_{t+s}, d_{t+s}\right\}_{s=0}^{\infty}} E_{t}\left[\sum_{s=0}^{\infty} \beta^{s}\left(\log \left(c_{t+s}-v c_{t-1+s}\right)-\Psi \frac{h_{t+s}^{1+\varphi}}{1+\varphi}\right)\right], \quad \beta \in(0,1), \quad v \in[0,1), \quad \varphi \geq 0$

where $c_{t}$ is consumption per household, and $h_{t}$ are hours worked by the members of the household that are workers. The utility function is maximized subject to the following budget constraint:

$$
c_{t}+d_{t}+\tau_{t}=w_{t} h_{t}+\left(1+r_{t}^{d}\right) d_{t-1}+\Pi_{t}
$$

Deposits $d_{t-1}$ are posted at the financial intermediary in period $t-1$, and pay real interest $r_{t}^{d}$ and principal at time $t . w_{t}$ is the real wage rate, $\tau_{t}$ are lump sum taxes the household has to pay to the government, and $\Pi_{t}$ are the profits from the firms owned by the households. The profits of the financial intermediary are net of the startup capital for new bankers, as will be explained below. The first order conditions are then given by:

$$
\begin{array}{ll}
c_{t} \quad: \quad \lambda_{t}=\left(c_{t}-v c_{t-1}\right)^{-1}-v \beta E_{t}\left[\left(c_{t+1}-v c_{t}\right)^{-1}\right] \\
d_{t} \quad: \quad 1=\beta E_{t}\left[\Lambda_{t, t+1}\left(1+r_{t+1}^{d}\right)\right]
\end{array}
$$

where $\lambda_{t}$ is the Lagrange multiplier of the budget constraint, and $\beta \Lambda_{t, t+i}$ the stochastic discount factor, where $\Lambda_{t, t+i}=\lambda_{t+i} / \lambda_{t}$ for $i \geq 0$.

\section{C.2 The Fiscal Authority and the Central Bank}

\section{Fiscal Authority}

The Fiscal Authority (the Government) levies lump sum taxes on households, issues bonds to finance its (exogeneous) expenditures $g_{t}$ and services outstanding government liabilities. The government can provide the financial sector with additional net worth $n_{t}^{g}$, while $\tilde{n}_{t}^{g}$ denotes repayment of previously administered support. Government bonds are modeled as in Woodford (1998, 2001) to have a flexible maturity structure. $q_{t}^{b}$ is the price of outstanding nominal bonds $B_{t}$ in terms of the consumption good, while the maturity is controlled by the parameter $\rho$. Let $B_{t-1}$ denote the stock of outstanding nominal government debt at the beginning of period $t$. These bonds pay a nominal coupon payment $x_{c}$ at the beginning of period $t$, a payment $\rho x_{c}$ at the beginning of period $t+1, \rho^{2} x_{c}$ at the beginning of period $t+2$, etc. The expected duration is therefore equal to $1 /(1-\beta \rho){ }^{13}$ The price of a bond issued in period $t-1$ should be a fraction $\rho$ of the price of a bond issued in period $t$. Outstanding nominal government liabilities at the

${ }^{13}$ Duration is defined as: $\frac{\sum_{j=1}^{\infty} j \beta^{j}\left(\rho^{j-1} x_{c}\right)}{\sum_{j=1}^{\infty} \beta^{j}\left(\rho^{j-1} x_{c}\right)}$ 
beginning of period $t$ are therefore equal to $\left(x_{c}+\rho q_{t}^{b}\right) B_{t-1}$. The nominal government budget constraint in the absence of sovereign default risk is given by:

$$
q_{t}^{b} B_{t}+P_{t} \tau_{t}+P_{t} \tilde{n}_{t}^{g}=P_{t} g_{t}+P_{t} n_{t}^{g}+x_{c} B_{t-1}+\rho q_{t}^{b} B_{t-1} .
$$

Division by the domestic price level $P_{t}$ gives the budget constraint in real terms:

$$
q_{t}^{b} b_{t}+\tau_{t}+\tilde{n}_{t}^{g}=g_{t}+n_{t}^{g}+\left(1+r_{t}^{b}\right) q_{t-1}^{b} b_{t-1},
$$

where $\pi_{t}=P_{t} / P_{t-1}$ is the gross inflation rate, $b_{t}=B_{t} / P_{t}$ is the real value of government bonds, and $1+r_{t}^{b}$ is given by:

$$
1+r_{t}^{b}=\frac{x_{c}+\rho q_{t}^{b}}{\pi_{t} q_{t-1}^{b}}
$$

Now we introduce sovereign default risk in a similar way as in Section 3 by assuming a stochastic maximum level of taxation, which arises because of the government's inability to raise enough funds to honor outstanding liabilities (Schabert and van Wijnbergen, 2006, 2014, Corsetti et al., 2013). This fiscal limit will be drawn each period from a generalised beta-distribution with parameters $\alpha_{b}, \beta_{b}$ and $\bar{b}_{\max }$ following Corsetti et al. (2013). As a result, we can write the ex ante probability of default $p_{t}^{\text {def }}$ for a given level of government debt $b_{t}$ by the following cumulative distribution function:

$$
p_{t}^{\text {def }}=F_{\beta}\left(\frac{b_{t}}{4 \bar{y}} \frac{1}{b_{\max }} ; \alpha_{b}, \beta_{b}\right) .
$$

When the level of taxes necessary to service outstanding liabilities is above the fiscal limit, the sovereign reduces the coupon payment $x_{c} b_{t-1} / \pi_{t}$ and the principal of the outstanding liabilities $\rho q_{t}^{b} b_{t-1} / \pi_{t}$ by a factor $1-\vartheta_{t}{ }^{14}$ The haircut $\vartheta_{t}$ depends on whether or not the required level of taxes surpasses the draw for the fiscal limit:

$$
\vartheta_{t}= \begin{cases}\vartheta_{d e f} & \text { with probability } p_{t}^{\text {def }} ; \\ 0 & \text { with probability } 1-p_{t}^{\text {def }}\end{cases}
$$

Savings from the (partial) default are returned in randomized fashion to households, which therefore do not anticipate this transfer. The aggregate real transfer $\tau_{t}^{t r}$ from the government to households is given by:

$$
\tau_{t}^{t r}=\vartheta_{t} x_{c} b_{t-1} / \pi_{t}+\vartheta_{t} \rho q_{t}^{b} b_{t-1} / \pi_{t}
$$

while the government budget constraint in the presence of sovereign default risk becomes:

$$
q_{t}^{b} b_{t}+\tau_{t}-\tau_{t}^{t r}+\tilde{n}_{t}^{g}=g_{t}+n_{t}^{g}+\left(1-\vartheta_{t}\right) x_{c} b_{t-1} / \pi_{t}+\left(1-\vartheta_{t}\right) \rho q_{t}^{b} b_{t-1} / \pi_{t} .
$$

\footnotetext{
${ }^{14}$ We assume bondholders know the government's inability to raise sufficient funds, and therefore voluntarily agree to a haircut on the coupon payment and a restructuring of the outstanding government bonds.
} 
Subsitution of 112 into the government budget constraint 113 provides us with the law of motion for real government debt:

$$
q_{t}^{b} b_{t}+\tau_{t}+\tilde{n}_{t}^{g}=g_{t}+n_{t}^{g}+x_{c} b_{t-1} / \pi_{t}+\rho q_{t}^{b} b_{t-1} / \pi_{t}=g_{t}+n_{t}^{g}+\left(1+r_{t}^{b}\right) q_{t-1}^{b} b_{t-1} .
$$

The ex post default government budget constraint is therefore the same as in the absence of sovereign default risk. Sovereign default risk, however, affects the government budget constraint indirectly through the bond price $q_{t}^{b}$, which incorporates expectations of a sovereign default, while not anticipating the redistribution of the default proceeds to households.

We assume that the government follows a simple fiscal rule for its core tax policy $\tau_{t}$, as in Bohn (1998):

$$
\tau_{t}=\bar{\tau}+\kappa_{b}\left(b_{t-1}-\bar{b}\right)+\kappa_{g}\left(g_{t}-\bar{g}\right)+\kappa_{n} n_{t}^{g}, \quad \kappa_{b} \in(0,1], \quad \kappa_{g}, \kappa_{n} \in[0,1]
$$

where $\bar{b}$ and $\bar{g}$ are the steady state levels of debt, respectively government spending. The Bohn (1998) policy rule formulation guarantees that the real value of public debt eventually grows at a rate smaller than the net real rate of interest. Bohn (1998) proves that following this rule is a sufficient condition for government solvency. If we set $\kappa_{n}=0$, the additional government transfers to the financial sector are completely financed by issuing new debt. $\kappa_{n}=1$ implies that the additional spending is completely financed by increasing lump sum taxes. Similarly $\kappa_{g}=0$ implies that all government spending above its steady state value is completely deficit financed, whereas $\kappa_{g}=1$ implies a completely tax-financed government spending stimulus.

Government purchases are driven by an exogenous stochastic process, and in addition can possibly respond to a recession caused by a financial crisis shock $\lambda_{t}^{k}>0$, to be specified in subsection 4.3. The second component would correspond to a Keynesian stimulus package, in that case the government attempts to stimulate the economy by increasing government purchases. Combining these two components yields the actual time path for government expenditures/purchases of final goods in period $t$ :

$$
\begin{aligned}
g_{t} & =\tilde{g}_{t}+\varsigma\left(\lambda_{t-l}^{k}-\bar{\lambda}^{k}\right), \quad \varsigma>0, \quad l \geq 0 \\
\log \left(\tilde{g}_{t} / \bar{g}\right) & =\rho_{g} \log \left(\tilde{g}_{t-1} / \bar{g}\right)+\varepsilon_{g, t-4}^{a}
\end{aligned}
$$

where $\varepsilon_{g}^{a} \sim N\left(0, \sigma_{a}^{2}\right)$. We assume that the autocorrelation coefficient $\rho_{g} \in[0,1)$, and the steady state value of government purchases to be larger than zero $(\bar{g}>0)$. This way we can study the effects of surprise shocks to government spending $\left(\varepsilon_{g, t}^{u}\right)$, but also the effects of shocks that are announced one year in advance $\left(\varepsilon_{g, t}^{a}\right)$. The parameter $\varsigma$ determines the size of the response to a financial crisis shock. If $\varsigma=0$, the government does not respond to a financial crisis shock. $\varsigma>0$ implies that the government reacts to a financial crisis shock by increasing government spending above the steady state value. The case where $l=0$ implies that the government reacts instantaneously to the financial crisis shock, while $l>0$ implies that the government reacts with 
some lag. Whereas it might be preferable in general to model the government response as an endogeneous optimizing feedback from output, we choose to model government intervention as an exogeneous process because of our focus on the size of fiscal multipliers. This allows us to make policy impact comparisons that are not "polluted" by second round effects triggered by the macroeconomic response to government expenditure shocks leading to subsequent rounds of government interventions.

\section{The Central Bank}

As is commonly assumed in the literature, the Central Bank sets the nominal interest rate on deposits $r_{t}^{n}$ according to the following Taylor rule, in order to minimize output and inflation deviations:

$$
r_{t}^{n}=\left(1-\rho_{r}\right)\left(r^{n}+\kappa_{\pi}\left(\pi_{t}-\bar{\pi}\right)+\kappa_{y} \log \left(y_{t} / y_{t-1}\right)\right)+\rho_{r} r_{t-1}^{n}+\varepsilon_{r, t}
$$

where $\varepsilon_{r, t} \sim N\left(0, \sigma_{r}^{2}\right)$, and $\kappa_{\pi}>0$ and $\kappa_{y}>0 . \rho_{r}$ is a smoothing parameter. The parameter $\bar{\pi}$ is the target inflation rate or the natural inflation rate. In order to satisfy the Taylor principle, we choose $\kappa_{\pi}>1$ (leaning against the wind). The values of $\kappa_{\pi}$ and $\kappa_{y}$ determine the strength with which the authorities react to deviations from the natural rate of inflation and output. The nominal and the real interest rate on deposits are linked through the following Fisher relation:

$$
1+r_{t}^{d}=\left(1+r_{t-1}^{n}\right) / \pi_{t}
$$

Hence monetary policy is executed through the control of interest rates on deposits rather than the interest rates on the government bonds: the latter are endogeneously determined in equilibrium.

\section{C.3 Financial intermediaries}

The financial sector is modeled in a similar fashion as in Section 3 Financial intermediaries lend to intermediate goods producers who use the funds to purchase physical capital. The banker's balance sheet is given by:

$$
p_{j, t}=n_{j, t}+d_{j, t}
$$

where $p_{j, t}$ are the assets on the balance sheet of bank $j$ in period $t, n_{j, t}$ denotes the net worth of the bank, while $d_{j, t}$ denotes the deposits of the bank. The financial intermediary invests the funds obtained from households in claims issued by intermediate goods producers and in government bonds. Hence the asset side of the bank's balance sheet has the following structure:

$$
p_{j, t}=q_{t}^{k} s_{j, t}^{k}+q_{t}^{b} s_{j, t}^{b}
$$


where $s_{j, t}^{k}$ are the number of claims financial intermediary $j$ acquired for a price $q_{t}^{k}$, paying out a net real return $r_{t+1}^{k}$ at the beginning of period $t+1$. The number of government bonds $s_{j, t}^{b}$ are acquired at a price $q_{t}^{b}$. At the beginning of period $t+1$ a net real return $r_{t+1}^{b *}$ is paid out, which includes the impact of a possible sovereign default. The law of motion for net worth of intermediary $j$ includes the possibility of government support, and evolves as follows:

$$
\begin{aligned}
n_{j, t+1} & =\left(1+r_{t+1}^{k}\right) q_{t}^{k} s_{j, t}^{k}+\left(1+r_{t+1}^{b *}\right) q_{t}^{b} s_{j, t}^{b}-\left(1+r_{t+1}^{d}\right) d_{j, t}+n_{j, t+1}^{g}-\tilde{n}_{j, t+1}^{g} \\
& =\left(r_{t+1}^{k}-r_{t+1}^{d}\right) q_{t}^{k} s_{j, t}^{k}+\left(r_{t+1}^{b *}-r_{t+1}^{d}\right) q_{t}^{b} s_{j, t}^{b}+\left(1+r_{t+1}^{d}\right) n_{j, t}+\tau_{t+1}^{n} n_{j, t}-\tilde{\tau}_{t+1}^{n} n_{j, t}
\end{aligned}
$$

where $n_{j, t+1}^{g}=\tau_{t+1}^{n} n_{j, t}$ denotes net worth provided by the government to financial intermediary $j$ (for example a capital injection). $\tilde{n}_{j, t+1}^{g}=\tilde{\tau}_{t+1}^{n} n_{j, t}$ denotes the repayment of government support received in previous periods.

The financial intermediary is interested in maximizing expected profits. We deviate from the setup in Section 3 by assuming that there is a probability of $1-\theta$ that the banker has to exit the industry next period, in which case he will bring the net worth $n_{j, t+1}$ to the household, while he is allowed to continue operating with a probability $\theta^{15}$ The banker discounts these outcomes by the household's stochastic discount factor $\beta \Lambda_{t, t+1}$, since the banker is part of the household, the ultimate owner of the financial intermediary. The banker's objective is then given by the following recursive optimization problem:

$$
V_{j, t}=\max E_{t}\left[\beta \Lambda_{t, t+1}\left\{(1-\theta) n_{j, t+1}+\theta V_{j, t+1}\right\}\right]
$$

where $\Lambda_{t, t+1}=\lambda_{t+1} / \lambda_{t}$. We conjecture the solution to be of the following form, and later check whether this is the case:

$$
V_{j, t}=\nu_{t}^{k} q_{t}^{k} s_{j, t}^{k}+\nu_{t}^{b} q_{t}^{b} s_{j, t}^{b}+\eta_{t} n_{j, t}
$$

Just as in Section 3 financial intermediaries have the possibility to divert assets at the end of period $t$, and therefore face an incentive compatibility constraint:

$$
V_{j, t} \geq \lambda_{t}^{k} q_{t}^{k} s_{j, t}^{k}+\lambda_{t}^{b} q_{t}^{b} s_{j, t}^{b}
$$

The optimization problem can now be formulated in the following way:

$$
\max _{\left\{s_{j, t}^{k}, s_{j, t}^{b}\right\}} V_{j, t}, \quad \text { s.t. } \quad V_{j, t} \geq \lambda_{t}^{k} q_{t}^{k} s_{j, t}^{k}+\lambda_{t}^{b} q_{t}^{b} s_{j, t}^{b}
$$

\footnotetext{
${ }^{15}$ The probability of dying bankers is introduced because otherwise financial intermediaries continue accumulating net worth to the point where the incentive compatibility constraint is no longer binding. As the focus of our paper is on the role of an undercapitalized banking system for the effectiveness of deficit-financed fiscal policy, we need the incentive compatibility constraint to be binding. To prevent overaccumulation of net worth, we therefore assume that each period an exogenous fraction of bankers exit the financial sector.
} 
The Lagrangian for this problem is now given by:

$$
\mathcal{L}=\left(1+\mu_{t}\right)\left(\nu_{t}^{k} q_{t}^{k} s_{j, t}^{k}+\nu_{t}^{b} q_{t}^{b} s_{j, t}^{b}+\eta_{t} n_{j, t}\right)-\mu_{t}\left(\lambda_{t}^{k} q_{t}^{k} s_{j, t}^{k}+\lambda_{t}^{b} q_{t}^{b} s_{j, t}^{b}\right)
$$

where $\mu_{t}$ is the Lagrangian multiplier on the constraint. Hence we get the following first order conditions:

$$
\begin{aligned}
s_{j, t}^{k} \quad: \quad\left(1+\mu_{t}\right) \nu_{t}^{k}-\lambda_{t}^{k} \mu_{t}=0 \Longrightarrow \nu_{t}^{k}=\lambda_{t}^{k}\left(\frac{\mu_{t}}{1+\mu_{t}}\right) \\
s_{j, t}^{b} \quad: \quad\left(1+\mu_{t}\right) \nu_{t}^{b}-\lambda_{t}^{b} \mu_{t}=0 \Longrightarrow \nu_{t}^{b}=\lambda_{t}^{b}\left(\frac{\mu_{t}}{1+\mu_{t}}\right) \\
\mu_{t} \quad: \quad\left\{\nu_{t}^{k} q_{t}^{k} s_{j, t}^{k}+\nu_{t}^{b} q_{t}^{b} s_{j, t}^{b}+\eta_{t} n_{j, t}-\lambda_{t}^{k} q_{t}^{k} s_{j, t}^{k}-\lambda_{t}^{b} q_{t}^{b} s_{j, t}^{b}\right\} \mu_{t}=0
\end{aligned}
$$

From the first order conditions we find that $\nu_{t}^{b}=\frac{\lambda_{t}^{b}}{\lambda_{t}^{k}} \nu_{t}^{k}$. Hence the leverage constraint 120 can be rewritten in the following way:

$$
q_{t}^{k} s_{j, t}^{k}+\frac{\lambda_{t}^{b}}{\lambda_{t}^{k}} q_{t}^{b} s_{j, t}^{b} \quad \leq \phi_{t} n_{j, t} \quad, \quad \phi_{t}=\frac{\eta_{t}}{\lambda_{t}^{k}-\nu_{t}^{k}}
$$

where $\phi_{t}$ is the ratio of assets (weighted by the relative diversion rates) to net worth, or the leverage constraint of the financial intermediary. The intuition for the leverage constraint is straightforward: a higher shadow value of private loans $\nu_{t}^{k}$ indicates a higher value from an additional unit of private loans, increasing expected profits everything else equal, thereby reducing the incentive for bankers to divert assets. A higher value of $\eta_{t}$ implies higher expected profits from an additional unit of net worth, therefore allowing a higher leverage ratio. A higher fraction $\lambda_{t}^{a}$ implies bankers can divert more, inducing households to provide less deposits everything else equal. The result is a tightening of the leverage constraint.

We model a financial crisis as a sudden increase in $\lambda_{t}^{a}$, see also Dedola et al. (2013). In particular, we assume the following processes for the diversion rates $\lambda_{t}^{a}$ :

$$
\begin{aligned}
\log \left(\frac{\lambda_{t}^{k}}{\bar{\lambda}^{k}}\right) & =\rho_{\lambda_{k}} \log \left(\frac{\lambda_{t-1}^{k}}{\bar{\lambda}^{k}}\right)+\varepsilon_{\lambda_{k}, t}, \\
\lambda_{t}^{b} & =\left(\frac{\bar{\lambda}_{b}}{\bar{\lambda}_{k}}\right) \lambda_{t}^{k},
\end{aligned}
$$

where we assume that the ratio $\lambda_{t}^{b} / \lambda_{t}^{k}$ is constant across time, and denote it by $\bar{\lambda}_{b} / \bar{\lambda}_{k}$. We also assume that $\varepsilon_{\lambda_{k}, t} \sim N\left(0, \sigma_{\lambda_{k}}^{2}\right)$.

Substitution of the conjectured solution into the right hand side of the Bellman equation and using the leverage constraint 121 gives the following expression for the continuation value of 
the financial intermediary:

$$
\begin{aligned}
V_{j, t} & =E_{t}\left[\beta \Lambda_{t, t+1}\left\{(1-\theta) n_{j, t+1}+\theta V_{j, t+1}\right\}\right]=E_{t}\left[\Omega_{t+1} n_{j, t+1}\right] \\
\Omega_{t+1} & =\beta \Lambda_{t, t+1}\left\{(1-\theta)+\theta\left[\eta_{t+1}+\nu_{t+1}^{k} \phi_{t+1}\right]\right\}
\end{aligned}
$$

$\Omega_{t+1}$ can be thought of as a stochastic discount factor that incorporates the financial friction. Now we can substitute the expression for next period's net worth into the expression above:

$$
\begin{aligned}
V_{j, t} & =E_{t}\left[\Omega_{t+1} n_{j, t+1}\right] \\
& =E_{t}\left[\Omega_{t+1}\left\{\left(1+r_{t+1}^{k}\right) q_{t}^{k} s_{j, t}^{k}+\left(1+r_{t+1}^{b *}\right) q_{t}^{b} s_{j, t}^{b}-\left(1+r_{t+1}^{d}\right) d_{j, t}+n_{j, t+1}^{g}-\tilde{n}_{j, t+1}^{g}\right\}\right] \\
& =E_{t}\left[\Omega_{t+1}\left\{\left(r_{t+1}^{k}-r_{t+1}^{d}\right) q_{t}^{k} s_{j, t}^{k}+\left(r_{t+1}^{b *}-r_{t+1}^{d}\right) q_{t}^{b} s_{j, t}^{b}+\left(1+r_{t+1}^{d}+\tau_{t+1}^{n}-\tilde{\tau}_{t+1}^{n}\right) n_{j, t}\right\}\right]
\end{aligned}
$$

After combining the conjectured solution with (124), we find the following first order conditions for the shadow values $\eta_{t}, \nu_{t}^{k}$ and $\nu_{t}^{b}$ :

$$
\begin{aligned}
\eta_{t} & =E_{t}\left[\Omega_{t+1}\left(1+r_{t+1}^{d}+\tau_{t+1}^{n}-\tilde{\tau}_{t+1}^{n}\right)\right], \\
\nu_{t}^{k} & =E_{t}\left[\Omega_{t+1}\left(r_{t+1}^{k}-r_{t+1}^{d}\right)\right], \\
\nu_{t}^{b} & =\frac{\lambda_{t}^{b}}{\lambda_{t}^{k}} \nu_{t}^{k}=E_{t}\left[\Omega_{t+1}\left(r_{t+1}^{b *}-r_{t+1}^{d}\right)\right], \\
\Omega_{t+1} & =\beta \Lambda_{t, t+1}\left\{(1-\theta)+\theta\left[\eta_{t+1}+\nu_{t+1}^{k} \phi_{t+1}\right]\right\} .
\end{aligned}
$$

Eventually we arrive at the following first order conditions for the financial intermediaries:

$$
\begin{aligned}
\frac{\lambda_{t}^{b}}{\lambda_{t}^{k}} E_{t}\left[\Omega_{t+1}\left(r_{t+1}^{k}-r_{t+1}^{d}\right)\right] & =E_{t}\left[\Omega_{t+1}\left(r_{t+1}^{b *}-r_{t+1}^{d}\right)\right], \\
E_{t}\left[\Omega_{t+1}\left(r_{t+1}^{k}-r_{t+1}^{d}\right)\right] & =\lambda_{t}^{k}\left(\frac{\mu_{t}}{1+\mu_{t}}\right), \\
\eta_{t} & =E_{t}\left[\Omega_{t+1}\left(1+r_{t+1}^{d}+\tau_{t+1}^{n}-\tilde{\tau}_{t+1}^{n}\right)\right],
\end{aligned}
$$

where $\Omega_{t+1}=\beta \Lambda_{t, t+1}\left\{(1-\theta)+\theta\left[\eta_{t+1}+\nu_{t+1}^{k} \phi_{t+1}\right]\right\}$ can be thought of as the household's stochastic discount factor, augmented to incorporate the financial friction. $\mu_{t}$ is the Lagrangian multiplier on the intermediary's incentive compatibility constraint 120 .

First order conditions 128 and 129 are the infinite horizon equivalent of first order condition (??) and (9) respectively, augmented with the intermediaries' stochastic discount factor $\Omega_{t+1}$ to reflect the fact that households, and thus financial intermediaries, are not risk-neutral anymore. In addition, we now have an expectations operator because returns have become stochastic.

Equation 130 shows the shadow value of an additional unit of net worth, which consists 
of the expected gross return on deposits $1+r_{t+1}^{d}$ augmented by the expected financial sector support per unit of net worth $\tau_{t+1}^{n}$ and the ecpected repayment per net worth $\tilde{\tau}_{t+1}^{n}$, converted into utility-terms by the intermediary's stochastic discount factor $\Omega_{t+1}$.

\section{C.4 Default-inclusive and default-exclusive return on government bonds}

Now we take a further look at the law of motion for financial intermediary $j$ is given by:

$$
\begin{aligned}
n_{j, t+1} & =\left(1+r_{t+1}^{k}\right) q_{t}^{k} s_{j, t}^{k}+\left(1-\vartheta_{t+1}\right) x_{c} b_{t} / \pi_{t+1}+\left(1-\vartheta_{t+1}\right) \rho q_{t+1}^{b} b_{t} / \pi_{t+1}-\left(1+r_{t+1}^{d}\right) d_{j, t}+n_{j, t+1}^{g}-\tilde{n}_{j, t+1}^{g} \\
& =\left(1+r_{t+1}^{k}\right) q_{t}^{k} s_{j, t}^{k}+\left(1-\vartheta_{t+1}\right)\left(\frac{x_{c}+\rho q_{t+1}^{b}}{\pi_{t+1} q_{t}^{b}}\right) q_{t}^{b} b_{t}-\left(1+r_{t+1}^{d}\right) d_{j, t}+\tau_{t+1}^{g} n_{j, t}-\tilde{\tau}_{t+1}^{g} n_{j, t} \\
& =\left(1+r_{t+1}^{k}\right) q_{t}^{k} s_{j, t}^{k}+\left(1+r_{t+1}^{b *}\right) q_{t}^{b} b_{t}-\left(1+r_{t+1}^{d}\right) d_{j, t}+\left(\tau_{t+1}^{g}-\tilde{\tau}_{t+1}^{g}\right)\left(q_{t}^{k} s_{j, t}^{k}+q_{t}^{b} s_{j, t}^{b}-d_{j, t}\right) \\
& =\left(1+r_{t+1}^{k}+\tau_{t+1}^{g}-\tilde{\tau}_{t+1}^{g}\right) q_{t}^{k} s_{j, t}^{k}+\left(1+r_{t+1}^{b *}+\tau_{t+1}^{g}-\tilde{\tau}_{t+1}^{g}\right) q_{t}^{b} b_{t}-\left(1+r_{t+1}^{d}+\tau_{t+1}^{g}-\tilde{\tau}_{t+1}^{g}\right) d_{j, t}
\end{aligned}
$$

We see that the law of motion for net worth is the same as under the no default case, except that the return on government bonds changes from $r_{t}^{b}$ in equation 200 into the default inclusive return $r_{t}^{b *}$ :

$$
1+r_{t}^{b *}=\left(1-\vartheta_{t}\right)\left(1+r_{t}^{b}\right)
$$

This implies that only the first order condition for bondholdings by financial intermediaries has to be adjusted:

$$
\nu_{t}^{b}=E_{t}\left[\Omega_{t, t+1}\left(r_{t+1}^{b *}-r_{t+1}^{d}\right)\right]=E_{t}\left[\Omega_{t, t+1}\left(\left(1-\vartheta_{t+1}\right)\left(1+r_{t+1}^{b}\right)-1-r_{t+1}^{d}\right)\right]
$$

We can see that the introduction of sovereign default risk drives up the default exclusive return $r_{t}^{b}$ everything else equal: investors want to be compensated for the larger risk of a default.

\section{C.4.1 Aggregation of financial variables}

Aggregating the balance sheet identities::

$$
p_{t}=q_{t}^{k} s_{t}^{k}+q_{t}^{b} s_{t}^{b}
$$

where $p_{t}$ denotes the aggregate quantity of assets that are on the balance sheets of the financial intermediaries. Since $\phi_{t}$ does not depend on firm specific factors, we can aggregate the leverage constraint 121) across financial intermediaries:

$$
q_{t}^{k} s_{t}^{k}+\frac{\lambda_{t}^{b}}{\lambda_{t}^{k}} q_{t}^{b} s_{t}^{b}=\phi_{t} n_{t}
$$

where $n_{t}$ denotes the aggregate intermediary net worth. The share of assets invested in 
private loans, to which we will refer in our simulations as "Portfolio weight claims" is given by:

$$
\omega_{t}=q_{t}^{k} s_{t}^{k} / p_{t}
$$

The aggregate law of motion for net worth of existing financial intermediaries that are allowed to continue operating $n_{e, t}$ is given by:

$$
\begin{aligned}
n_{e, t} & =\theta\left[\left(1+r_{t}^{k}\right) q_{t-1}^{k} s_{t-1}^{k}+\left(1+r_{t}^{b *}\right) q_{t-1}^{b} s_{t-1}^{b}-\left(1+r_{t}^{d}\right) d_{t-1}\right] \\
& =\theta\left[\left(1+r_{t}^{k}\right) q_{t-1}^{k} s_{t-1}^{k}+\left(1-\vartheta_{t}\right)\left(\frac{x_{c}+\rho q_{t}^{b}}{\pi_{t}}\right) s_{t-1}^{b}-\left(1+r_{t}^{d}\right) d_{t-1}\right] .
\end{aligned}
$$

where $\theta$ is the exogenous probability that a financial intermediary is allowed to continue operating. A newly started financial intermediary $j$ obtains an amount of new net worth which is equal to $\left(\frac{\chi}{1-\theta}\right) p_{j, t-1}$. In addition, financial intermediaries can be recapitalized by the government $n_{t}^{g}$, or forced to repay previous period government support $\tilde{n}_{t}^{g}$. Besides this term, we assume that each household uses all default proceeds to recapitalize their existing financial intermediaries. The households with an exiting banker do not use the proceeds to provide net worth to the newly starting banker, but only proivde the amount $\left(\frac{\chi}{1-\theta}\right) p_{j, t-1}$. Even though the proceeds are randomly distributed among households, in the aggregate an amount of $\theta\left(\frac{\vartheta_{t} x_{c}+\vartheta_{t} \rho q_{t}^{b}}{\pi_{t}}\right) s_{t-1}^{b}$ will be added to aggregate net worth. Total new aggregate net worth therefore becomes:

$$
\begin{aligned}
n_{t} & =\theta\left[\left(1+r_{t}^{k}\right) q_{t-1}^{k} s_{t-1}^{k}+\left(1-\vartheta_{t}\right)\left(\frac{x_{c}+\rho q_{t}^{b}}{\pi_{t}}\right) s_{t-1}^{b}-\left(1+r_{t}^{d}\right) d_{t-1}\right] \\
& +(1-\theta)\left(\frac{\chi}{1-\theta}\right) p_{t-1}+n_{t}^{g}-\tilde{n}_{t}^{g}+\theta\left(\frac{\vartheta_{t} x_{c}+\vartheta_{t} \rho q_{t}^{b}}{\pi_{t}}\right) s_{t-1}^{b} \\
& =\theta\left[\left(1+r_{t}^{k}\right) q_{t-1}^{k} s_{t-1}^{k}+\left(\frac{x_{c}+\rho q_{t}^{b}}{\pi_{t}}\right) s_{t-1}^{b}-\left(1+r_{t}^{d}\right) d_{t-1}\right]+\chi p_{t-1}+n_{t}^{g}-\tilde{n}_{t}^{g} \\
& =\theta\left[\left(1+r_{t}^{k}\right) q_{t-1}^{k} s_{t-1}^{k}+\left(1+r_{t}^{b}\right) q_{t-1}^{b} s_{t-1}^{b}-\left(1+r_{t}^{d}\right) d_{t-1}\right]+\chi p_{t-1}+n_{t}^{g}-\tilde{n}_{t}^{g} .
\end{aligned}
$$

As mentioned before, the proceeds from a sovereign default are randomly distributed to the households. Importantly, we assume that these proceeds are used by the household to recapitalize their respective financial intermediary ${ }^{16}$ Financial intermediaries, however, do not anticipate this recapitalization, as the households who perform the recap, receive a random payment. However, on an aggregate level, the financial intermediaries do not suffer ex post losses from the sovereign default because of the recap. Hence we can replace the default inclusive bond return $r_{t}^{b *}$ by the default exclusive bond return $r_{t}^{b}$ from equation 20 . Note that this is only possible for the aggregate law of motion but not for the individual intermediaries' first order conditions!

\footnotetext{
${ }^{16}$ We do so because otherwise a sovereign default would introduce a kink in intermediaries' net worth, which would force us to solve the model nonlinearily. Because we estimate the model with Bayesian techniques, we need to solve the model with first order perturbation approximation, which would not be possible in the presence of nonlinearities.
} 


\section{C.5 Production side}

\section{C.5.1 Intermediate Goods Producers}

There exists a continuum of intermediate goods producers indexed by $i \in[0,1]$. Each of these firms produce a differentiated good. The intermediate goods producers borrow from the financial intermediaries against future profits. We assume that there are no financial frictions between the financial intermediaries and the intermediate goods producers. Hence there are no monitoring costs for the financial intermediaries, and the intermediate goods producers can commit next period's profits to the financial intermediaries. The securities issued by the intermediate goods producers are therefore really state-contingent debt, like in Gertler and Kiyotaki (2010) ${ }^{17}$ The production technology of the intermediate goods producers is given by:

$$
y_{i, t}=a_{t} k_{i, t-1}^{\alpha} h_{i, t}^{1-\alpha}
$$

where $a_{t}$ equals total factor productivity, which follow a lognormal $\operatorname{AR}(1)$ process:

$$
\log \left(a_{t}\right)=\rho_{x} \log \left(a_{t-1}\right)+\varepsilon_{a, t}
$$

The innovations $\varepsilon_{a, t}$ are distributed as $\varepsilon_{a, t} \sim N\left(0, \sigma_{a}^{2}\right)$. The intermediate goods producer acquires the capital at the end of period $t-1$, while the production only occurs after the productivity shock $\xi_{t}$ has hit at the beginning of period $t$. We see that if a negative realization of $\varepsilon_{a, t}$ occurs, the firm will not be able to produce as much as when the shock does not occur. Remember that the number of claims $\left(s_{i, t}^{k}\right)$ is equal to the number of units of capital purchased $\left(k_{i, t}\right)$; hence the return on the claims of the financial intermediary will be lower. The intermediate goods producer decides at the end of period $t-1$ how much capital to purchase. At the moment the intermediate goods producer purchases the capital, he does not know the realization of $a_{t}$ in period $t$ yet. To finance his purchase at the end of period $t-1$, he needs to issue claims $s_{i, t-1}^{k}$, with the number of claims $s_{i, t-1}^{k}$ equal to the number of capital units $\left(k_{i, t-1}\right)$ acquired. The price at which the claims are sold equals $q_{t-1}^{k}$, and they pay a state-contingent net real return $r_{t}^{k}$ in period $t$. The intermediate goods producer also hires labor $h_{i, t}$ for a wage rate $w_{t}$ after the productivity shock $\left(a_{t}\right)$ has been realized. When the firm has produced in period $t$, the output is sold for a relative price $m_{t}$ to the retail firms. $m_{t}$ is the relative price of the intermediate goods with respect to the price level of the final goods, i.e. $m_{t}=P_{t}^{m} / P_{t}$. After production, the intermediate goods producing firms sell back what remains of the effective capital to the capital producers at a price of $q_{t}^{k}$. The capital stock is also subject to regular depreciation $\delta$ during production. So the intermediate goods producer receives $q_{t}^{k}(1-\delta) k_{i, t-1}$ for his end of period capital stock and real

\footnotetext{
${ }^{17}$ The claims of financial intermediaries can therefore be better thought of as equity. Occhino and Pescatori (2015) explicitly model loans to producers with a fixed face value, and include the possibility of a default by the goods producers. We refrain from explicitly modelling the producers' default, and note the equity characteristics of debt when firms have not enough funds to pay off the loan.
} 
profits in period $t$ are given by:

$$
\Pi_{i, t}=m_{t} a_{t} k_{i, t-1}^{\alpha} h_{i, t}^{1-\alpha}+q_{t}^{k}(1-\delta) k_{i, t-1}-\left(1+r_{t}^{k}\right) q_{t-1}^{k} k_{i, t-1}-w_{t} h_{i, t}
$$

The intermediate goods producing firms take the relative output price $\left(m_{t}\right)$, and the input prices $q_{t}^{k}, r_{t}^{k}$ and $w_{t}$ as given when hiring labor in a perfectly competitive market:

$$
h_{i, t} \quad: \quad w_{t}=(1-\alpha) m_{t} y_{i, t} / h_{i, t}
$$

Firms pay out residual revenues to the financial intermediaries. By substituting the first order condition for the wage rate into the zero-profit condition $\Pi_{i, t}=0$, we can find an expression for the ex-post return on capital:

$$
r_{t}^{k}=\left(q_{t-1}^{k}\right)^{-1}\left(\alpha m_{t} y_{i, t} / k_{i, t-1}+q_{t}^{k}(1-\delta)\right)-1
$$

The first order condition for labor and the expression for the ex-post return on capital can be rearranged to derive factor demands. These are given by:

$$
\begin{aligned}
k_{i, t-1} & =\alpha m_{t} y_{i, t} /\left[q_{t-1}^{k}\left(1+r_{t}^{k}\right)-q_{t}^{k}(1-\delta)\right] \\
h_{i, t} & =(1-\alpha) m_{t} y_{i, t} / w_{t}
\end{aligned}
$$

Finally the relative intermediate output price $m_{t}$ can be obtained by substituting the factor demands into the production function:

$$
m_{t}=\alpha^{-\alpha}(1-\alpha)^{\alpha-1} a_{t}^{-1}\left(w_{t}^{1-\alpha}\left[q_{t-1}^{k}\left(1+r_{t}^{k}\right)-q_{t}^{k}(1-\delta)\right]^{\alpha}\right)
$$

\section{C.5.2 Capital Producers}

In this section we describe the capital producers. At the end of period $t$, when the intermediate goods firms have produced, they sell what remains of the capital stock after depreciation $\delta$ to the capital producers at a price $q_{t}^{k}$. The capital producers also buy $i_{t}$ final goods from the final good producers; these purchases (investment) are an input in the capital production process: they are used to produce additional capital. Capital producers combine this additional capital with the old, partially depreciated stock bought earlier from the intermediate goods producers and so produce the new capital stock. This new capital is being sold to the intermediate goods producers at a price $q_{t}^{k}$. We assume that the capital producers face convex adjustment costs whenever investment $i_{t}$ deviates from previous period investment $i_{t-1}$. These adjustment costs are the reason that one unit of investment goods cannot be transformed into one unit of capital, unless $i_{t}=i_{t-1}$. Hence we have the following capital production technology:

$$
k_{t}=(1-\delta) k_{t-1}+\left(1-\Psi\left(\iota_{t}\right)\right) i_{t}, \quad \Psi(x)=\frac{\gamma}{2}(x-1)^{2}, \quad \iota_{t}=i_{t} / i_{t-1}
$$


The capital producers are profit maximizing, and profits are passed on to the households, who are the owners of the capital producers. The profit in period $t$ is given by:

$$
\Pi_{t}^{c}=q_{t}^{k} k_{t}-q_{t}^{k}(1-\delta) k_{t-1}-i_{t}
$$

The capital producers' optimization problem is then given by:

$$
\max _{\left\{i_{t+i}\right\}_{i=0}^{\infty}} E_{t}\left[\sum_{i=0}^{\infty} \beta^{i} \Lambda_{t, t+i}\left(q_{t+i}^{k}\left(1-\Psi\left(\iota_{t+i}\right)\right) i_{t+i}-i_{t+i}\right)\right]
$$

Differentiation with respect to investment gives the first order condition for the capital producers:

$$
q_{t}^{k}\left(1-\Psi\left(\iota_{t}\right)\right)-1-q_{t}^{k} \iota_{t} \Psi^{\prime}\left(\iota_{t}\right)+\beta E_{t} \Lambda_{t, t+1} q_{t+1}^{k} \iota_{t+1} \Psi^{\prime}\left(\iota_{t+1}\right)=0
$$

This equation can be rewritten to find the price of capital to be:

$$
\frac{1}{q_{t}^{k}}=1-\frac{\gamma}{2}\left(\frac{i_{t}}{i_{t-1}}-1\right)^{2}-\frac{\gamma i_{t}}{i_{t-1}}\left(\frac{i_{t}}{i_{t-1}}-1\right)+\beta E_{t}\left[\Lambda_{t, t+1} \frac{q_{t+1}^{k}}{q_{t}^{k}}\left(\frac{i_{t+1}}{i_{t}}\right)^{2} \gamma\left(\frac{i_{t+1}}{i_{t}}-1\right)\right]
$$

\section{C.5.3 Retail firms}

The relevant part of the optimization problem of the typical retail firm is now given by:

$$
\max _{P_{f, t}} E_{t}\left[\sum_{s=0}^{\infty}(\beta \psi)^{s} \Lambda_{t, t+s}\left(1 / P_{t+s}\right)\left[P_{f, t}-P_{t+s}^{m}\right]\right] y_{f, t+s}
$$

where $y_{f, t}=\left(P_{f, t} / P_{t}\right)^{-\epsilon} y_{t}$ is the demand function. $y_{t}$ is the output of the final good producing firms, and $P_{t}$ the general price level. The expression for the demand function for the retail firms products will be derived in the next section. Since all the retail firms have access to the same technology, all the firms that are allowed to reset their prices will choose the same new price $\left(P_{t}^{*}\right)$ for their goods. We remember that the relative price $m_{t}$ is equal to $m_{t}=P_{t}^{m} / P_{t}$. Differentiation with respect to $P_{f, t}$ gives the first order condition for the price the retail firms will charge for their products:

$$
\frac{P_{t}^{*}}{P_{t}}=\frac{\epsilon}{\epsilon-1} \frac{E_{t} \sum_{s=0}^{\infty}(\beta \psi)^{s} \lambda_{t+s} P_{t+s}^{\epsilon} P_{t}^{-\epsilon} m_{t+s} y_{t+s}}{E_{t} \sum_{s=0}^{\infty}(\beta \psi)^{s} \lambda_{t+s} P_{t+s}^{\epsilon-1} P_{t}^{1-\epsilon} y_{t+s}}
$$

We define the relative price of the firms that are allowed to reset their prices to be equal to $\pi_{t}^{*}=P_{t}^{*} / P_{t}$, while gross inflation is defined to be equal to $\pi_{t}=P_{t} / P_{t-1}$. The above first order 
condition can now be rewritten in the following form:

$$
\begin{aligned}
\pi_{t}^{*} & =\frac{\epsilon}{\epsilon-1} \frac{\Xi_{1, t}}{\Xi_{2, t}} \\
\Xi_{1, t} & =\lambda_{t} m_{t} y_{t}+\beta \psi E_{t} \pi_{t+1}^{\epsilon} \Xi_{1, t+1} \\
\Xi_{2, t} & =\lambda_{t} y_{t}+\beta \psi E_{t} \pi_{t+1}^{\epsilon-1} \Xi_{2, t+1}
\end{aligned}
$$

The aggregate price level equals:

$$
P_{t}^{1-\epsilon}=(1-\psi)\left(P_{t}^{*}\right)^{1-\epsilon}+\psi P_{t-1}^{1-\epsilon}
$$

The aggregate price level will be given by the following law of motion:

$$
(1-\psi)\left(\pi_{t}^{*}\right)^{1-\epsilon}+\psi \pi_{t}^{\epsilon-1}=1
$$

\section{C.5.4 Final Good Producers}

The final good firms purchase intermediate goods which have been repackaged by the retail firms in order to produce the final good. The technology that is applied in producing the final good is given by $y_{t}^{(\epsilon-1) / \epsilon}=\int_{0}^{1} y_{f, t}^{(\epsilon-1) / \epsilon} d f$, where $y_{f, t}$ is the output of the retail firm indexed by $f . \epsilon$ is the elasticity of substitution between the intermediate goods purchased from the different retail firms. We assume that the final good firms operate in an environment of perfect competition, and hence they maximize profits by choosing $y_{f, t}$ such that $P_{t} y_{t}-\int_{0}^{1} P_{f, t} y_{f, t} d f$ is maximized. The final good producer takes $P_{t}$ and $P_{f, t}$ as given. Taking the first order conditions with respect to $y_{f, t}$ gives the demand function of the final good producers for the retail goods. Substitution of the demand function into the technology constraint gives the relation between the price level of the final good and the price level of the individual retail firms:

$$
\begin{aligned}
y_{f, t} & =\left(P_{f, t} / P_{t}\right)^{-\epsilon} y_{t} \\
P_{t}^{1-\epsilon} & =\int_{0}^{1} P_{f, t}^{1-\epsilon} d f
\end{aligned}
$$

\section{C.6 Labor Market}

\section{C.6.1 Labor Agencies}

Labor Agencies operate in the economy to combine differentiated labor $h_{t}(i)$ provided by household $i$. The technology to combine the differentiated labor supplied by the individual households has a constant elasticity of substitution $\epsilon_{w}$, and is given by:

$$
h_{t}=\left[\int_{0}^{1} h_{t}(i)^{\frac{\epsilon_{w}-1}{\epsilon_{w}}} d i\right]^{\frac{\epsilon_{w}}{\epsilon_{w}-1}}
$$


The representative labor agency that combines the different labor-types into a homogenous aggregate labor supply takes the nominal aggregate wage $W_{t}$, and the nominal wage rate $W_{t}(i)$ of labor type $i$, as well as the aggregate labor demand $h_{t}$ as given, and maximizes profits by adjusting his/her demand for labor $h_{t}(i)$ of type $i$, subject to the labor technology 143:

$$
\max _{\left\{h_{t}(i)\right\}} W_{t} h_{t}-\int_{0}^{1} W_{t}(i) h_{t}(i) d i
$$

where $W_{t}$ denotes the wage index and $W_{t}(i)$ the wage rate for the type $i$ labor input. The maximization problem of the labor agency results in the following first order condition for the demand of the labor agency for labor of type $i$ :

$$
h_{t}(i)=\left(\frac{W_{t}(i)}{W_{t}}\right)^{-\epsilon_{w}} h_{t} .
$$

Substitution of the labor demand curve 145 into the labor technology 143 provides us with the aggregate wage-index $W_{t}$ :

$$
\left(W_{t}\right)^{1-\epsilon_{w}}=\int_{0}^{1} W_{t}(i)^{1-\epsilon_{w}} d i
$$

\section{C.6.2 Household Wage Decision}

With regards to the labor supply, households face a perfectly competititve monopolistic labor market. The household that provides labor of type $i$ is the sole provider of that type of labor, and can therefore charge a markup. However, for a given wage rate $W_{t}(i)$ the household of type $i$ provides as much labor as demanded by the labor agency.

When setting the nominal wage rate $W_{t}(i)$, the household takes into account that there is an exogenous probability of $\psi_{w}$ that it is not allowed to change the nominal wage rate next period, while it is allowed to change with probability $1-\psi_{w}$. Not being allowed to change wages does not imply that there is no change at all. The household, however, is only allowed to partially index the wage with the previous period wage adjustment $\omega_{t}^{a d j}$. In setting the nominal wage rate $\tilde{W}_{t}(i)$ when allowed to change, the household weighs off the effects on total wage income, and the anticipated effect on the disutility from providing labor. This results in the following optimization problem for the household in setting the optimal nominal wage rate $\tilde{W}_{t}(i)$ :

$$
\max _{\left\{\tilde{W}_{t}(i)\right\}} E_{t}\left\{\sum_{s=0}^{\infty}\left(\beta \psi_{w}\right)\left[\lambda_{t+s} \frac{\tilde{W}_{t}(i)\left(\Pi_{j=1}^{j=s} \omega_{t+j}^{a d j}\right)}{P_{t+s}} h_{t+s}(i)-\chi \frac{h_{t+s}(i)^{1+\varphi}}{1+\varphi}\right]\right\},
$$

where $\lambda_{t+s}$ is the marginal utility of consumption for household $i$, with which the household discounts the future real wage income $\frac{\tilde{W}_{t}(i)\left(\Pi_{j=1}^{j=s} \omega_{t+j}^{a d j}\right)}{P_{t+s}} h_{t+s}(i)$. As the household is the monopolistic supplier of labor of type $i$, it takes the labor demand schedule 145 into account when setting 
the new nominal wage rate $\tilde{W}_{t}(i)$. Now we substitute 145 into the household's optimization problem, formulated in the following way to capture the case when household $i$ cannot change the nominal wage rate for $s$ periods:

$$
W_{t+s}(i)=\left(\frac{\tilde{W}_{t}(i)\left(\Pi_{j=1}^{j=s} \omega_{t+j}^{a d j}\right)}{W_{t+s}}\right)^{-\epsilon_{w}} h_{t+s}
$$

This results in the following reformulation of the household's problem:

$$
\begin{aligned}
& \max _{\left\{\tilde{W}_{t}(i)\right\}} E_{t} {\left[\sum_{s=0}^{\infty}\left(\beta \psi_{w}\right)^{s} \lambda_{t+s} \frac{\tilde{W}_{t}(i)\left(\Pi_{j=1}^{j=s} \omega_{t+j}^{a d j}\right)}{P_{t+s}}\left(\frac{\tilde{W}_{t}(i)\left(\Pi_{j=1}^{j=s} \omega_{t+j}^{a d j}\right)}{W_{t+s}}\right)^{-\epsilon_{w}} h_{t+s}\right] } \\
&- E_{t}\left[\sum_{s=0}^{\infty}\left(\beta \psi_{w}\right)^{s} \chi \frac{\left.\left(\left(\frac{\tilde{W}_{t}(i)\left(\Pi_{j=1}^{j=s} \omega_{t+j}^{a d j}\right)}{W_{t+s}}\right)^{-\epsilon_{w}} h_{t+s}\right)^{1+\varphi}\right]}{1+\varphi}\right]= \\
&=\max _{\left\{\tilde{W}_{t}(i)\right\}} E_{t}\left[\sum_{s=0}^{\infty}\left(\beta \psi_{w}\right)^{s} \lambda_{t+s} \frac{\left(\Pi_{j=1}^{j=s} \omega_{t+j}^{a d j}\right)^{1-\epsilon_{w}} h_{t+s}}{\left.P_{t+s} W_{t+s}^{-\epsilon_{w}} \tilde{W}_{t}(i)^{1-\epsilon_{w}}\right]}\right] \\
&-E_{t}\left[\sum_{s=0}^{\infty}\left(\beta \psi_{w}\right)^{s} \chi \frac{\left(\left(\frac{\left(\Pi_{j=1}^{j=s} \omega_{t+j}^{a d j}\right)}{W_{t+s}}\right)^{-\epsilon_{w}} h_{t+s}\right)^{1+\varphi}}{1+\varphi} \tilde{W}_{t}(i)^{-\epsilon_{w}(1+\varphi)}\right]
\end{aligned}
$$

Differentiation with respect to $\tilde{W}_{t}(i)$ gives the following first order condition:

$$
\begin{aligned}
E_{t} & {\left[\sum_{s=0}^{\infty}\left(\beta \psi_{w}\right)^{s} \lambda_{t+s} \frac{\left(\Pi_{j=1}^{j=s} \omega_{t+j}^{a d j}\right)^{1-\epsilon_{w}} h_{t+s}}{P_{t+s} W_{t+s}^{-\epsilon_{w}}}\left(1-\epsilon_{w}\right) \tilde{W}_{t}(i)^{-\epsilon_{w}}\right] } \\
-E_{t} & {\left[\sum_{s=0}^{\infty}\left(\beta \psi_{w}\right)^{s} \chi \frac{\left(\left(\frac{\left(\Pi_{j=1}^{j=s} \omega_{t+j}^{a d j}\right)}{W_{t+s}}\right)^{-\epsilon_{w}} h_{t+s}\right)^{1+\varphi}}{1+\varphi}\left(-\epsilon_{w}\right)(1+\varphi) \tilde{W}_{t}(i)^{-\epsilon_{w}(1+\varphi)-1}\right]=0 . }
\end{aligned}
$$


Or alternatively:

$$
\begin{aligned}
& \left(\epsilon_{w}-1\right) \tilde{W}_{t}(i)^{-\epsilon_{w}} E_{t}\left[\sum_{s=0}^{\infty}\left(\beta \psi_{w}\right)^{s} \lambda_{t+s} \frac{\left(\Pi_{j=1}^{j=s} \omega_{t+j}^{a d j}\right)^{1-\epsilon_{w}} h_{t+s}}{P_{t+s} W_{t+s}^{-\epsilon_{w}}}\right] \\
= & \epsilon_{w}(1+\varphi) \tilde{W}_{t}(i)^{-\epsilon_{w}(1+\varphi)-1} E_{t}\left[\sum_{s=0}^{\infty}\left(\beta \psi_{w}\right)^{s} \chi \frac{\left(\left(\frac{\left(\Pi_{j=1}^{j=s} \omega_{t+j}^{a d j}\right)}{W_{t+s}}\right)^{-\epsilon_{w}} h_{t+s}\right)^{1+\varphi}}{1+\varphi}\right] .
\end{aligned}
$$

Rewriting the last expression:

$$
\tilde{W}_{t}^{-\epsilon_{w}+\epsilon_{w}(1+\varphi)+1}=\left(\frac{\epsilon_{w}(1+\varphi)}{\epsilon_{w}-1}\right) \frac{E_{t}\left[\sum_{s=0}^{\infty}\left(\beta \psi_{w}\right)^{s} \chi \frac{\left(\left(\frac{\left(\Pi_{j=1}^{j=1} \omega_{t+j}^{a d j}\right)}{W_{t+s}}\right)^{-\epsilon_{w}} h_{t+s}\right)^{1+\varphi}}{1+\varphi}\right]}{E_{t}\left[\sum_{s=0}^{\infty}\left(\beta \psi_{w}\right)^{s} \lambda_{t+s} \frac{\left(\Pi_{j=1}^{j=s} \omega_{t+j}^{a d j}\right)^{1-\epsilon_{w}} h_{t+s}}{P_{t+s} W_{t+s}^{-\epsilon_{w}}}\right]} .(152)
$$


Or equivalently:

$$
\begin{aligned}
\tilde{W}_{t}^{1+\epsilon_{w} \varphi}= & \left(\frac{\epsilon_{w}}{\epsilon_{w}-1}\right) \frac{E_{t}\left[\sum_{s=0}^{\infty}\left(\beta \psi_{w}\right)^{s} \chi\left(\left(\frac{\left(\Pi_{j=1}^{j=s} \omega_{t+j}^{a d j}\right)}{W_{t+s}}\right)^{-\epsilon_{w}} h_{t+s}\right)^{1+\varphi}\right]}{E_{t}\left[\sum_{s=0}^{\infty}\left(\beta \psi_{w}\right)^{s} \lambda_{t+s} \frac{\left(\Pi_{j=1}^{j=s} \omega_{t+j}^{a d j}\right)^{1-\epsilon_{w}}}{P_{t+s} W_{t+s}^{-\epsilon}} h_{t+s}\right]} \\
= & \left(\frac{\epsilon_{w}}{\epsilon_{w}-1}\right) \frac{E_{t}\left[\sum_{s=0}^{\infty}\left(\beta \psi_{w}\right)^{s} \chi\left(W_{t}^{\epsilon_{w}}\left(\frac{W_{t}\left(\Pi_{j=1}^{j=s} \omega_{t+j}^{a d j}\right)}{W_{t+s}}\right)^{-\epsilon_{w}} h_{t+s}\right)^{1+\varphi}\right]}{E_{t}\left[\sum_{s=0}^{\infty}\left(\beta \psi_{w}\right)^{s} \lambda_{t+s} \frac{W_{t+s}}{P_{t+s}}\left(\Pi_{j=1}^{j=s} \omega_{t+j}^{a d j}\right)^{1-\epsilon_{w}} W_{t+s}^{\epsilon_{w}-1} h_{t+s}\right]} \\
= & \left(\frac{\epsilon_{w}}{\epsilon_{w}-1}\right) \frac{E_{t}\left[\sum_{s=0}^{\infty}\left(\beta \psi_{w}\right)^{s} \chi\left(W_{t}^{\epsilon_{w}}\left(\frac{W_{t}}{W_{t+s}}\right)^{-\epsilon_{w}}\left(\Pi_{j=1}^{j=s} \omega_{t+j}^{a d j}\right)^{-\epsilon_{w}} h_{t+s}\right)^{1+\varphi}\right]}{E_{t}\left[\sum_{s=0}^{\infty}\left(\beta \psi_{w}\right)^{s} \lambda_{t+s} w_{t+s} W_{t}^{\epsilon_{w}-1}\left(\frac{W_{t}}{W_{t+s}}\right)^{1-\epsilon_{w}}\left(\Pi_{j=1}^{j=s} \omega_{t+j}^{a d j}\right)^{1-\epsilon_{w}} h_{t+s}\right]} \\
= & \left(\frac{\epsilon_{w}}{\epsilon_{w}-1}\right)\left(\frac{W_{t}^{\epsilon_{w}(1+\varphi)}}{W_{t}^{\epsilon_{w}-1}}\right) \frac{E_{t}\left[\sum_{s=0}^{\infty}\left(\beta \psi_{w}\right)^{s} \chi\left(\left(\frac{W_{t+s}}{W_{t}}\right)^{\epsilon_{w}}\left(\Pi_{j=1}^{j=s} \omega_{t+j}^{a d j}\right)^{-\epsilon_{w}} h_{t+s}\right)^{1+\varphi}\right]}{E_{t}\left[\sum_{s=0}^{\infty}\left(\beta \psi_{w}\right)^{s} \lambda_{t+s} w_{t+s}\left(\frac{W_{t+s}}{W_{t}}\right)^{\epsilon_{w}-1}\left(\Pi_{j=1}^{j=s} \omega_{t+j}^{a d j}\right)^{1-\epsilon_{w}} h_{t+s}\right]} \\
= & \left(\frac{\epsilon_{w}}{\epsilon_{w}-1}\right) W_{t}^{1+\epsilon_{w} \varphi} \frac{E_{t}\left\{\sum_{s=0}^{\infty}\left(\beta \psi_{w}\right)^{s} \chi\left[\left(\Pi_{j=1}^{j=s} \omega_{t+j}\right)^{\epsilon_{w}}\left(\Pi_{j=1}^{j=s} \omega_{t+j}^{a d j}\right)^{-\epsilon_{w}} h_{t+s}\right]\right.}{E_{t}\left[\sum_{s=0}^{\infty}\left(\beta \psi_{w}\right)^{s} \lambda_{t+s} w_{t+s}\left(\Pi_{j=1}^{j=s} \omega_{t+j}\right)^{\epsilon_{w}-1}\left(\Pi_{j=1}^{j=s} \omega_{t+j}^{a d j}\right)^{1-\epsilon_{w}} h_{t+s}\right]},
\end{aligned}
$$

where $\omega_{t+j}=W_{t+j} / W_{t-1+j}$ is the rate of gross nominal wage inflation from period $t-1+j$ to period $t+j$, and $w_{t+j}=W_{t+j} / P_{t+j}$ is the real wage in terms of the CPI. This expression can be rewritten in the following way:

$$
\left(\frac{\tilde{W}_{t}}{W_{t}}\right)^{1+\epsilon_{w} \varphi}=\left(\frac{\epsilon_{w}}{\epsilon_{w}-1}\right) \frac{E_{t}\left\{\sum_{s=0}^{\infty}\left(\beta \psi_{w}\right)^{s} \chi\left[\left(\Pi_{j=1}^{j=s} \omega_{t+j}\right)^{\epsilon_{w}}\left(\Pi_{j=1}^{j=s} \omega_{t+j}^{a d j}\right)^{-\epsilon_{w}} h_{t+s}\right]^{1+\varphi}\right\}}{E_{t}\left[\sum_{s=0}^{\infty}\left(\beta \psi_{w}\right)^{s} \lambda_{t+s} w_{t+s}\left(\Pi_{j=1}^{j=s} \omega_{t+j}\right)^{\epsilon_{w}-1}\left(\Pi_{j=1}^{j=s} \omega_{t+j}^{a d j}\right)^{1-\epsilon_{w}} h_{t+s}\right]},
$$

Defining the relative wage of the households that are allowed to change wages as $\omega_{t}^{\text {new }}=\tilde{W}_{t} / W_{t}$, we can write this recursively in the following way:

$$
\left(\omega_{t}^{n e w}\right)^{1+\epsilon_{w} \varphi}=\left(\frac{\chi \epsilon_{w}}{\epsilon_{w}-1}\right) \frac{\Xi_{1, t}^{w}}{\Xi_{2, t}^{w}},
$$


where $\Xi_{1, t}^{w}$ and $\Xi_{2, t}^{w}$ are given by:

$$
\begin{aligned}
& \Xi_{1, t}^{w}=h_{t}^{1+\varphi}+E_{t}\left[\beta \psi_{w}\left(\omega_{t+1}\right)^{\epsilon_{w}(1+\varphi)}\left(\omega_{t+1}^{a d j}\right)^{-\epsilon_{w}(1+\varphi)} \Xi_{1, t+1}^{w}\right], \\
& \Xi_{2, t}^{w}=\lambda_{t} w_{t} h_{t}+E_{t}\left[\beta \psi_{w}\left(\omega_{t+1}\right)^{\epsilon_{w}-1}\left(\omega_{t+1}^{a d j}\right)^{1-\epsilon_{w}} \Xi_{2, t+1}^{w}\right] .
\end{aligned}
$$

Now we look at the aggregate wage index in the economy:

$$
W_{t}^{1-\epsilon_{w}}=\int_{0}^{1} W_{t}^{1-\epsilon_{w}} d i=\left(1-\psi_{w}\right) \tilde{W}_{t}^{1-\epsilon_{w}}+\psi_{w}\left(\omega_{t}^{a d j} W_{t-1}\right)^{1-\epsilon_{w}}
$$

Division by $W_{t}^{1-\epsilon_{w}}$ gives the following expression:

$$
\begin{aligned}
1 & =\left(1-\psi_{w}\right)\left(\frac{\tilde{W}_{t}}{W_{t}}\right)^{1-\epsilon_{w}}+\psi_{w}\left(\omega_{t}^{a d j}\right)^{1-\epsilon_{w}}\left(\frac{W_{t-1}}{W_{t}}\right)^{1-\epsilon_{w}} \\
& =\left(1-\psi_{w}\right)\left(\omega_{t}^{\text {new }}\right)^{1-\epsilon_{w}}+\psi_{w}\left(\omega_{t}^{a d j}\right)^{1-\epsilon_{w}}\left(\omega_{t}\right)^{\epsilon_{w}-1}
\end{aligned}
$$

Finally, we introduce the wage-dispersion parameter $\mathcal{D}_{t}^{w}$ :

$$
\begin{aligned}
\mathcal{D}_{t}^{w} & =\int_{0}^{1}\left(\frac{W_{t}(i)}{W_{t}}\right)^{-\epsilon_{w}} d i=\left(1-\psi_{w}\right)\left(\frac{\tilde{W}_{t}}{W_{t}}\right)^{-\epsilon_{w}}+\psi_{w} \int_{0}^{1}\left(\frac{\omega_{t}^{a d j} W_{t-1}(i)}{W_{t}}\right)^{-\epsilon_{w}} d i \\
& =\left(1-\psi_{w}\right)\left(\frac{\tilde{W}_{t}}{W_{t}}\right)^{-\epsilon_{w}}+\psi_{w}\left(\omega_{t}^{a d j}\right)^{-\epsilon_{w}}\left(\frac{W_{t-1}}{W_{t}}\right)^{-\epsilon_{w}} \int_{0}^{1}\left(\frac{W_{t-1}(i)}{W_{t-1}}\right)^{-\epsilon_{w}} d i \\
& =\left(1-\psi_{w}\right)\left(\omega_{t}^{n e w}\right)^{-\epsilon_{w}}+\psi_{w}\left(\omega_{t}^{a d j}\right)^{-\epsilon_{w}}\left(\omega_{t}\right)^{\epsilon_{w}} \mathcal{D}_{t-1}^{w}
\end{aligned}
$$

\section{C.6.3 Aggregation}

First recall that $y_{i, t}=y_{f, t}=y_{t}\left(P_{f, t} / P_{t}\right)^{-\epsilon}$, for all $f$ and $i$. Hence we can write the factor demands by firm $i$ as:

$$
h_{i, t}=(1-\alpha) m_{t} y_{f, t} / w_{t}, \quad k_{i, t-1}=\alpha m_{t} y_{f, t} /\left[q_{t-1}^{k}\left(1+r_{t}^{k}\right)-q_{t}^{k}(1-\delta)\right]
$$

Aggregation over all firms $i$ gives us aggregate labor and capital:

$$
h_{t}=(1-\alpha) m_{t} y_{t} \mathcal{D}_{t} / w_{t}, \quad k_{t-1}=\alpha m_{t} y_{t} \mathcal{D}_{t} /\left[q_{t-1}^{k}\left(1+r_{t}^{k}\right)-q_{t}^{k}(1-\delta)\right]
$$

where $\mathcal{D}_{t}=\int_{0}^{1}\left(P_{f, t} / P_{t}\right)^{-\epsilon} d f$ denotes the price dispersion. It is given by the following recursive form:

$$
\mathcal{D}_{t}=(1-\psi)\left(\pi_{t}^{*}\right)^{-\epsilon}+\psi \pi_{t}^{\epsilon} \mathcal{D}_{t-1}
$$


Now we calculate the aggregate capital-labor ratio, and see that it is equal to the individual capital-labor ratio:

$$
k_{t-1} / h_{t}=\alpha(1-\alpha)^{-1} w_{t} /\left[q_{t-1}^{k}\left(1+r_{t}^{k}\right)-q_{t}^{k}(1-\delta)\right]=k_{i, t-1} / h_{i, t}
$$

Calculate aggregate supply by aggregating $y_{i, t}=a_{t} k_{i, t-1}^{\alpha} h_{i, t}^{1-\alpha}$ :

$$
\int_{0}^{1} a_{t} k_{i, t-1}^{\alpha} h_{i, t}^{1-\alpha} d i=a_{t}\left(\frac{k_{t-1}}{h_{t}}\right)^{\alpha} \int_{0}^{1} h_{i, t} d i=a_{t} k_{t-1}^{\alpha} h_{t}^{1-\alpha}
$$

while aggregation over $y_{i, t}$ gives:

$$
\int_{0}^{1} y_{i, t} d f=y_{t} \int_{0}^{1}\left(P_{f, t} / P_{t}\right)^{-\epsilon} d f=y_{t} \mathcal{D}_{t}
$$

Hence we get the following relation for aggregate supply $y_{t}$ :

$$
y_{t} \mathcal{D}_{t}=a_{t} k_{t-1}^{\alpha} h_{t}^{1-\alpha}
$$

\section{Calibration \& Bayesian estimation}

\section{D.1 Calibration}

To match the Spanish economy as closely as possible, we take the posterior mean of several parameters from Burriel et al. (2010), who perform a Bayesian estimation with Spanish data. These variables are the subjective discount factor $\beta$, the degree of habit formation $v$, the inverse Frisch elasticity $\varphi$, the effective capital share $\alpha$, the elasticity of substitution for goods and labor, respectively $\epsilon$ and $\epsilon_{w}$, Calvo probability for goods and labor, respectively $\psi$ and $\psi_{w}$, the degree of price-indexation $\gamma_{P}$ and wage-indexation $\gamma_{W}$, and the inflation coefficient $\kappa_{\pi}$ and the output coefficient $\kappa_{y}$ of the Taylor rule. We set the interest rate smoothing parameter $\rho_{r}$ to 0.8 , and the standard deviation of a monetary policy shock $\sigma_{r}$ to 25 basis points, which are both standard values in the New-Keynesian literature. As mentioned before, we perform robustness checks in the appendix to make sure that these values do not drive our results.

The average lifetime of bankers is set to 24 quarters, which results in a survival rate $\theta$ of 0.9583. We calibrate the maturity structure of Spanish government debt to reflect the weighted average maturity between 1998 and 2008, which is approximately 25 quarters according to the OECD Stats database. The annual fixed cash flow payment $x_{c}$ is set to $4.1 \%$, which is the average interest rate on 10 year Spanish government bonds in 1998-2008 period according to the Statistical Data Warehouse of the European Central Bank (2016)

Several steady state targets can be found in Table 1. We retrieve the steady state ratio of investment, government consumption and government debt over GDP from Eurostat (2014). Steady state investment over GDP is computed as the average ratio of private investment over 
GDP in the 1994-2008 period, which is equal to $22.6 \%$. Similarly, we find the average ratio of government consumption over GDP over the same period to be $17.8 \%$. The steady state spread $\Gamma_{k}$ is found by taking the difference between the loans to non-financial corporations ("Total"), and the deposit rate on "Household deposits redeemable at notice, Total, New Business" over the 2003-2007 period. Loan rates are not available before 2003, while we end the sample after 2007 to exclude the Great Recession period. We find an average annual credit spread of 188 basis points, or equivalently, a quarterly steady state credit spread of 47 basis points.

We set the ratio of the diversion rate for government bonds over the diversion rate of private loans $\lambda_{t}^{b} / \lambda_{t}^{k}$ equal to 0.5 in all periods, as in Gertler and Karadi (2013). To make sure that our results are not driven by this particular choice, we perform robustness checks in the appendix for several other values of $\lambda_{t}^{b} / \lambda_{t}^{k}=\bar{\lambda}^{b} / \bar{\lambda}^{k}$.

We compute the average ratio of consolidated financial assets over consolidated equity for the Spanish financial sector between 2001 and 2008 from the OECD Stats database as a proxy for the steady state leverage ratio. This ratio is equal to 5.1, and is close to the value used by Gertler and Karadi (2011). Although this value is rather low in the light of leverage ratios above 10 for several large commercial banks, we retain this value for the same reason as Gertler and Karadi (2013): the loans to the private sector are state-contingent in our setup, and thus more equity-like. Net worth of financial intermediaries will be more volatile everything else equal. A lower steady state leverage ratio compensates the higher volatility induced by our equity-like debt contracts. Our leverage ratio results in a sovereign debt exposure of $146 \%$ of net worth, which is close to the number in Figure 2 .

We set the steady state ratio of government debt to annual output equal to $80 \%$, or $320 \%$ of quarterly output. We set the haircut parameter $\vartheta$ equal to 0.5 following Corsetti et al. (2013). Regarding the calibration of the default probability function [21], we apply the following targets: we set $\bar{b}_{\max }$ equal to $60 \%$ of annual output, in line with the Maastricht criterium. Note, however, that $\bar{b}_{\text {max }}$ does not coincide with the maximum level of debt, which is drawn each period from the default probability function! To find the parameters $\alpha_{b}$ and $\beta_{b}$, we use the following targets: we set the steady state default probability equal to $\bar{p}_{d e f}=0.0050$, which implies a $2 \%$ annual default probability. This value is in line with 5-year CDS spreads on Spanish government bonds at the end of 2010. We also target the first derivative of the default probability function 21. with respect to government bonds $b_{t}$, and set it equal to 0.2 in the steady state. This results in a spread of 100 basis points (annually) between the steady state return on government bonds for the model version which includes long-term bonds and sovereign default risk on the one hand, and the steady state return on bonds for the model version without sovereign risk on the other hand. This difference is rather conservative when compared with a spread of 200 basis points between 10 year Spanish government bonds and 10 year German Bunds at the end of 2010. By setting these two targets, we find $\alpha_{b}=22.86$ and $\beta_{b}=18.90$.

Finally we choose $\rho_{\lambda_{k}}$ and $\sigma_{\lambda_{k}}$ for the $\operatorname{AR}(1)$ process that is driving the diversion rate $\lambda_{t}^{k}$. We calibrate these parameters to match the fall in Spanish quarterly output of $1 \%$ after December 
2010, and to have the shock die out after approximately 10 quarters. We then find $\rho_{\lambda_{k}}=0.7$ and $\sigma_{\lambda_{k}}=0.08$.

Table 4 shows the parameter values that were discussed in section 5.2 .

\begin{tabular}{|c|c|c|}
\hline Parameter & Definition & Value \\
\hline \multicolumn{3}{|l|}{ Households } \\
\hline$\beta$ & Subjective discount factor & 0.990 \\
\hline$v$ & Degree of habit formation & 0.847 \\
\hline$\Psi$ & Disutility weight of labour & 4.753 \\
\hline$\varphi$ & Inverse Frisch elasticity & 0.545 \\
\hline \multicolumn{3}{|c|}{ Financial Intermediaries } \\
\hline$\theta$ & Survival rate of bankers & 0.9583 \\
\hline $\bar{\lambda}_{k}$ & Steady state diversion rate private loans & 0.4419 \\
\hline $\bar{\lambda}_{b}$ & Steady state diversion rate domestic bonds & 0.2210 \\
\hline $\begin{array}{l}\chi \\
\text { Production }\end{array}$ & \multicolumn{2}{|c|}{ Production Sector } \\
\hline$\alpha$ & Effective capital share & 0.362 \\
\hline$\epsilon$ & Elasticity of substit. (goods) & 8.577 \\
\hline$\psi$ & Calvo prob. (price stickiness) & 0.800 \\
\hline \multicolumn{3}{|c|}{ Labor Sector } \\
\hline$\epsilon_{w}$ & Elasticity of substit. (labor) & 7.758 \\
\hline$\psi_{w}$ & Calvo prob. (wage stickiness) & 0.457 \\
\hline \multicolumn{3}{|c|}{ Policy Parameters } \\
\hline$\rho$ & Government debt maturity par. & 0.96 \\
\hline$x_{c}$ & Real payment to bondholder & 0.041 \\
\hline$\rho_{r}$ & Interst rate smoothing par. & 0.8 \\
\hline$\kappa_{y}$ & Output feedback on $r^{n}$ & 0.125 \\
\hline $\bar{\pi}$ & Inflation rate target & 1.005 \\
\hline \multicolumn{3}{|c|}{ AR(1) parameters } \\
\hline $\begin{array}{l}\sigma_{\lambda_{k}} \\
\text { Default par }\end{array}$ & Std. dev. diversion rate shock & 0.08 \\
\hline$\vartheta_{d e f}^{c f}$ & Cash flow haircut & 0.5 \\
\hline$\vartheta_{d e f}^{p}$ & Principal haircut & 0.5 \\
\hline$\alpha_{b}$ & First parameter beta-cdf & 22.86 \\
\hline$\beta_{b}$ & Second parameter beta-cdf & 18.90 \\
\hline
\end{tabular}

Table 4: List of calibrated parameter values and source of calibration.

\section{D.2 Prior and posterior distributions}

Figure 9 reports the prior and posterior marginal densities of the structural parameters of the model. The data suggest that the data is informative about most of the estimated parameters as the posterior distribution significantly differs from the prior distribution. The exception is the posterior distribution for the tax feedback parameter $\kappa_{b}$. However, this is not surprising given 

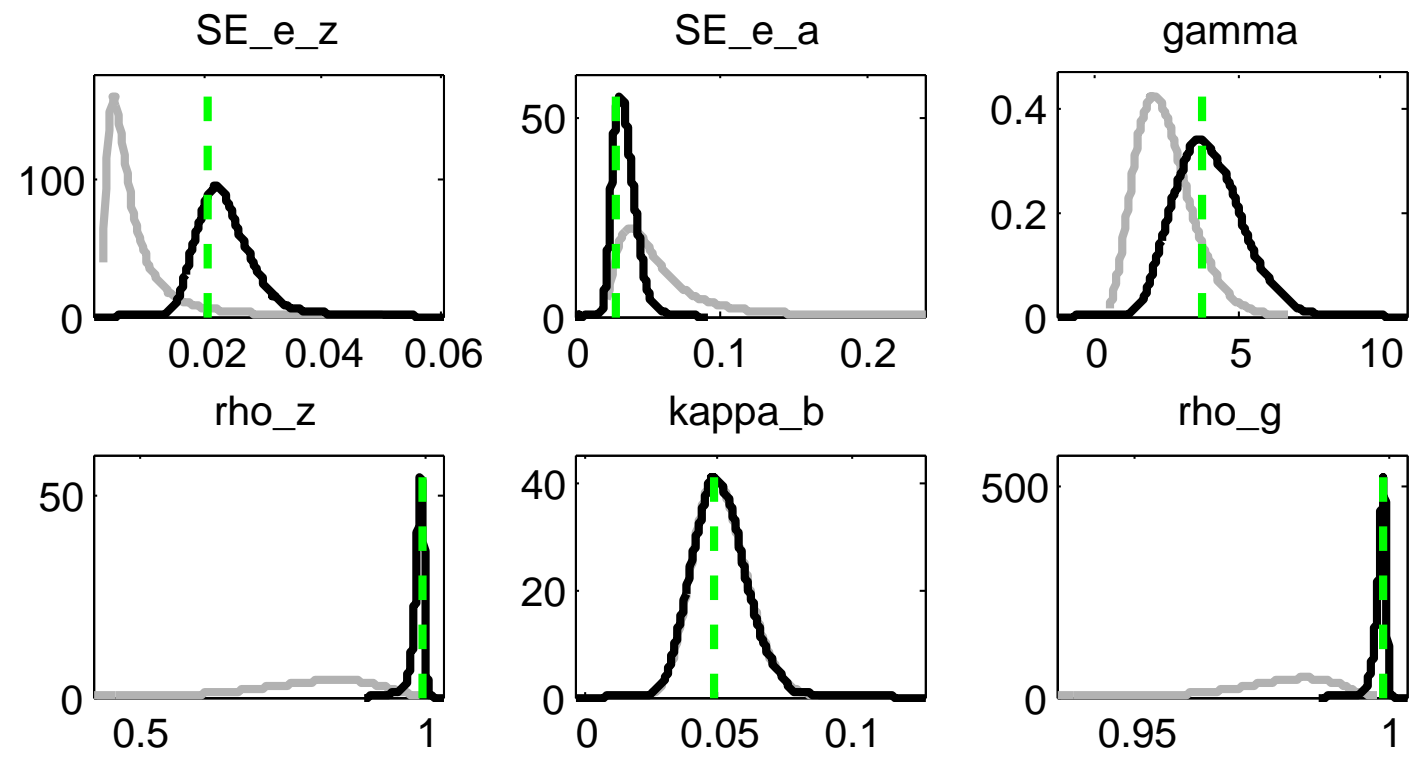

Figure 9: Prior and posterior marginal distributions. The grey/light solid line is the prior distribution, while the black/dark solid line is the posterior marginal distribution. The green slashed vertical bar is the mode of the The marginal posterior densities are based on 5 chains with 100,000 draws based on the Metropolis-Hastings algorithm. "SE_e_z" denotes the standard deviation of productivity $\sigma_{z}$, "SE_e_a" denotes the standard deviation of government spending $\sigma_{g}$, "gamma" denotes the investment adjustment costs parameter $\gamma$, "rho_z" the AR(1) coefficient for productivity $\rho_{z}$, "kappa_b" the debt feedback parameter on taxes $\kappa_{b}$ and "rho_g" the AR(1) coefficient for government spending $\rho_{g}$.

the fact that we took the posterior mean and standard deviation from Burriel et al. (2010).

Figure 10 reports the multivariate MCMC diagnostics as constructed by Brooks and Gelman (1998). The red line is the so-called within variance, and is an average of the variance of the different chains. Good convergence requires the within variance to settle down, become constant. We see that this is the case in Figure 10, although the red line is on an upward trend at the end of the sample for the first order moment.

The blue line is the so-called between variance, which consists of the empirical between variance and within variance. The between variance is a measure of the variance of the mean, and should go to zero as the length of the chain goes to infinity. This implies that the red and the blue line should converge.

Summarizing, the Brooks and Gelman (1998) convergence criteria imply that the red line should become flat, and the blue line should approximate the red line. This seems to be the case, except at the end of the chain for the first order moment, which shows a small upward trend. However, we believe we can conclude that the convergence properties have been satisfied. 
Brooks-Gelman convergens criterion
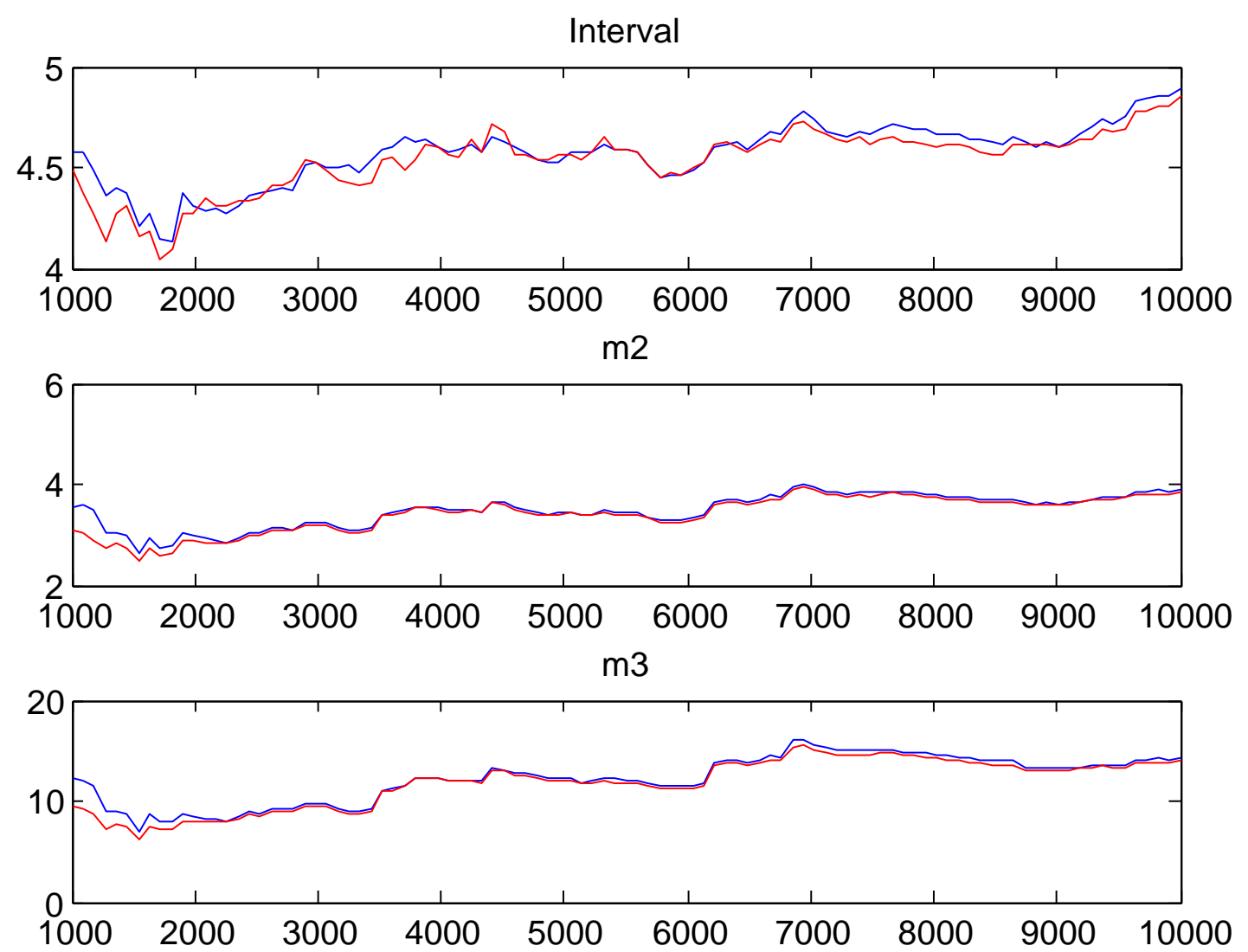

Figure 10: The Brooks and Gelman (1998) convergence criteria are displayed. The red line is the so-called within variance, while the blue line is the so-called between variance, see also the text. 


\section{D.3 Data sources}

Output: Quarterly GDP at market prices, seasonally and calendar adjusted, chain linked volumes (2010) in million euros from Eurostat. We take the natural logarithm and find the cyclical component by applying the HP filter with a smoothing parameter of 1600 .

Consumption: Quarterly Consumption of households and nonprofit institutions serving households (NPISH) at market prices, seasonally and calendar adjusted, chain linked volumes (2010) in million euros from Eurostat. We take the natural logarithm and find the cyclical component by applying the HP filter with a smoothing parameter of 1600 .

Credit spread: The timeseries for the credit spread was explained in section 5.2 , which comes from the ECB website. The quarterly timeseries are obtained by taking an unweighted average of the monthly data. We find the cyclical component by applying the HP filter with a smoothing parameter of 1600 .

\section{E Robustness}

In this section we report some alternative simulations. These are intended to show that the results we obtain do not depend upon the particular parameter values chosen. We will first show the results for a simulation where we change the relative diversion ratio $\bar{\lambda}_{b} / \bar{\lambda}_{k}$ from 0.5 to 2 in Figure 11 and 12. This implies that bankers can divert a larger fraction of government bonds than private loans, contrary to the assumption in the main text of the paper. The discounted cumulative multiplier is $\mu_{D}=0.08$, which is slightly hgiher than the $\mu_{D}=-0.02$ of the main text, but still very close to it.

Our second experiment is to show in Figure 13 and 14 , and Table ?? that our results still hold for a larger $\bar{b}_{\max }$. The discounted cumulative multiplier $\mu_{D}=0.03$, which is close to the value in the main text.

Third, we look at alternative monetary policies. As mentioned in the main text of the paper, a domestic central bank that follows a Taylor rule is not necessarily a realistic description of the monetary policy that is set by the ECB. We vary monetary policy along several dimensions. First we play around with the interest rate smoothing parameter $\rho_{r}$ in Figure 15 and 16 . We find that the multiplier $\mu_{D}=0.09$.

A summary of the results for the different robustness checks can be found in Table 5 , where we list the discounted cumulative multiplier $\mu_{D}$ for the cases mentioned above. We find in all cases that $\mu_{D}$ stays very close to zero, as in the main text. This implies that our result that the effectiveness of a fiscal stimulus in the presence of weakly capitalized banks with a large exposure to risky sovereign debt is robust against variations of several important model parameters. 


\begin{tabular}{|l|l|}
\hline Stimulus policy & $\mu_{D}$ \\
\hline \hline $\bar{\lambda}_{b} / \bar{\lambda}_{k}=2$ & 0.08 \\
\hline$b_{\max }=2.8$ & 0.03 \\
\hline$\rho_{r}=0.4$ & 0.09 \\
\hline
\end{tabular}

Table 5: Table displaying the discounted cumulative multiplier $\mu_{D}$ for a debt-financed fiscal stimulus of $5 \%$ of quarterly output when sovereign debt is long term and subject to default risk for alternative parameter specifications. 
Relative diversion rate $\bar{\lambda}_{b} / \bar{\lambda}_{k}=2$
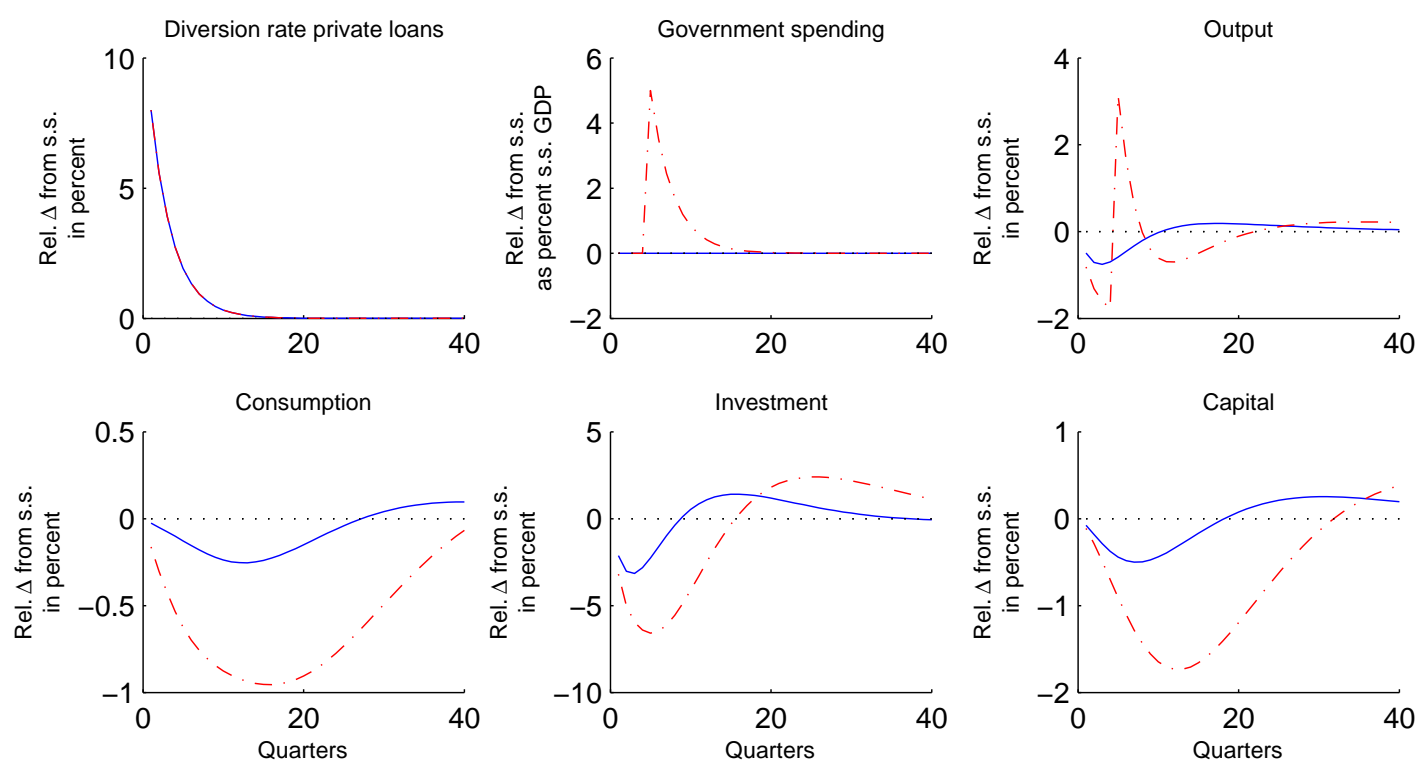

(a)
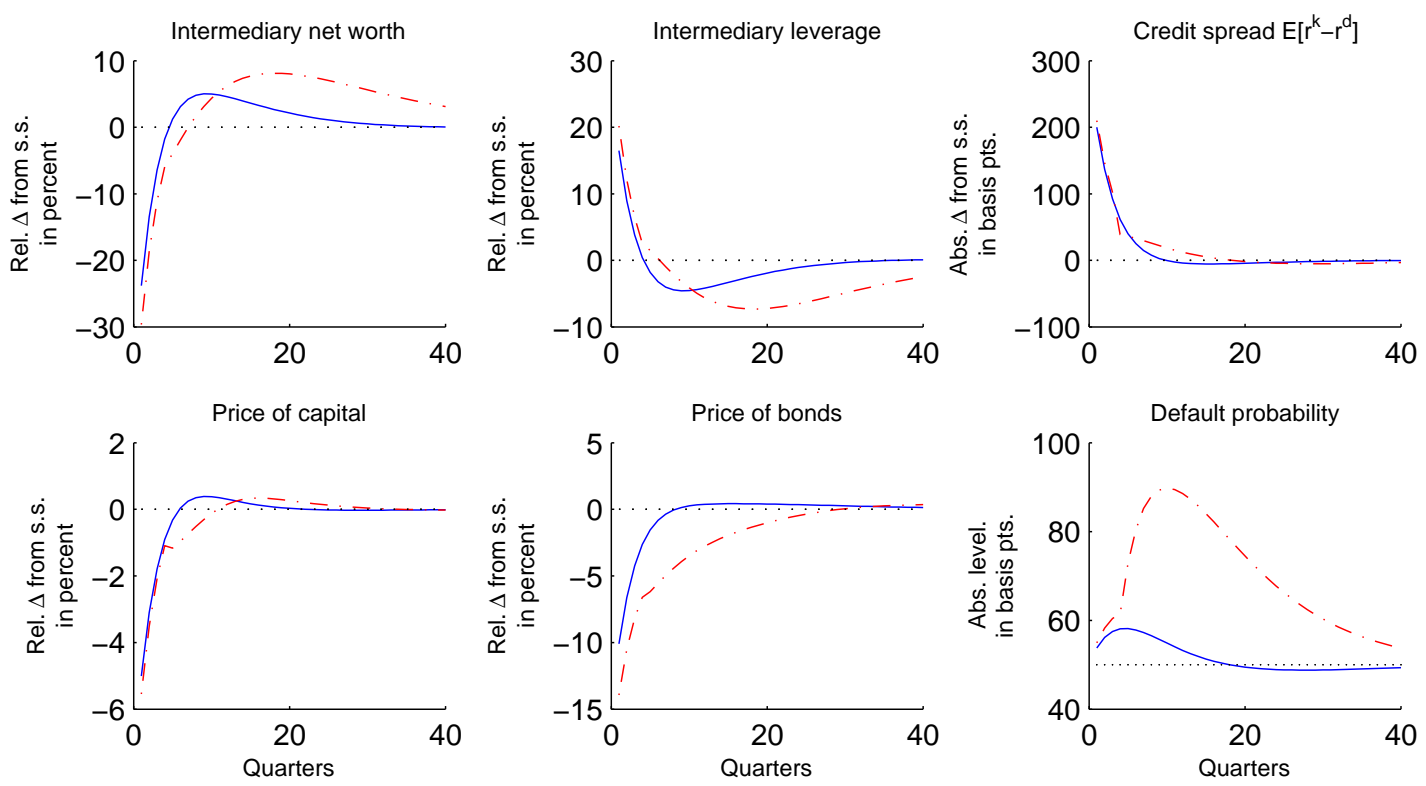

(b)

Figure 11: Plot of the impulse response functions comparing no additional policy (blue, solid) and fiscal stimulus (red, slotted). The stimulus is announced as the crisis hits, and implemented 4 quarters later through additional debt issuance, and equal to $1.25 \%$ of annual steady state GDP. The financial crisis is initiated through a shock to the diversion rate of private loans of 8 percent relative to the steady state. In contrast to the main text, the relative diversion rate has been set to $\bar{\lambda}_{b} / \bar{\lambda}_{k}=2$. 
Relative diversion rate $\bar{\lambda}_{b} / \bar{\lambda}_{k}=2$

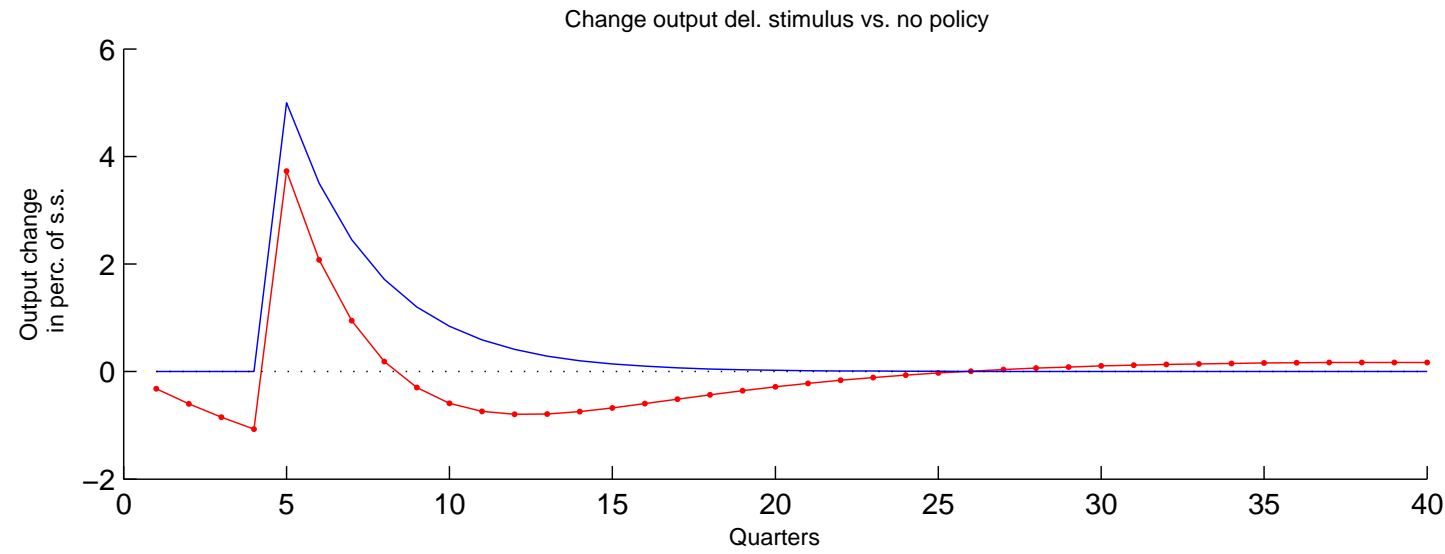

Figure 12: The solid (blue) line represents the fiscal stimulus itself, expressed as a percentage of quarterly steady state output. The red dotted line is the difference in output (expressed as a percentage of steady state output) between the case with a fiscal stimulus of $5 \%$ of quarterly GDP announced as the crisis hits but implemented four quarters later and the case without a fiscal stimulus in the benchmark case with long term debt and sovereign risk. The relative diversion rate has been set to $\bar{\lambda}_{b} / \bar{\lambda}_{k}=2$. 


$$
\bar{b}_{\text {max }}=2.8
$$
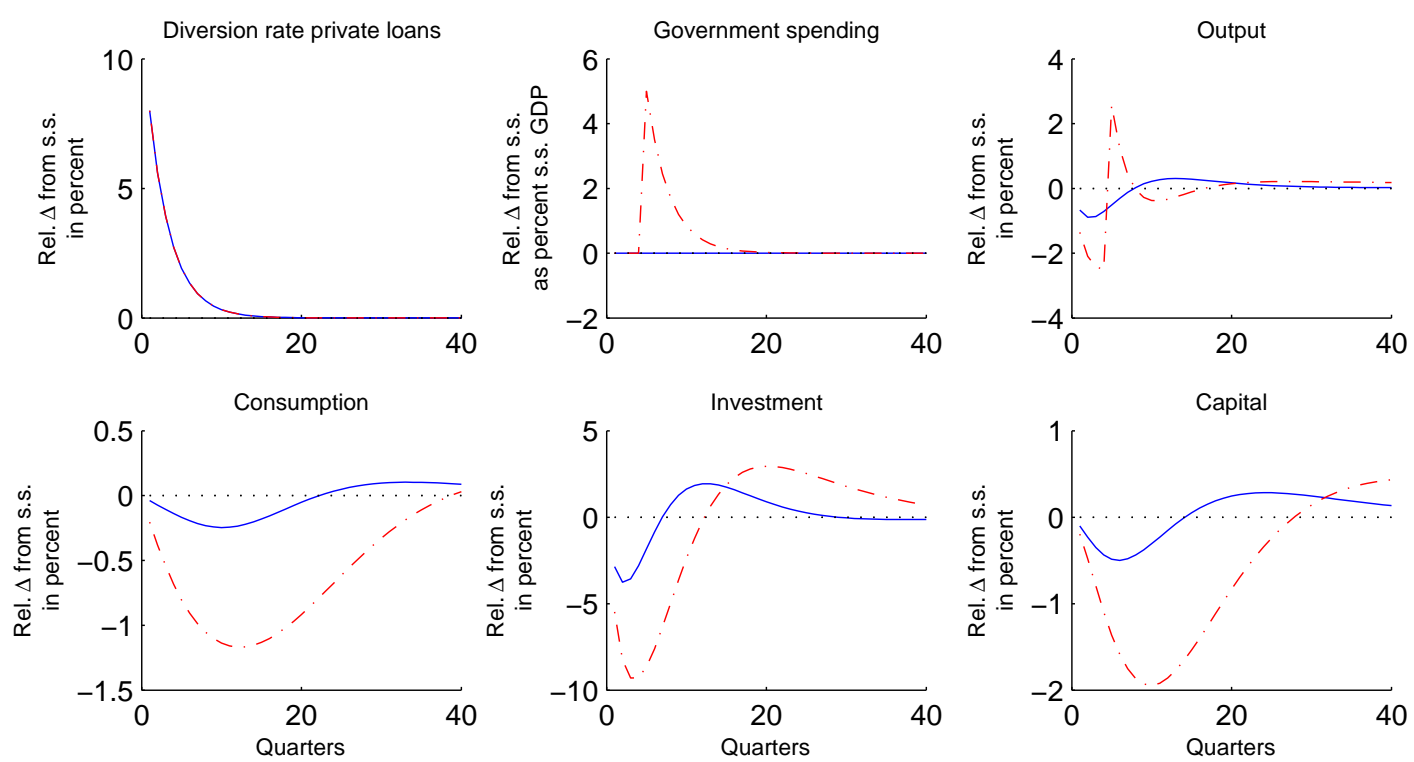

(a)
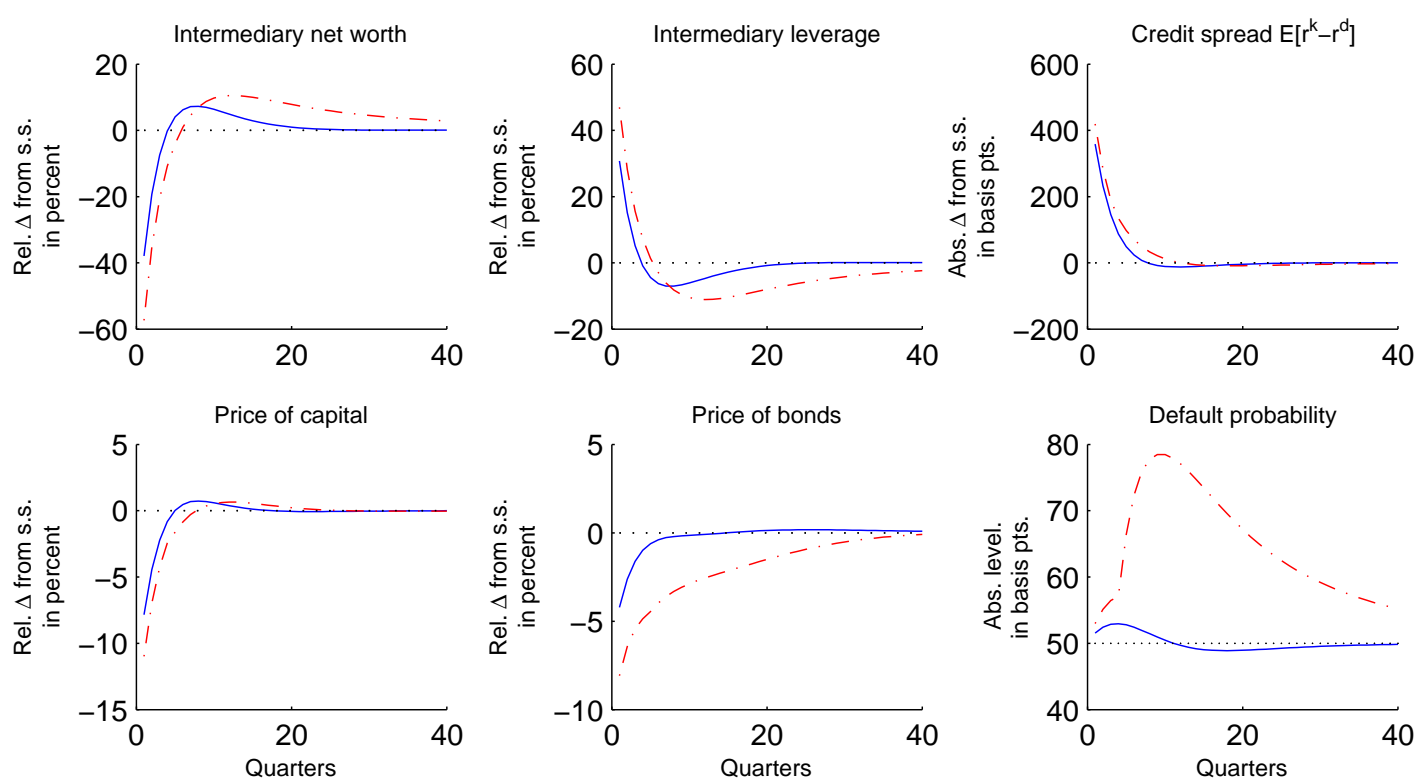

(b)

Figure 13: Plot of the impulse response functions comparing no additional policy (blue, solid) and fiscal stimulus (red, slotted). The stimulus is announced as the crisis hits, and implemented 4 quarters later through additional debt issuance, and equal to $1.25 \%$ of annual steady state GDP. The financial crisis is initiated through a shock to the diversion rate of private loans of 8 percent relative to the steady state. In contrast to the main text, $\bar{b}_{\max }$ has been set to $\bar{b}_{\max }=2.8$. 


$$
\bar{b}_{\max }=2.8
$$

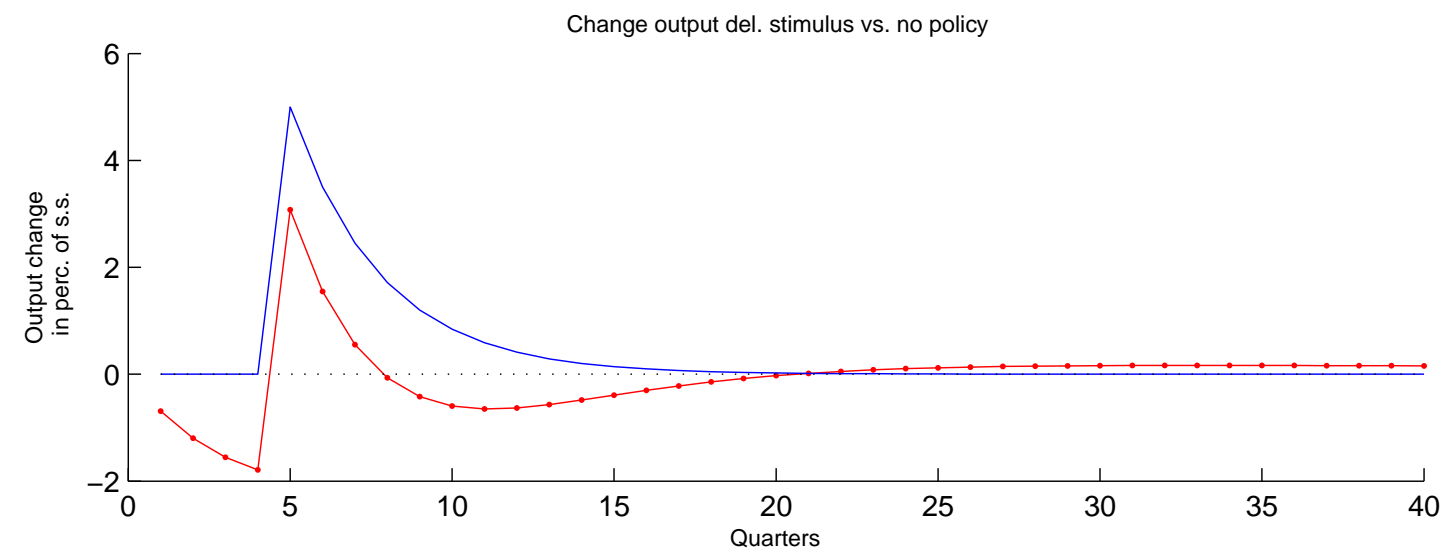

Figure 14: The solid (blue) line represents the fiscal stimulus itself, expressed as a percentage of quarterly steady state output. The red dotted line is the difference in output (expressed as a percentage of steady state output) between the case with a fiscal stimulus of $5 \%$ of quarterly GDP announced as the crisis hits but implemented four quarters later and the case without a fiscal stimulus in the benchmark case with long term debt and sovereign risk. In contrast to the main text, $\bar{b}_{\max }$ has been set to $\bar{b}_{\max }=2.8$. 


$$
\rho_{r}=0.4
$$
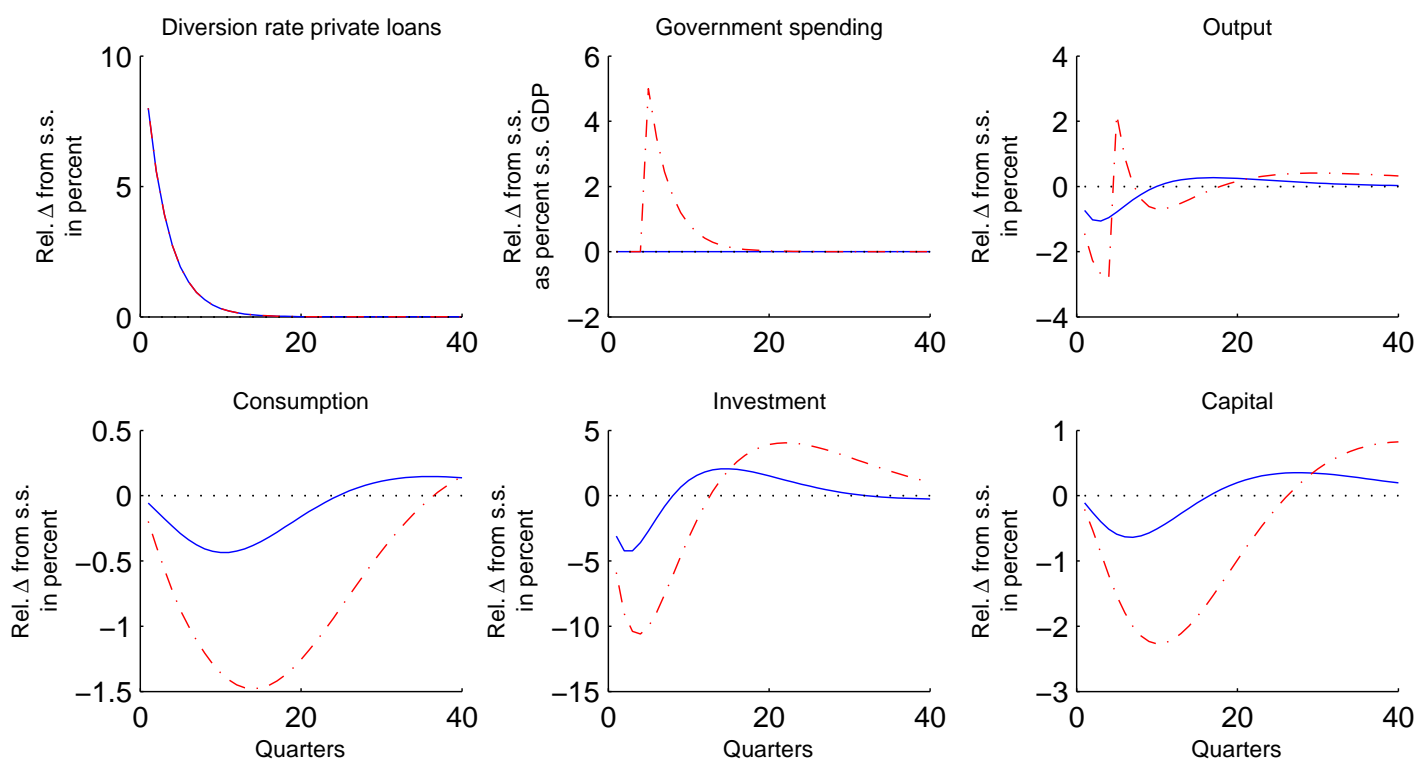

(a)
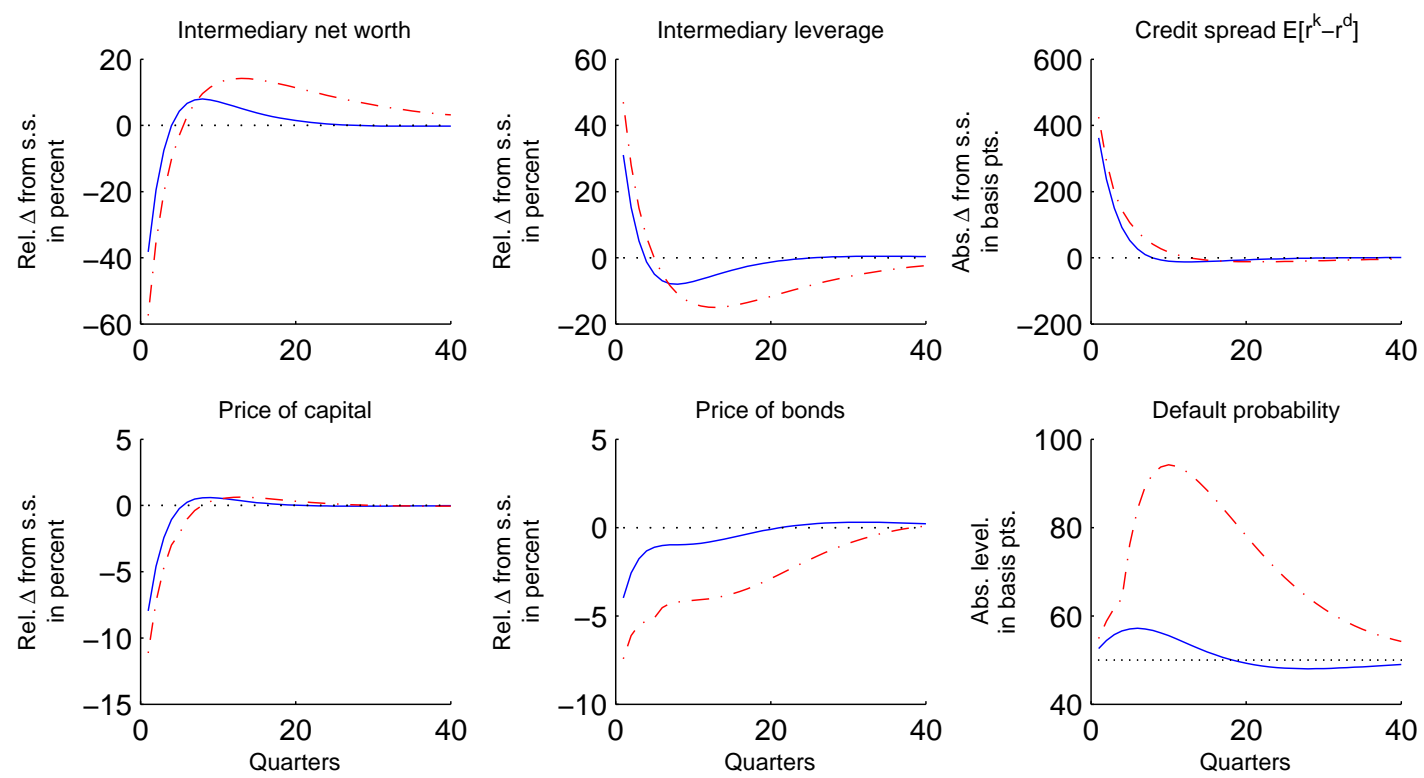

(b)

Figure 15: Plot of the impulse response functions comparing no additional policy (blue, solid) and fiscal stimulus (red, slotted). The stimulus is announced as the crisis hits, and implemented 4 quarters later through additional debt issuance, and equal to $1.25 \%$ of annual steady state GDP. The financial crisis is initiated through a shock to the diversion rate of private loans of 8 percent relative to the steady state. In contrast to the main text, $\rho_{r}$ has been set to $\rho_{r}=0.4$. 


$$
\rho_{r}=0.4
$$

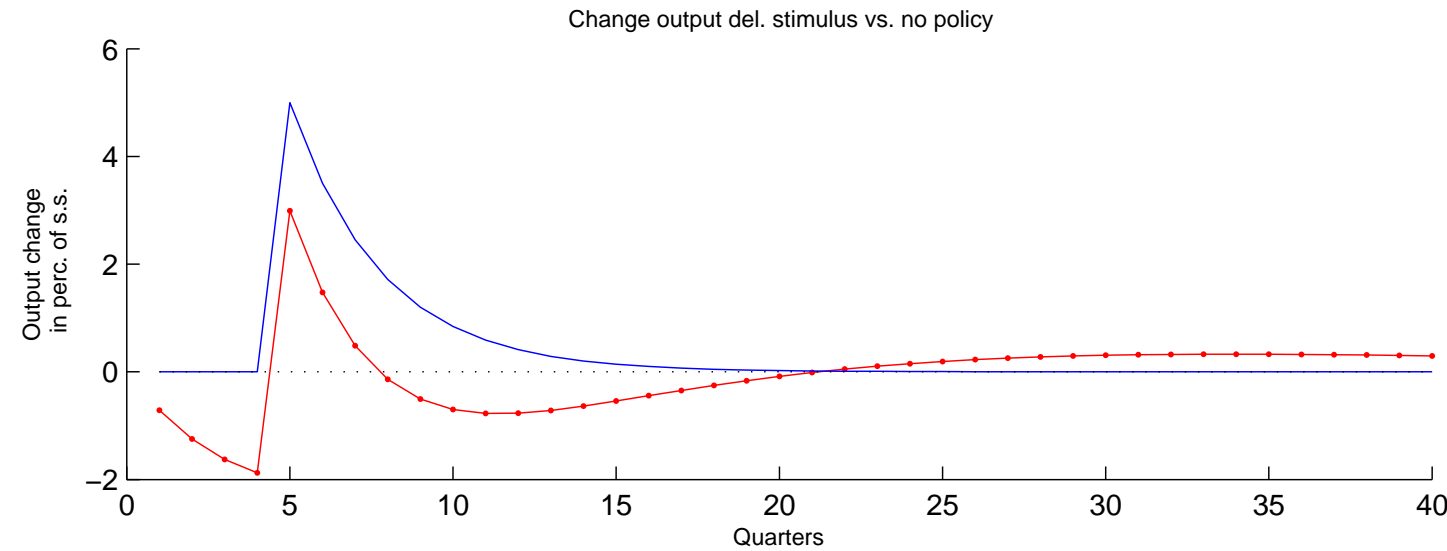

Figure 16: The solid (blue) line represents the fiscal stimulus itself, expressed as a percentage of quarterly steady state output. The red dotted line is the difference in output (expressed as a percentage of steady state output) between the case with a fiscal stimulus of $5 \%$ of quarterly GDP announced as the crisis hits but implemented four quarters later and the case without a fiscal stimulus in the benchmark case with long term debt and sovereign risk. In contrast to the main text, $\rho_{r}$ has been set to $\rho_{r}=0.4$. 